\title{
Anti-cancer effects of honokiol via mitochondrial dysfunction are strongly enhanced by the mitochondria-targeting carrier berberine
}

Xiaojia Shił, Tao Zhang ${ }^{\ddagger}$, Hongxiang Lou ${ }^{\dagger}$,Huina Song ${ }^{\dagger}$, Changhao Lit, Peihong Fan ${ }^{*}{ }^{\dagger}$

'Department of Natural Product Chemistry, Key Lab of Chemical Biology of Ministry of Education, School of Pharmaceutical Sciences, Cheeloo College of Medicine, Shandong University, Jinan 250012, P. R. China.

$¥$ Shandong Provincial Key Laboratory of Neuroprotective drug, Zibo 255400, P. R. China.

\section{Table of contents}

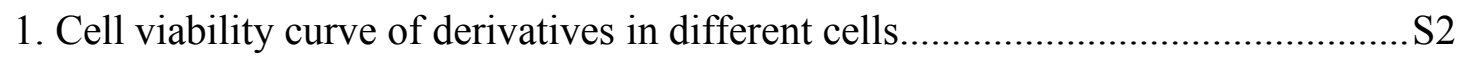

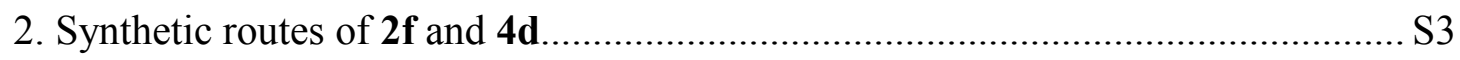

3. Morphological change of cells treated with target and parent compounds..............S4

4. Combination index values analyzed by CompuSyn software................................S9

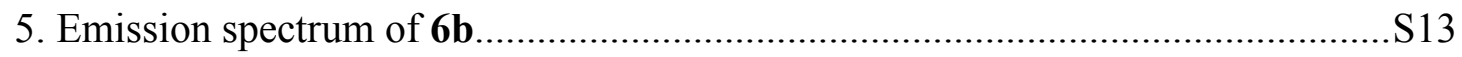

6. NMR spectra, HPLC chromatography and ESI-MS of all derivatives................. S14 


\section{Cell viability curve of derivatives in different cells}

Cells were incubated with indicated drugs for $48 \mathrm{~h}$. MTT assays was performed to test the cell viability.

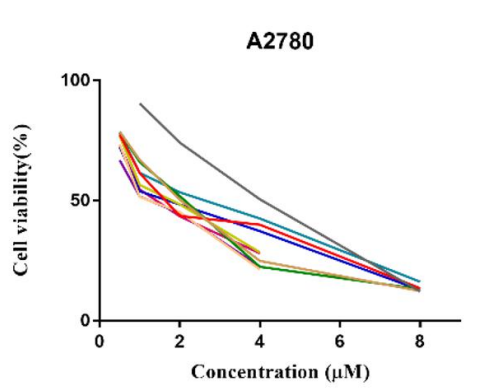

A549

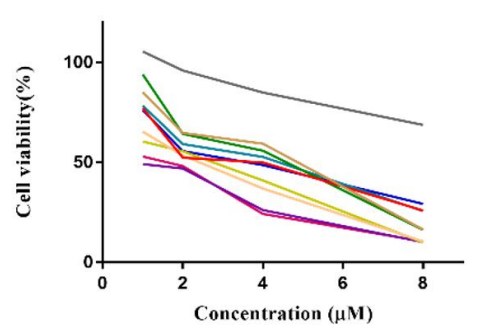

Hepg2

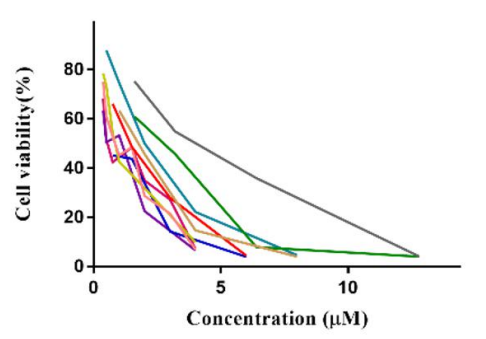

HT29

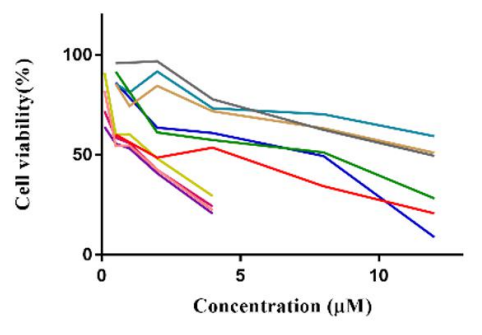

Panc1

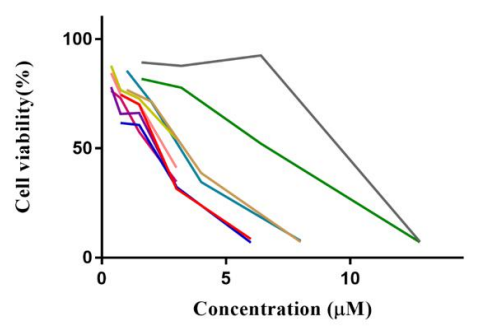

A2780

$-5 a$
$-5 b$
$-5 c$
$-5 d$
$-5 e$
$-6 a$
$-6 b$
$-6 c$
$-6 d$
$-6 e$
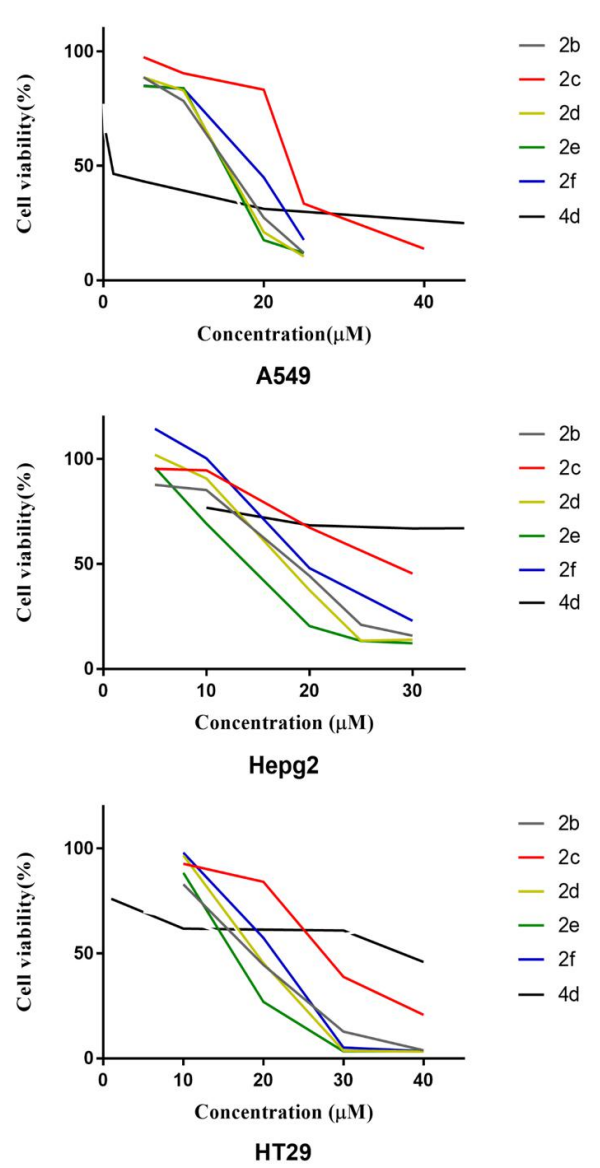

$-2 \mathrm{~b}$

$-2 \mathrm{c}$

$-2 \mathrm{~d}$

$-2 \mathrm{e}$

$-2 f$

- $4 \mathrm{~d}$

- $6 c$

$-6 e$

$-5 a$
$-5 b$
$-5 c$
$-5 d$
$-5 e$
$-6 a$
$-6 b$
$-6 c$
$-6 d$
$-6 e$

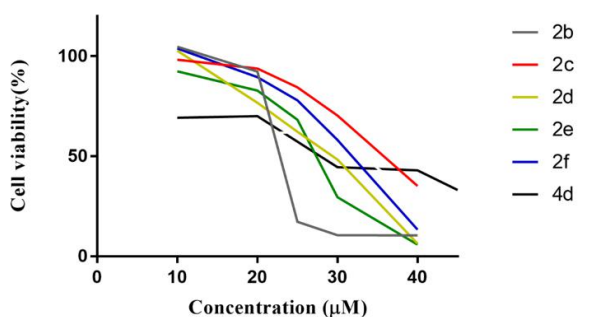

Panc1

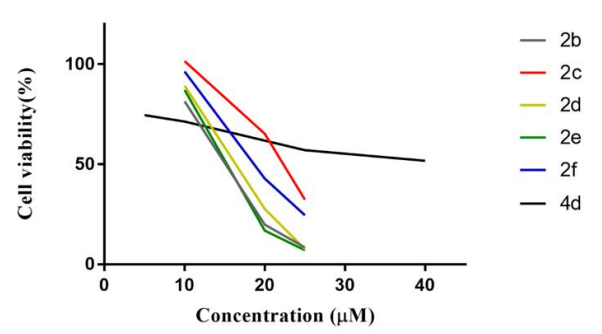



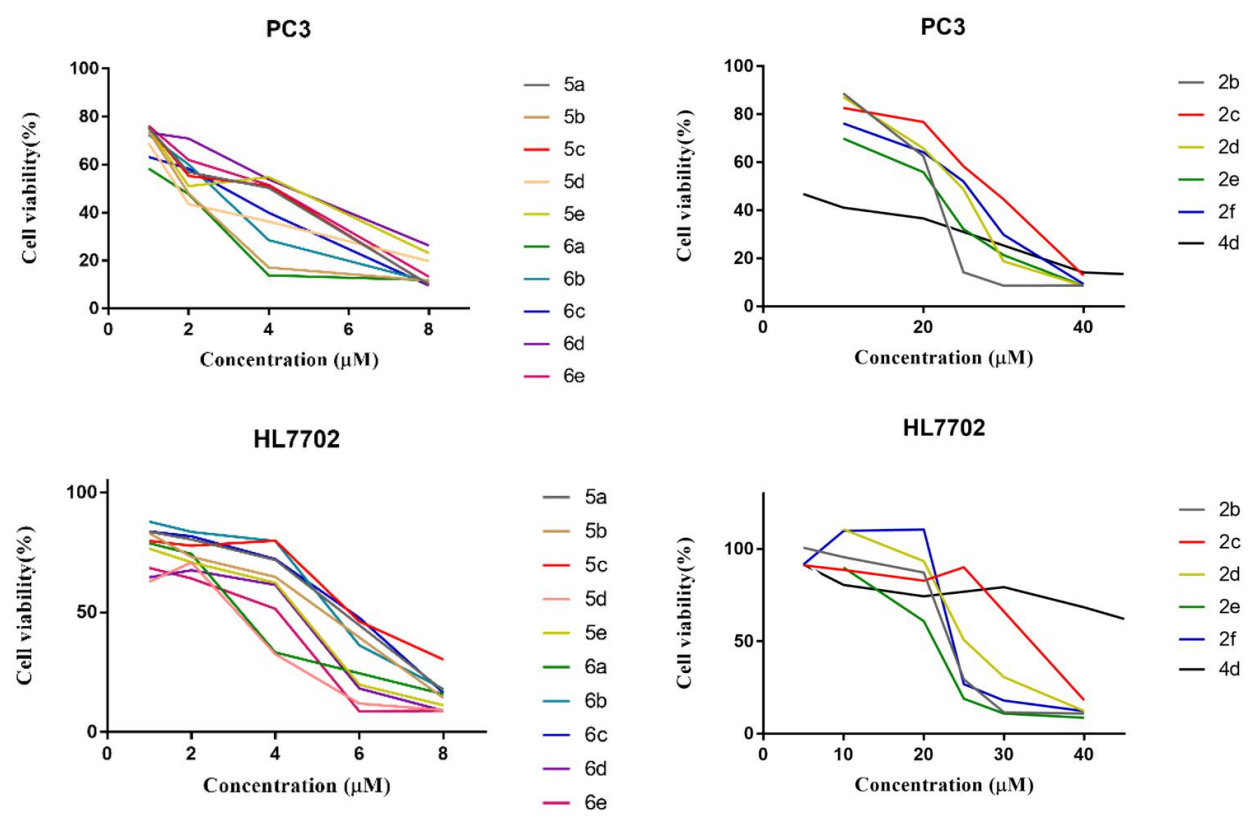

Figure S1. Viability of all cells response to different dose of indicated derivatives for 48 h. Cell viability was detected by MTT assays.

\section{Synthetic routes of $2 \mathrm{f}$ and $4 d$}

Scheme S1. Synthesis of derivatives $2 \mathrm{f}$ and $\mathbf{4} \mathbf{d}^{a}$.<smiles>COc1ccc2cc3[n+](cc2c1OC)CCc1cc2c(cc1-3)OCO2</smiles>

1<smiles>COc1ccc2c(c1OC)C(CC(C)=O)N1CCc3cc4c(cc3C1=C2)OCO4</smiles>

3<smiles></smiles>

$4 d$<smiles>C=CCc1ccc(O)c(-c2ccc(O)c(CC=C)c2)c1</smiles>

$2 a$<smiles>C=CCc1ccc(O)c(-c2ccc(OCCCCC)c(CC=C)c2)c1</smiles> 
${ }^{a}$ Reagents and conditions: (a) $5 \mathrm{~N} \mathrm{NaOH}$, acetone, rt, stir 30 min. (b) $\mathrm{MeCN}, \mathrm{N}_{2}$, 1-iodobutane, avoid light, reflux $5 \sim 8$ h. (c) $\mathrm{K}_{2} \mathrm{CO}_{3}$, DMF, 1-iodobutane, rt, stir overnight.

\section{Morphological change of cells treated with target and parent compounds}

Numerous cytoplasmic vacuoles in cancer cells were observed via optical microscopy. As shown in Figure S2, Compounds of series 5 and 6 could bring about cytoplasmic vacuoles in various degrees in HepG2 cells. And various cancer cells, such as HepG2, MCF-7, PC3, HT29, A2780, A549, in control group showed a uniform and steric shape with abundant cytoplasm, whereas cells treated with $\mathbf{6 b}$, displayed flat and amorphous phenomenon along with vacuoles of different sizes filled in cytoplasm (Figure S3). The parent agent BBR had no effect on vacuolization in tested dose and $\mathrm{HN}$ over $30 \mu \mathrm{M}$ could induce few (Figure S4, S5). The effect on vacuolization of intermediate $\mathbf{2} \mathbf{f}$ is weaker than that of its parent compound $\mathrm{HN}$, while BBR derivative $4 \mathbf{d}$ exhibited ability to inducing vacuoles at $40 \mu \mathrm{M}$ as well. In drug combinations, more obvious vacuolation were observed than that in single compound group (Figure S5). 

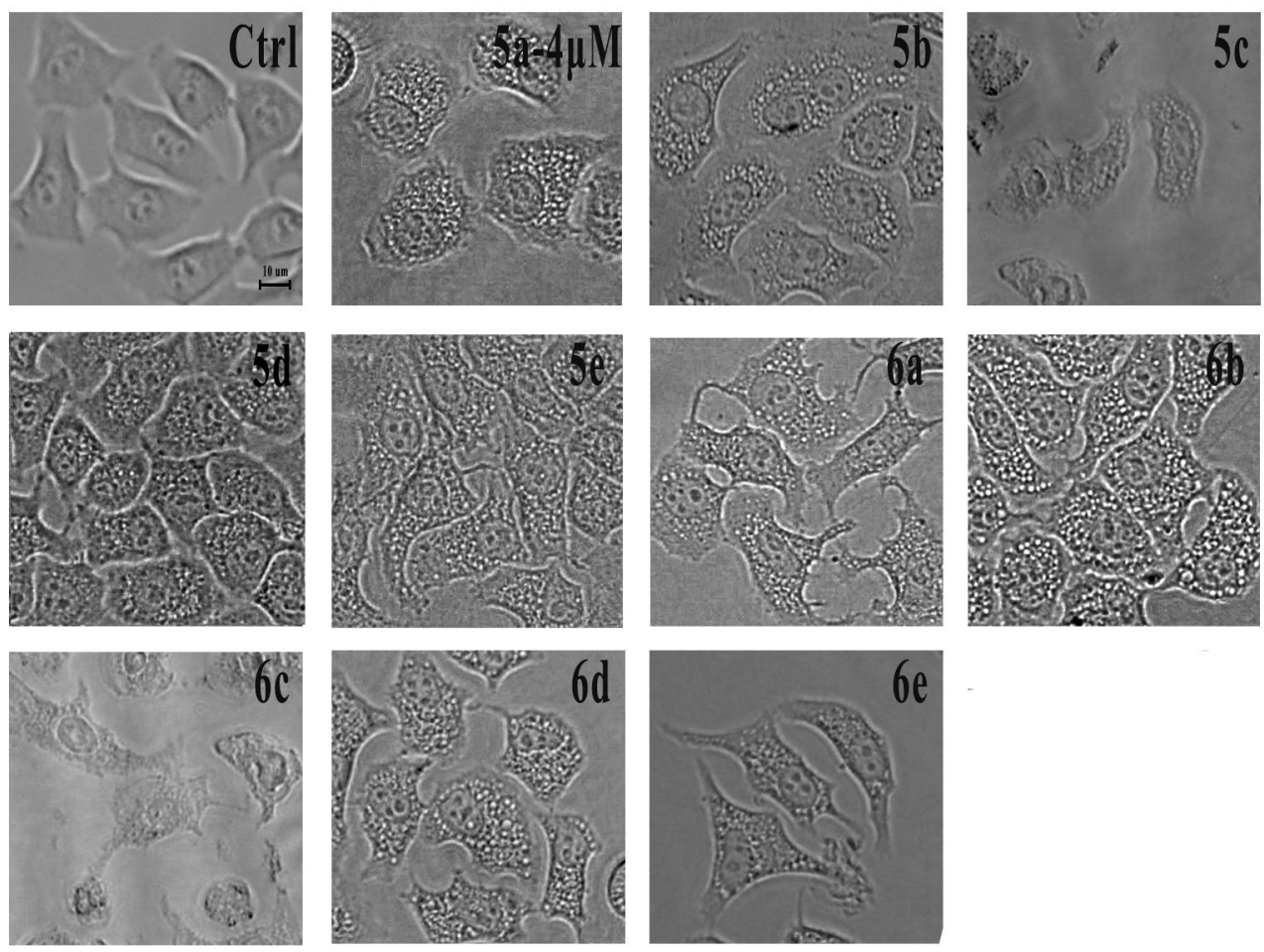

Figure S2. Cytoplasmic vacuoles initiated by synthetic compounds. HepG2 cells were treated with synthetic compound of $4 \mu \mathrm{M}$. Images were obtained by optical microscopy. Scar bar $10 \mu \mathrm{m}$. 

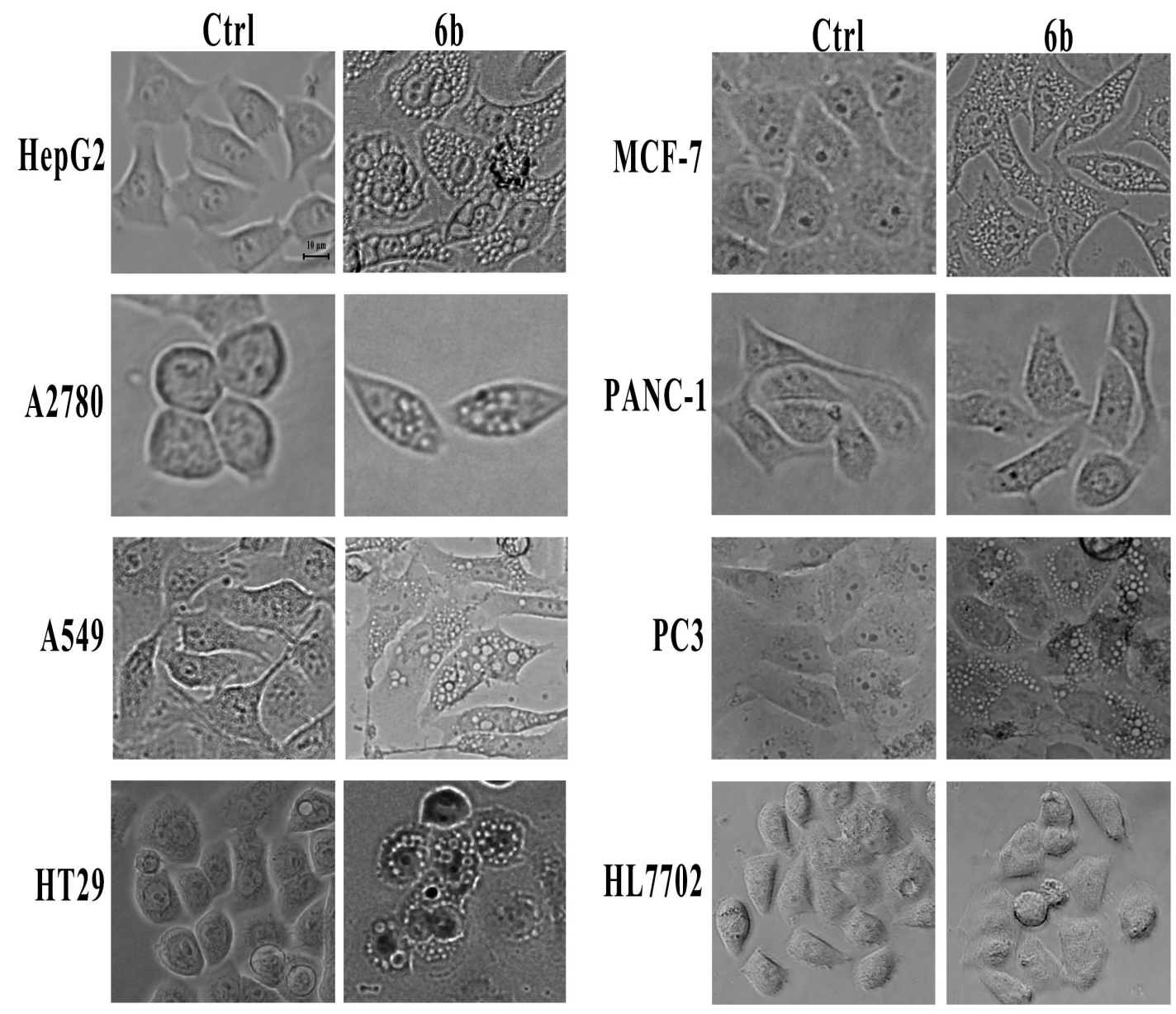

Figure S3. Compound $\mathbf{6 b}$ induced vacuoles in various cancer cells. Phase-contrast images of vacuoles in different cells treated with $4 \mu \mathrm{M}$ 6b for $24 \mathrm{~h}$. Scar bar $10 \mu \mathrm{m}$. 


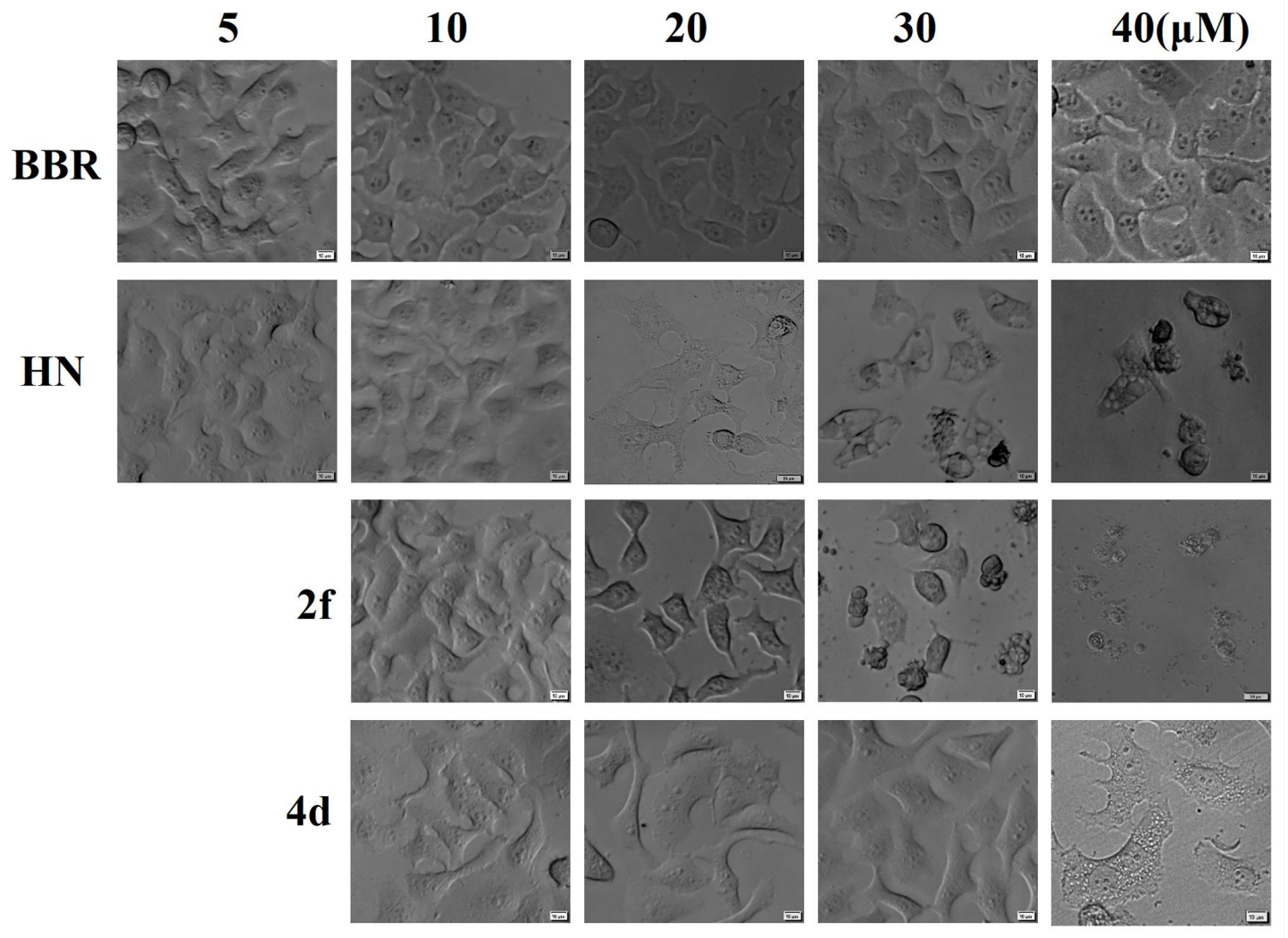

Figure S4. Cytoplasmic vacuoles were observed in HepG2 cells after treatment with indicated parent and intermediate compounds for $24 \mathrm{~h}$. Scar bar $10 \mu \mathrm{m}$. 


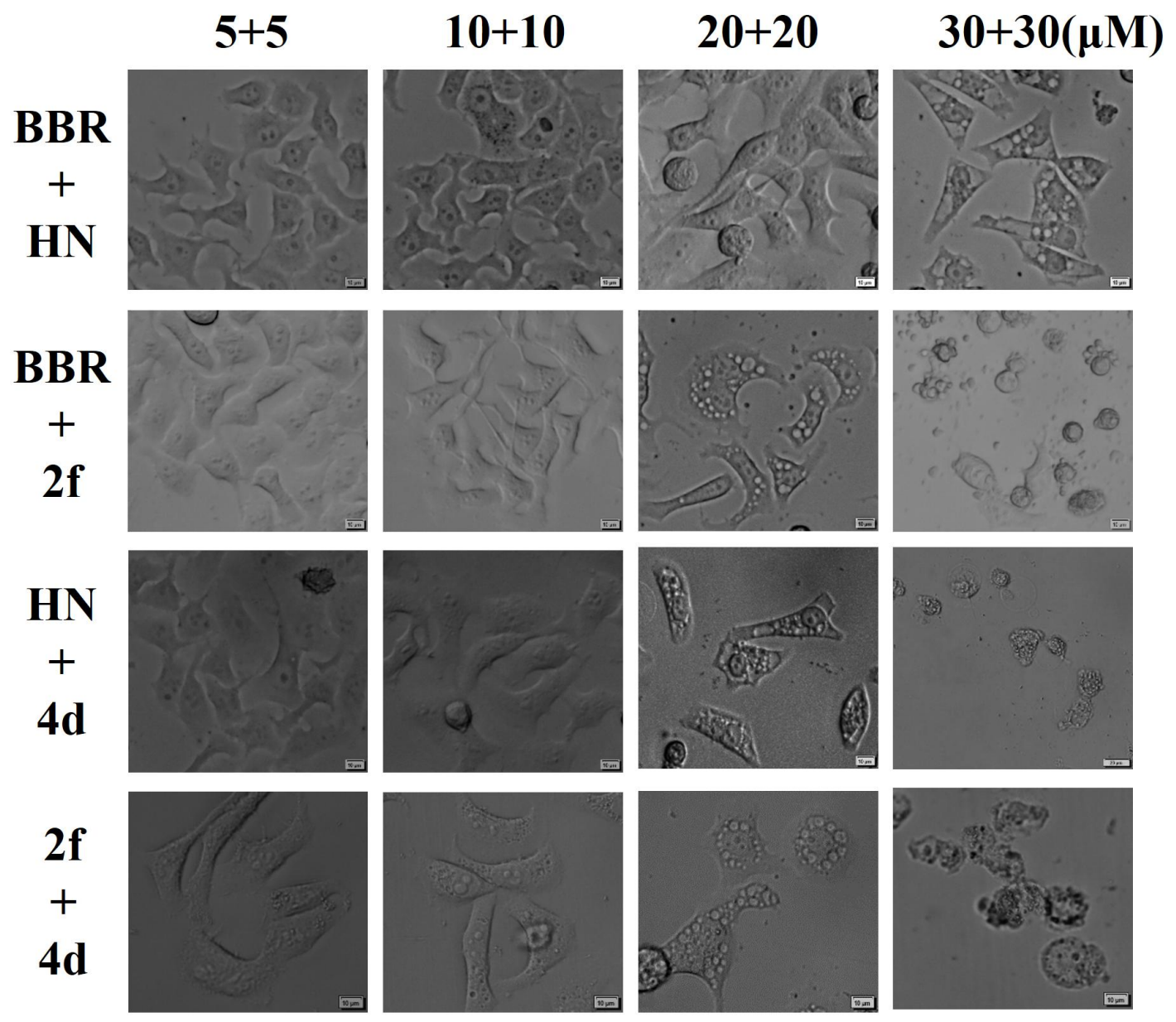

Figure S5. The effect inducing vacuolation in various drug combinations. Cells were incubated for $48 \mathrm{~h}$ and images were captured. Scar bar $10 \mu \mathrm{m}$. 


\section{Combination index values analyzed by CompuSyn software}

HepG2 cells were incubated with different concentrations of single agents or drug combinations of BBR moiety with $\mathrm{HN}$ moiety for $48 \mathrm{~h}$. Cell viability was determined by MTT assays. CI data for drug combos were calculated by CompuSyn software. CI $<1,=1$, and $>1$ indicated synergism, additive effect and antagonism, respectively.

Table S1. Effects and CI values for drug combo of $\mathrm{BBR}^{\text {and }} \mathrm{HN}^{a}$.

\begin{tabular}{cccc}
\hline Dose of BBR $(\mu \mathrm{M})$ & Dose of HN $(\mu \mathrm{M})$ & Effect & CI \\
\hline 20 & - & 0.252 & - \\
40 & - & 0.305 & - \\
60 & - & 0.382 & - \\
80 & - & 0.444 & - \\
- & 10 & 0.001 & - \\
- & 20 & 0.307 & - \\
- & 30 & 0.874 & - \\
- & 40 & 0.952 & - \\
20 & 10 & 0.171 & 2.585 \\
40 & 10 & 0.283 & 1.927 \\
60 & 10 & 0.363 & 1.655 \\
80 & 10 & 0.401 & 1.673 \\
20 & 20 & 0.305 & 1.616 \\
40 & 20 & 0.353 & 1.819 \\
60 & 20 & 0.433 & 1.655 \\
80 & 20 & 0.496 & 1.531 \\
20 & 30 & 0.765 & 1.099 \\
40 & 30 & 0.639 & 1.323 \\
60 & 30 & 0.698 & 1.265 \\
80 & 30 & 0.784 & 1.133 \\
20 & 40 & 0.950 & 1.048 \\
40 & 40 & 0.919 & 1.154 \\
60 & 40 & 0.921 & 1.151 \\
80 & 40 & 0.936 & 1.105 \\
\hline
\end{tabular}

${ }^{a}$ The values represent the mean of three independent experiments. 
Table S2. Effects and CI values for drug combo of BBR and $\mathbf{2} \mathbf{f}^{a}$.

\begin{tabular}{cccc}
\hline Dose of BBR $(\mu \mathrm{M})$ & Dose of $\mathbf{2 f}(\mu \mathrm{M})$ & Effect & CI \\
\hline 20 & - & 0.181 & - \\
40 & - & 0.250 & - \\
60 & - & 0.348 & - \\
80 & - & 0.347 & - \\
- & 10 & 0.012 & - \\
- & 20 & 0.582 & - \\
- & 30 & 0.908 & - \\
- & 40 & 0.954 & - \\
20 & 10 & 0.164 & 1.815 \\
40 & 10 & 0.275 & 1.469 \\
60 & 10 & 0.315 & 1.571 \\
80 & 10 & 0.367 & 1.500 \\
20 & 20 & 0.592 & 0.951 \\
40 & 20 & 0.615 & 0.984 \\
60 & 20 & 0.703 & 0.908 \\
80 & 20 & 0.690 & 0.960 \\
20 & 30 & 0.926 & 0.910 \\
40 & 30 & 0.927 & 0.910 \\
60 & 30 & 0.941 & 0.875 \\
80 & 30 & 0.930 & 0.908 \\
20 & 40 & 0.956 & 1.098 \\
40 & 40 & 0.955 & 1.104 \\
60 & 40 & 0.954 & 1.110 \\
80 & 40 & 0.957 & 1.097 \\
\hline
\end{tabular}

${ }^{a}$ The values represent the mean of three independent experiments. 
Table S3. Effects and CI values for drug combo of $\mathrm{HN}$ and $\mathbf{4} \mathbf{d}^{a}$.

\begin{tabular}{cccc}
\hline Dose of HN $(\mu \mathrm{M})$ & Dose of $\mathbf{4 d}(\mu \mathrm{M})$ & Effect $^{b}$ & CI $^{c}$ \\
\hline 10 & - & 0.001 & - \\
20 & - & 0.208 & - \\
30 & - & 0.913 & - \\
40 & - & 0.952 & - \\
- & 10 & 0.461 & - \\
- & 20 & 0.555 & - \\
- & 30 & 0.557 & - \\
- & 40 & 0.645 & - \\
10 & 10 & 0.485 & 1.178 \\
20 & 10 & 0.625 & 1.075 \\
30 & 10 & 0.925 & 0.892 \\
40 & 10 & 0.961 & 1.073 \\
10 & 20 & 0.567 & 1.301 \\
20 & 20 & 0.690 & 1.127 \\
30 & 20 & 0.961 & 0.809 \\
40 & 20 & 0.965 & 1.060 \\
10 & 30 & 0.564 & 1.781 \\
20 & 30 & 0.732 & 1.140 \\
30 & 30 & 0.967 & 0.793 \\
40 & 30 & 0.968 & 1.049 \\
10 & 40 & 0.716 & 1.003 \\
20 & 40 & 0.832 & 0.881 \\
30 & 40 & 0.968 & 0.792 \\
40 & 40 & 0.969 & 1.047 \\
\hline
\end{tabular}

${ }^{a}$ The values represent the mean of three independent experiments. 
Table S4. Effects and CI values for drug combo of $\mathbf{2 f}$ and $\mathbf{4 d}{ }^{a}$.

\begin{tabular}{cccc}
\hline Dose of $\mathbf{2 f}(\mu \mathrm{M})$ & Dose of $\mathbf{4 d}(\mu \mathrm{M})$ & Effect & CI \\
\hline 10 & - & 0.014 & - \\
20 & - & 0.256 & - \\
30 & - & 0.851 & - \\
40 & - & 0.845 & - \\
- & 10 & 0.374 & - \\
- & 20 & 0.355 & - \\
- & 30 & 0.371 & - \\
- & 40 & 0.391 & - \\
10 & 10 & 0.355 & 3.090 \\
20 & 10 & 0.404 & 0.909 \\
30 & 10 & 0.414 & 1.328 \\
40 & 10 & 0.587 & 1.513 \\
10 & 20 & 0.590 & 0.377 \\
20 & 20 & 0.658 & 0.709 \\
30 & 20 & 0.789 & 0.921 \\
40 & 20 & 0.841 & 1.139 \\
10 & 30 & 0.854 & 0.279 \\
20 & 30 & 0.866 & 0.546 \\
30 & 30 & 0.871 & 0.811 \\
40 & 30 & 0.870 & 1.083 \\
10 & 40 & 0.873 & 0.269 \\
20 & 40 & 0.872 & 0.539 \\
30 & 40 & 0.867 & 0.817 \\
40 & 40 & 0.867 & 1.089 \\
\hline
\end{tabular}

${ }^{a}$ The values represent the mean of three independent experiments. 


\section{Emission spectrum of $6 b$}

Cary eclipse fluorospectrophotometer was performed to examine the emission spectrum of $\mathbf{6 b}$. From 3D spectrum, we found two strong emission areas, $450 \sim 500$ $\mathrm{nm}$ (blue emission region) and $510 \sim 550 \mathrm{~nm}$ (green emission region), indicating $6 \mathbf{b}$ has ability to emit blue and green dual fluorescence.
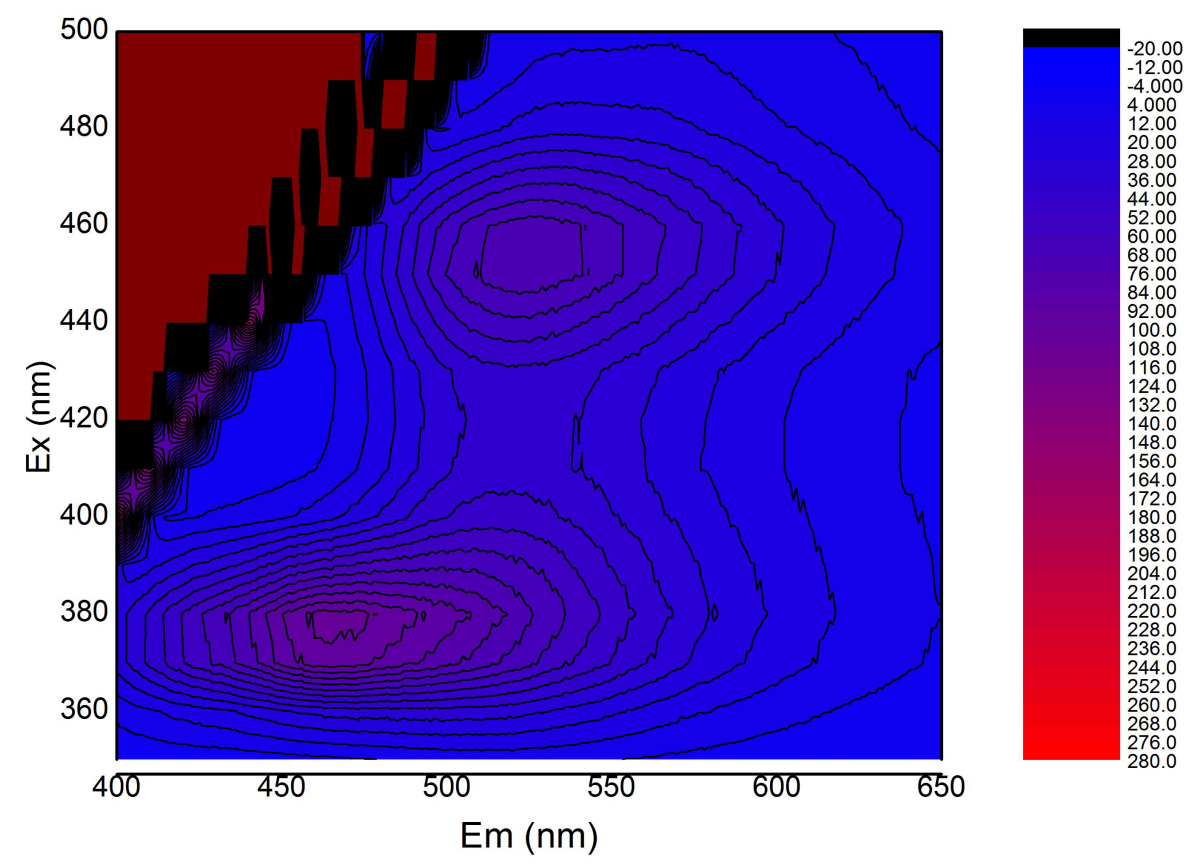

Figure S6. 3D emission spectrum of $\mathbf{6 b}$. 
6. NMR spectra, HPLC chromatography and ESI-MS of all derivatives

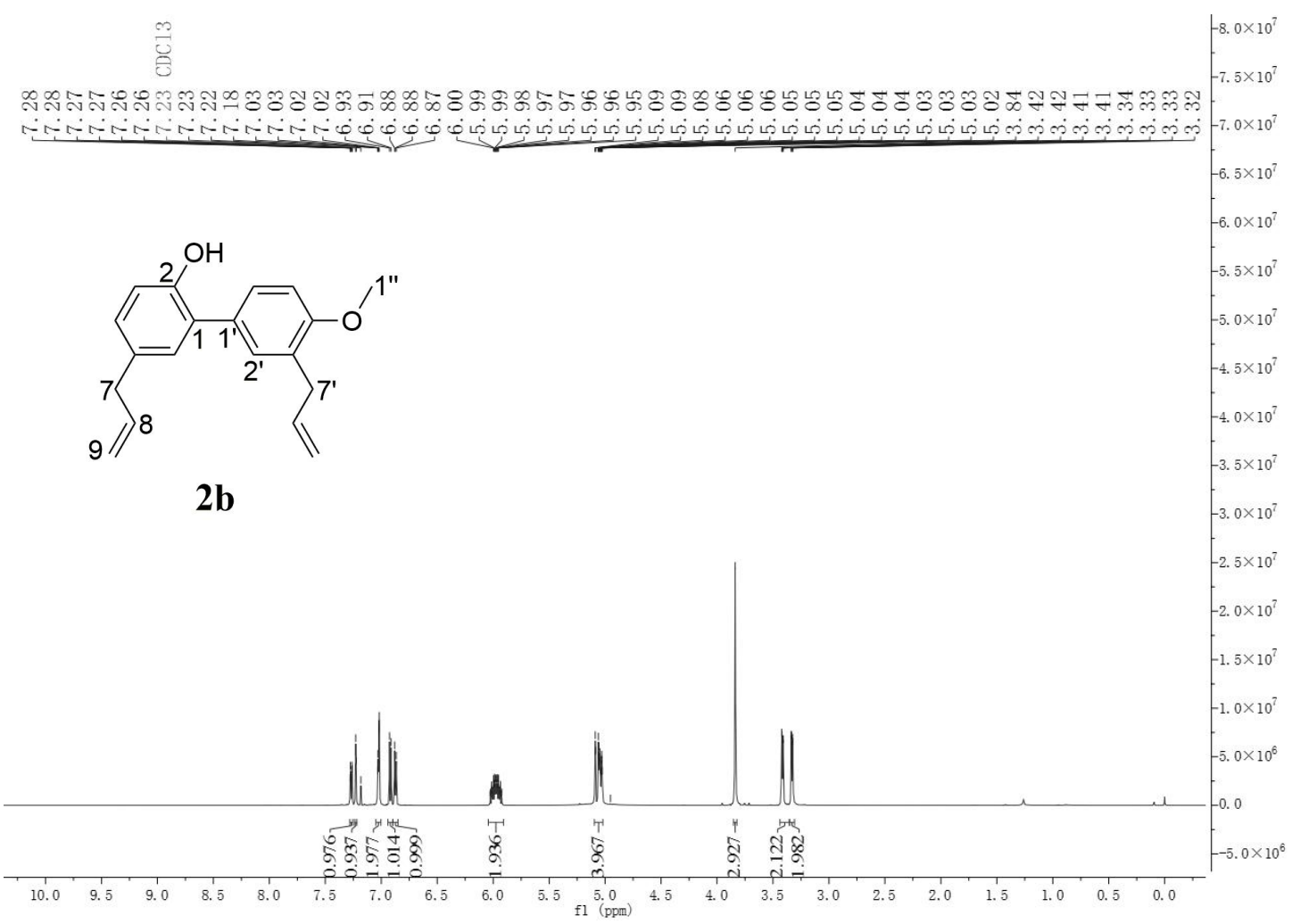

Figure S7. ${ }^{1} \mathrm{H}$ NMR spectrum of $\mathbf{2} \mathbf{b}$ in $\mathrm{CDCl}_{3}$.

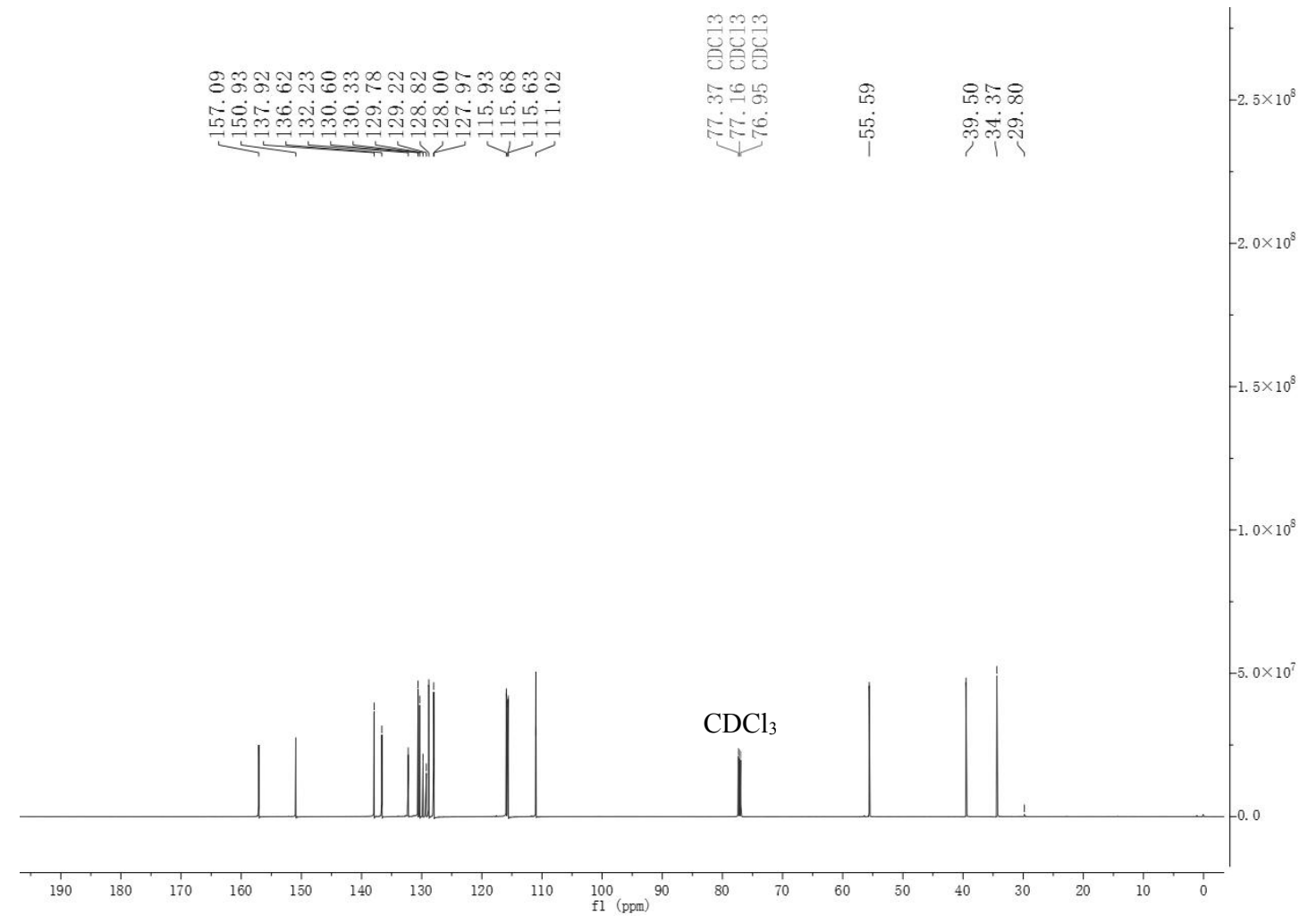


Figure S8. ${ }^{13} \mathrm{C}$ NMR spectrum of $\mathbf{2 b}$ in $\mathrm{CDCl}_{3}$.

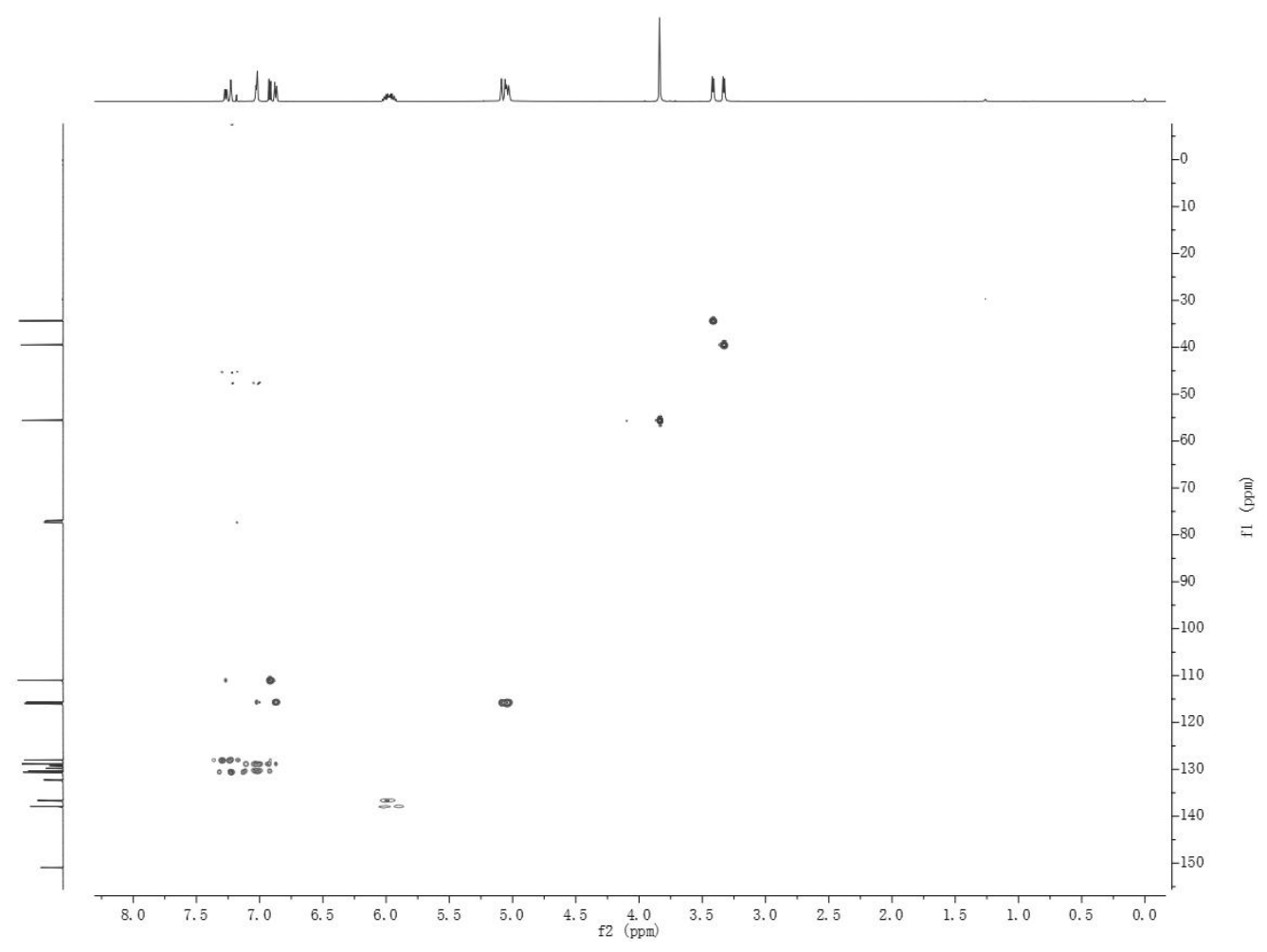

Figure S9. HSQC spectrum of $\mathbf{2 b}$ in $\mathrm{CDCl}_{3}$.

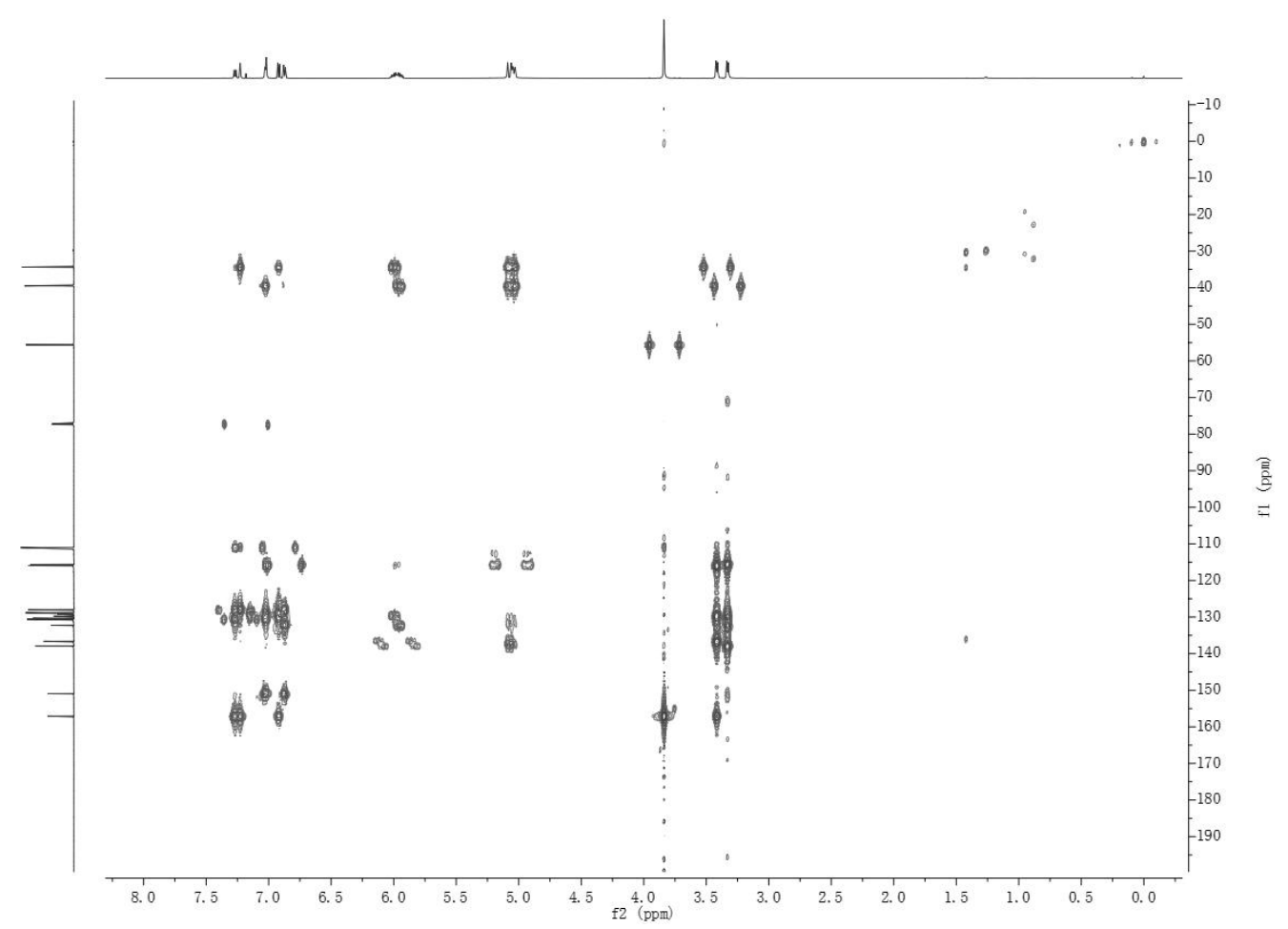


Figure S10. HMBC spectrum of $\mathbf{2 b}$ in $\mathrm{CDCl}_{3}$.

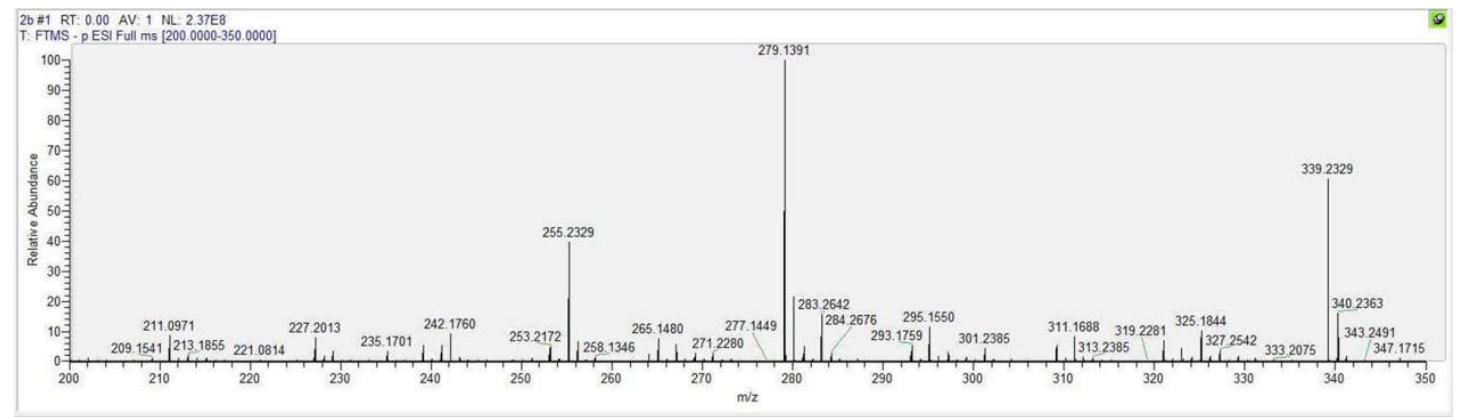

Figure S11. HR-ESI-MS spectrum of $\mathbf{2 b}$.

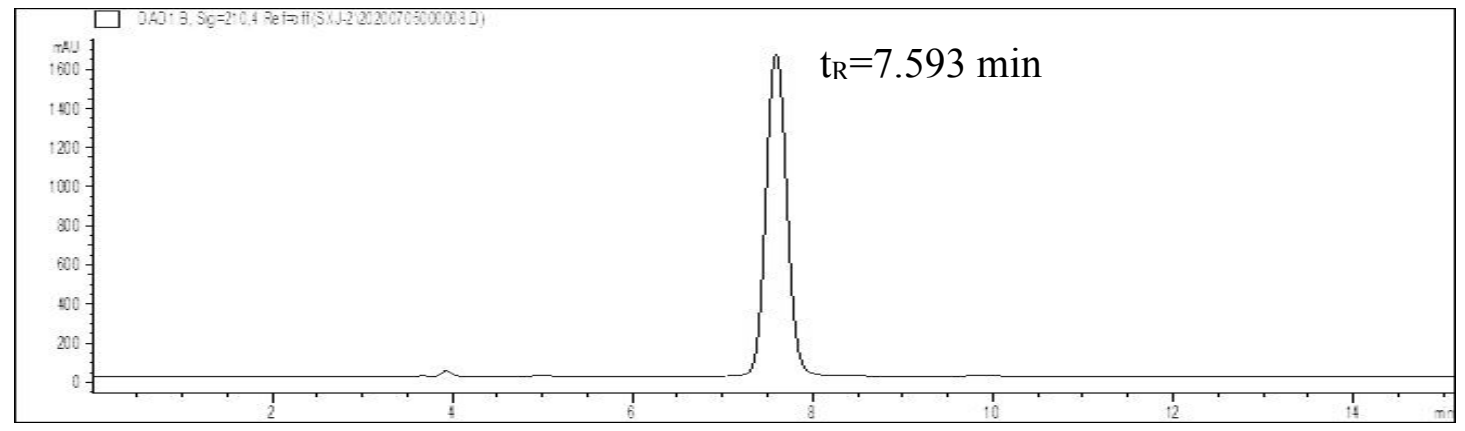

Figure S12. HPLC chromatogram of $\mathbf{2 b}$.
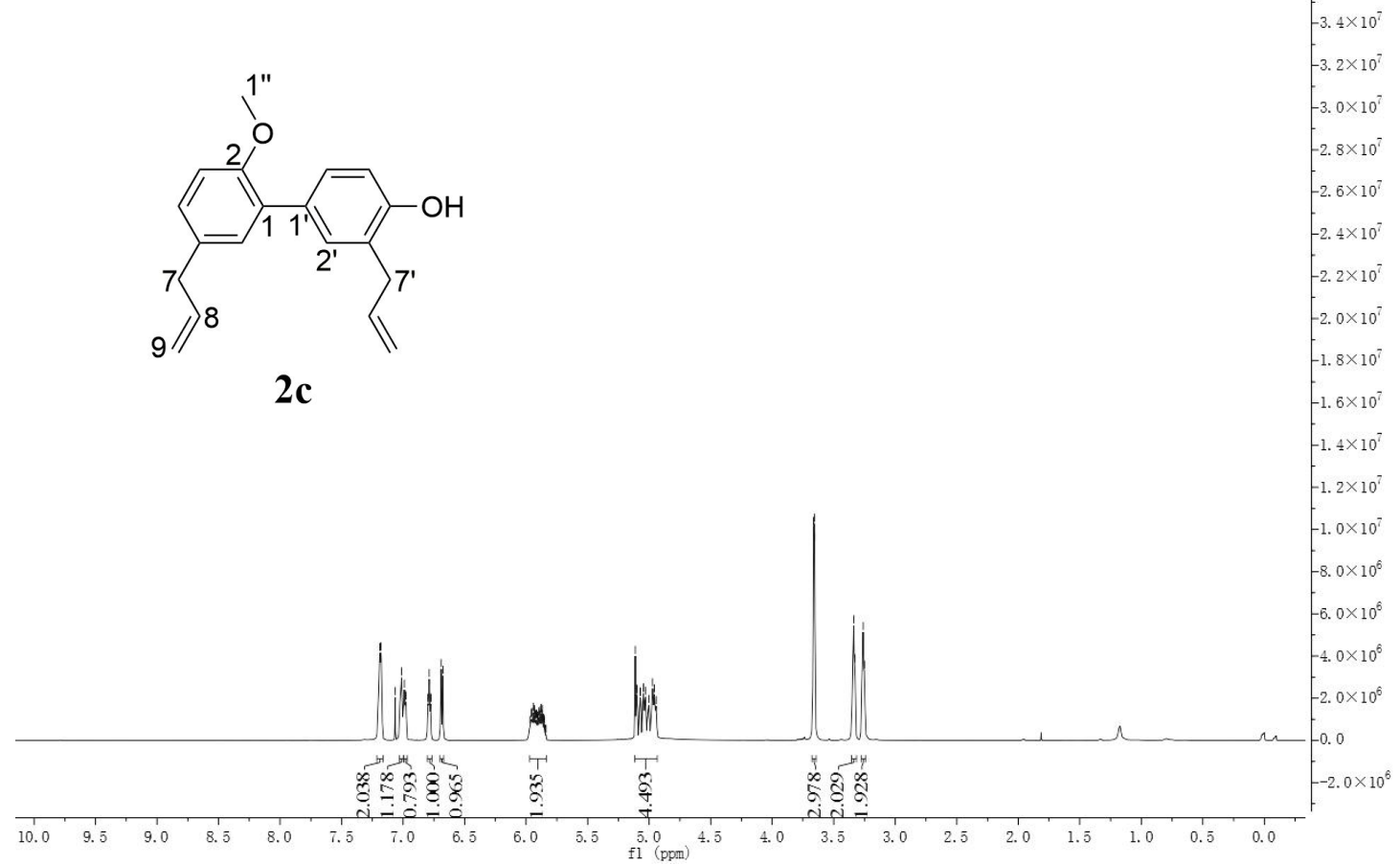
Figure S13. ${ }^{1} \mathrm{H}$ NMR spectrum of $2 \mathrm{c}$ in $\mathrm{CDCl}_{3}$.

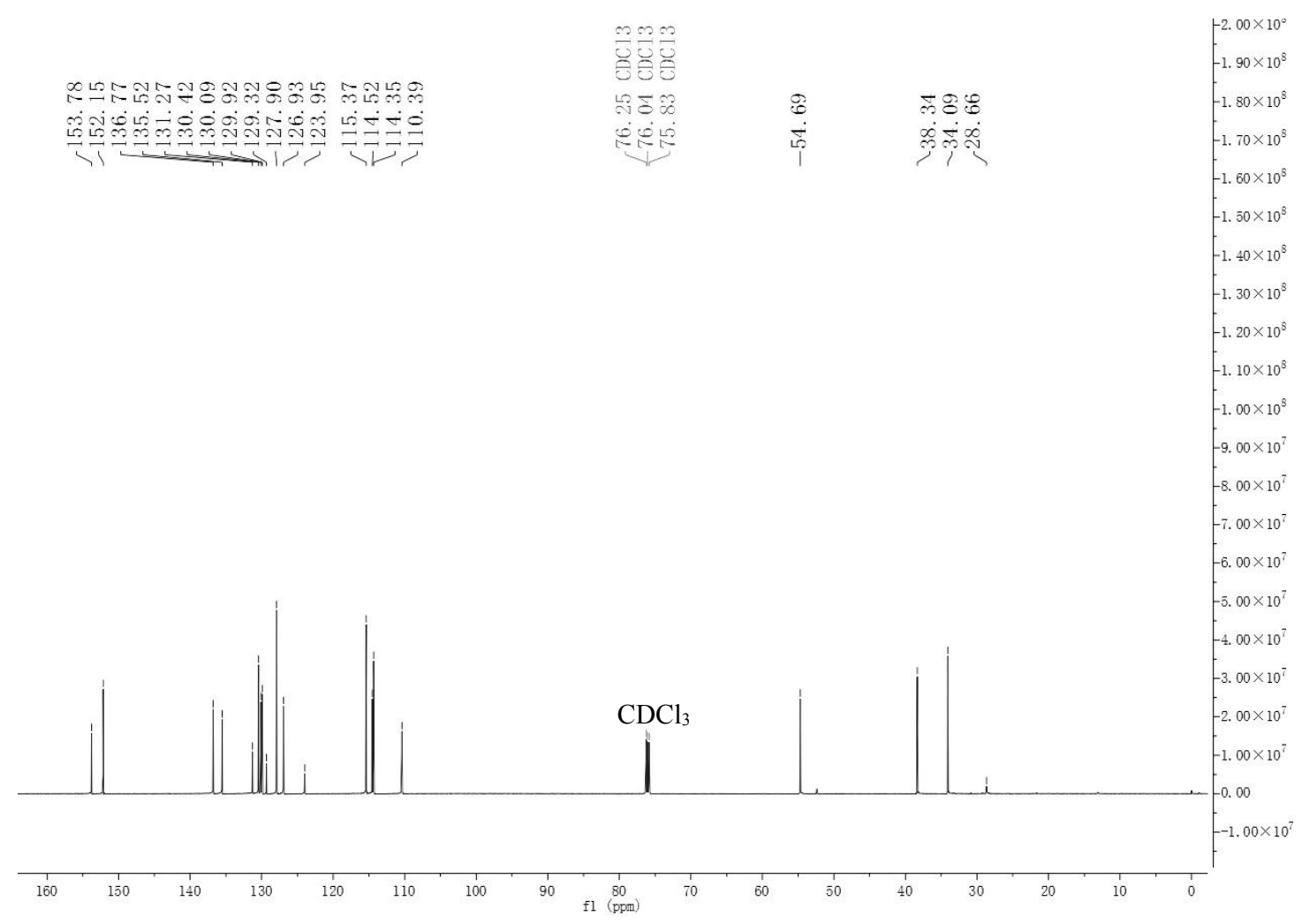

Figure S14. ${ }^{13} \mathrm{C}$ NMR spectrum of $2 \mathrm{c}$ in $\mathrm{CDCl}_{3}$.

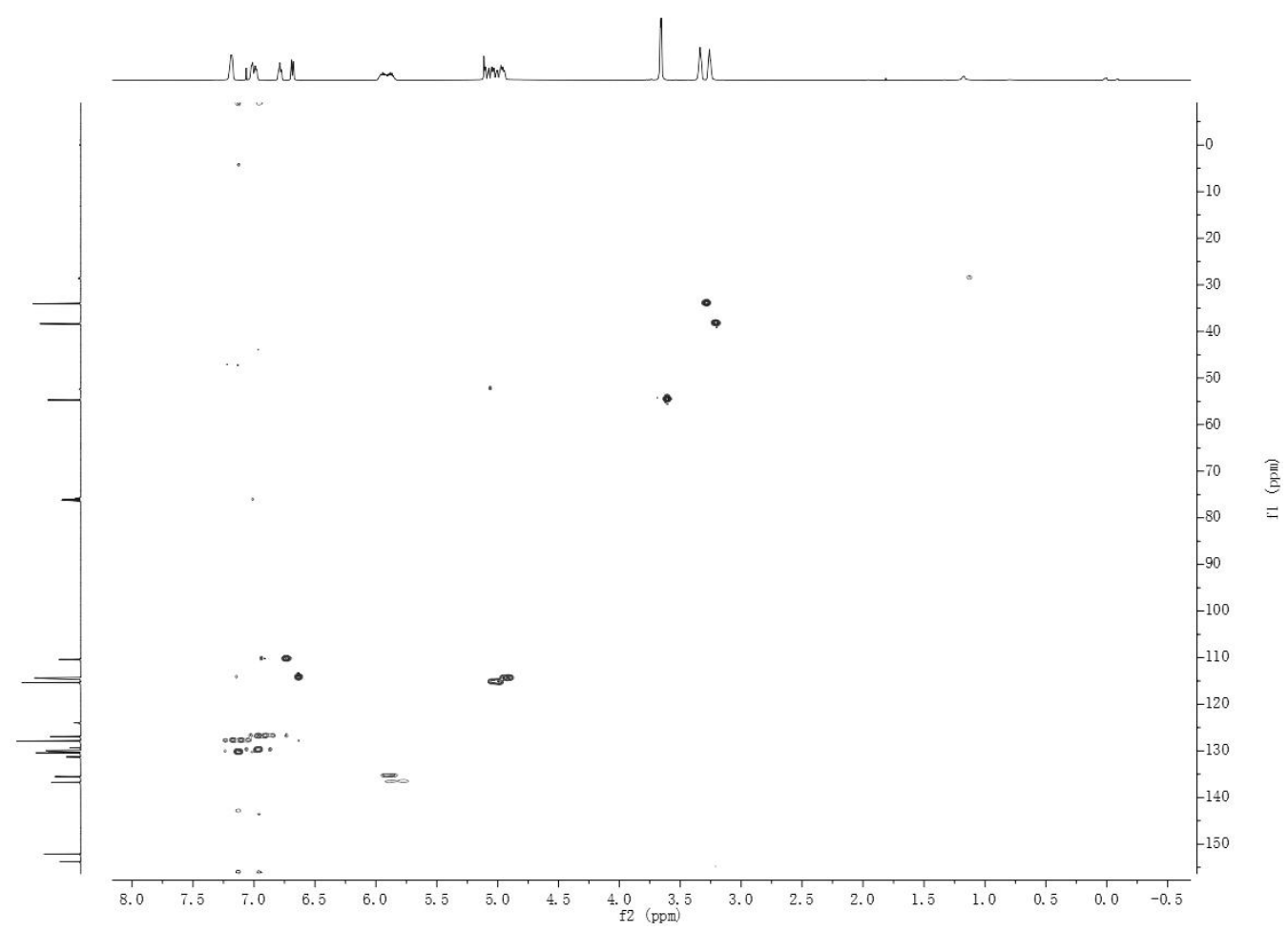


Figure S15. HSQC spectrum of $2 \mathbf{c}$ in $\mathrm{CDCl}_{3}$.

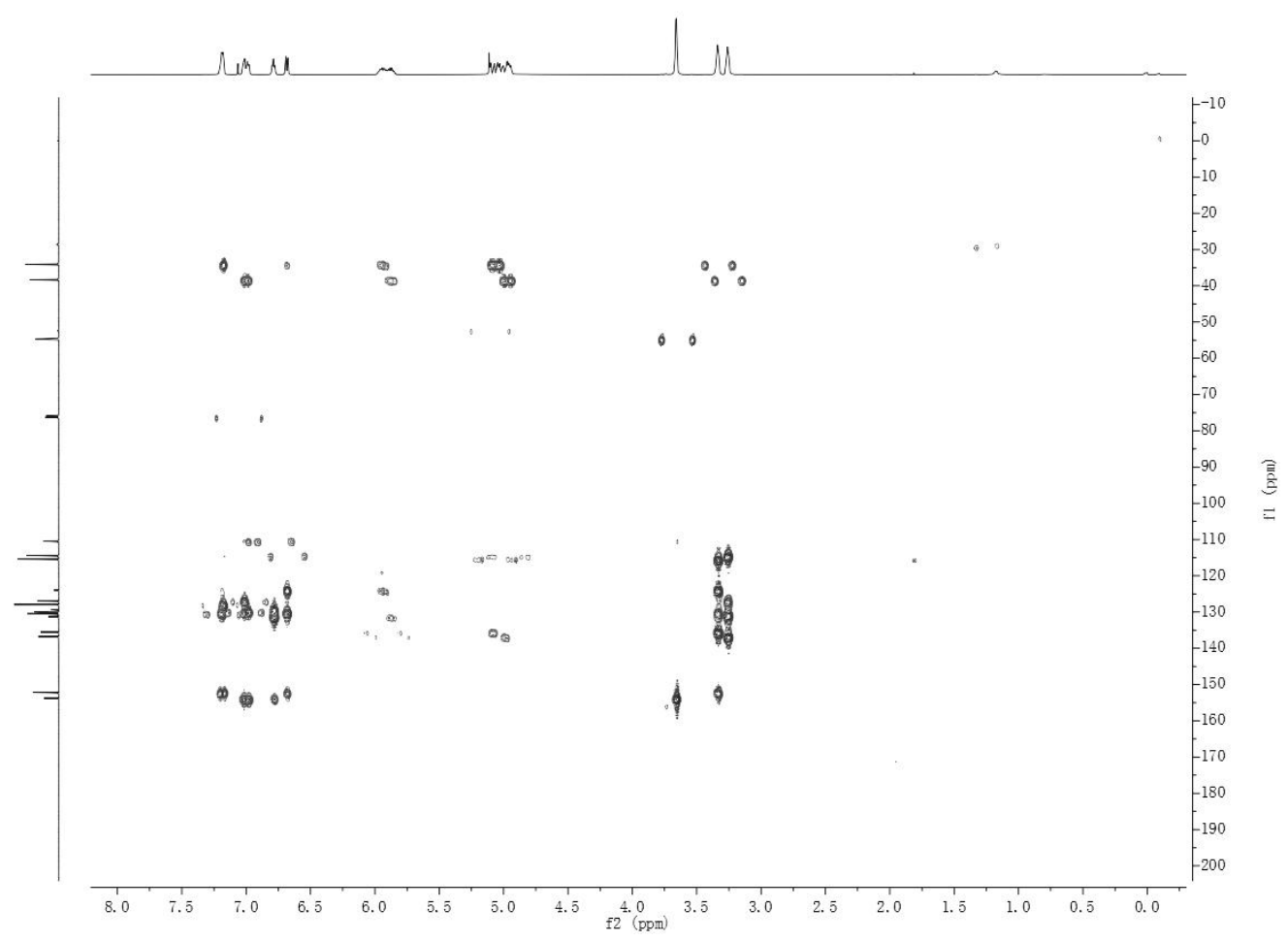

Figure S16. $\mathrm{HMBC}$ spectrum of $2 \mathrm{c}$ in $\mathrm{CDCl}_{3}$.

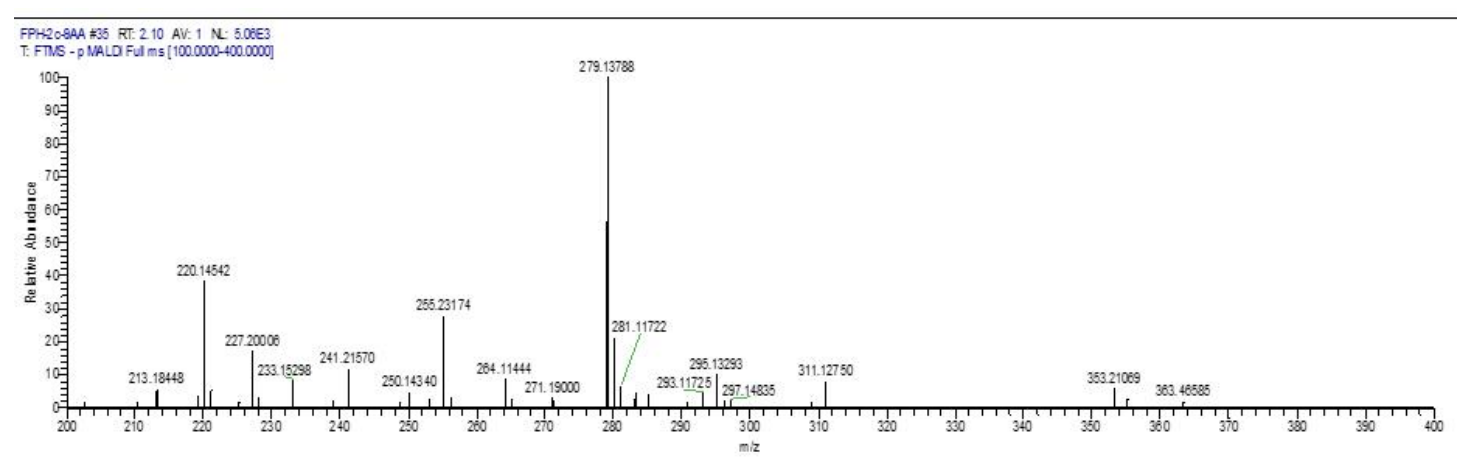

Figure S17. HR-ESI-MS spectrum of $2 c$. 


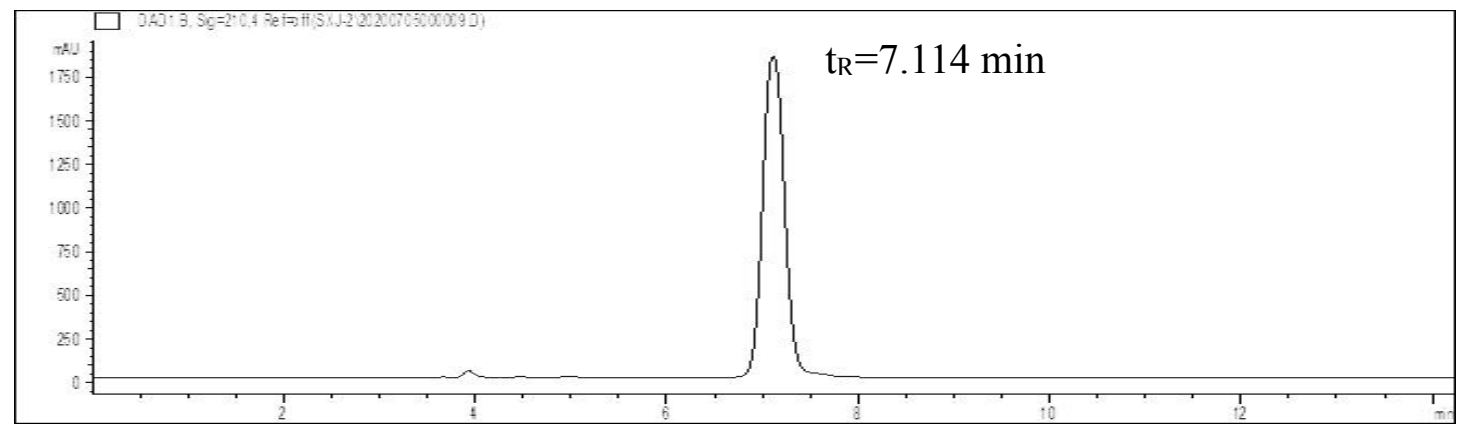

Figure S18. HPLC chromatogram of 2c.

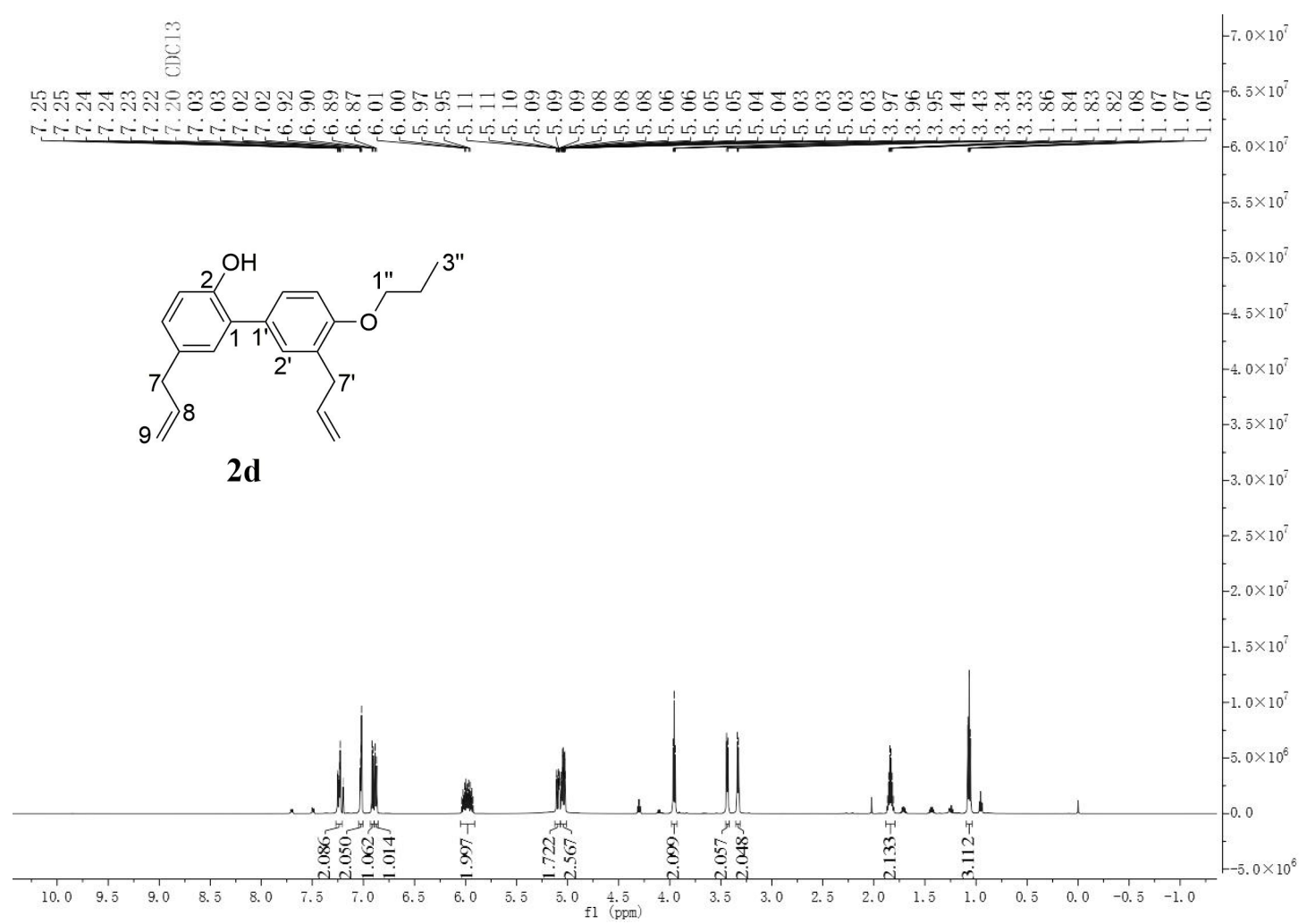

Figure S19. ${ }^{1} \mathrm{H}$ NMR spectrum of $\mathbf{2 d}$ in $\mathrm{CDCl}_{3}$. 


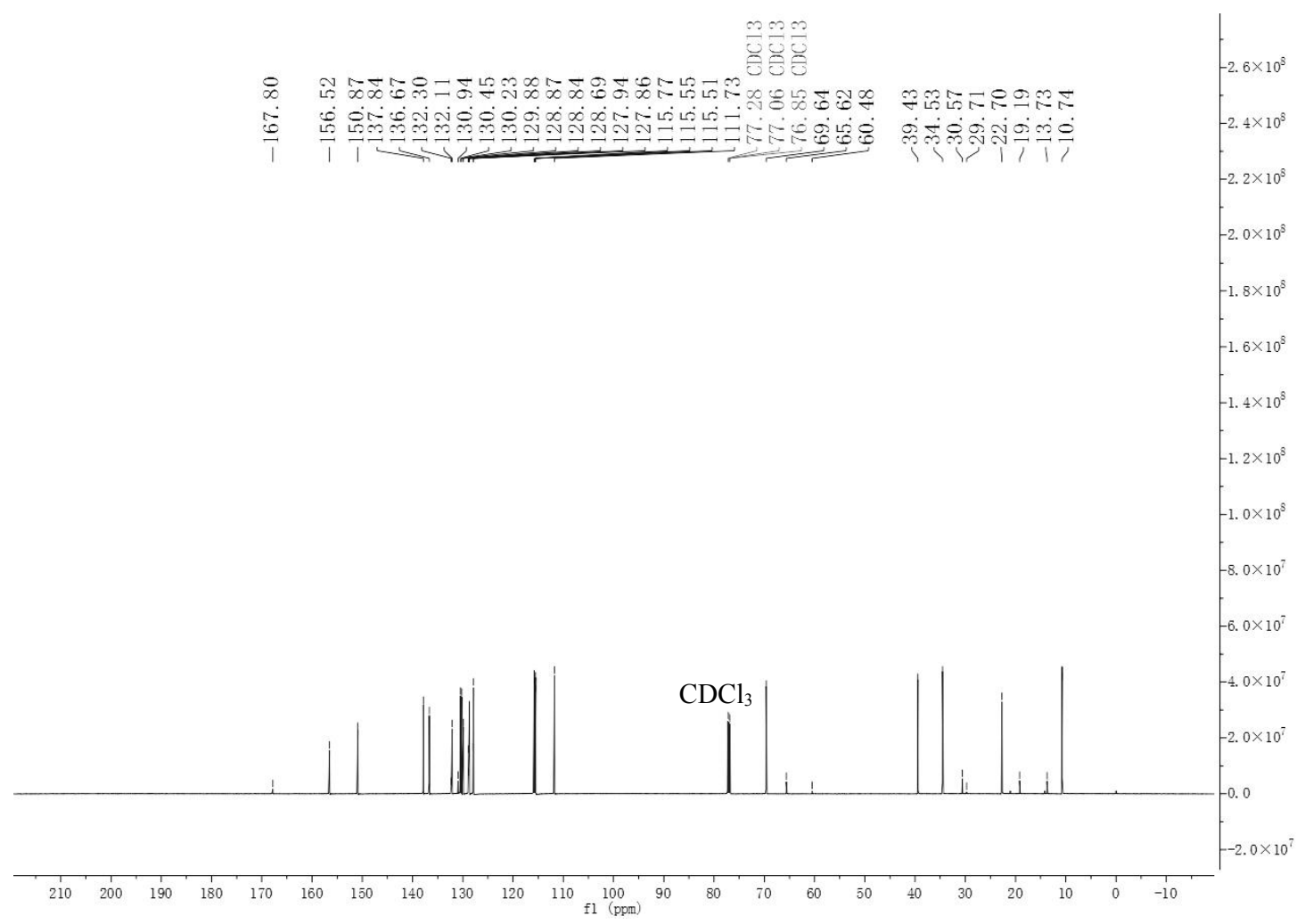

Figure S20. ${ }^{13} \mathrm{C}$ NMR spectrum of $\mathbf{2 d}$ in $\mathrm{CDCl}_{3}$.

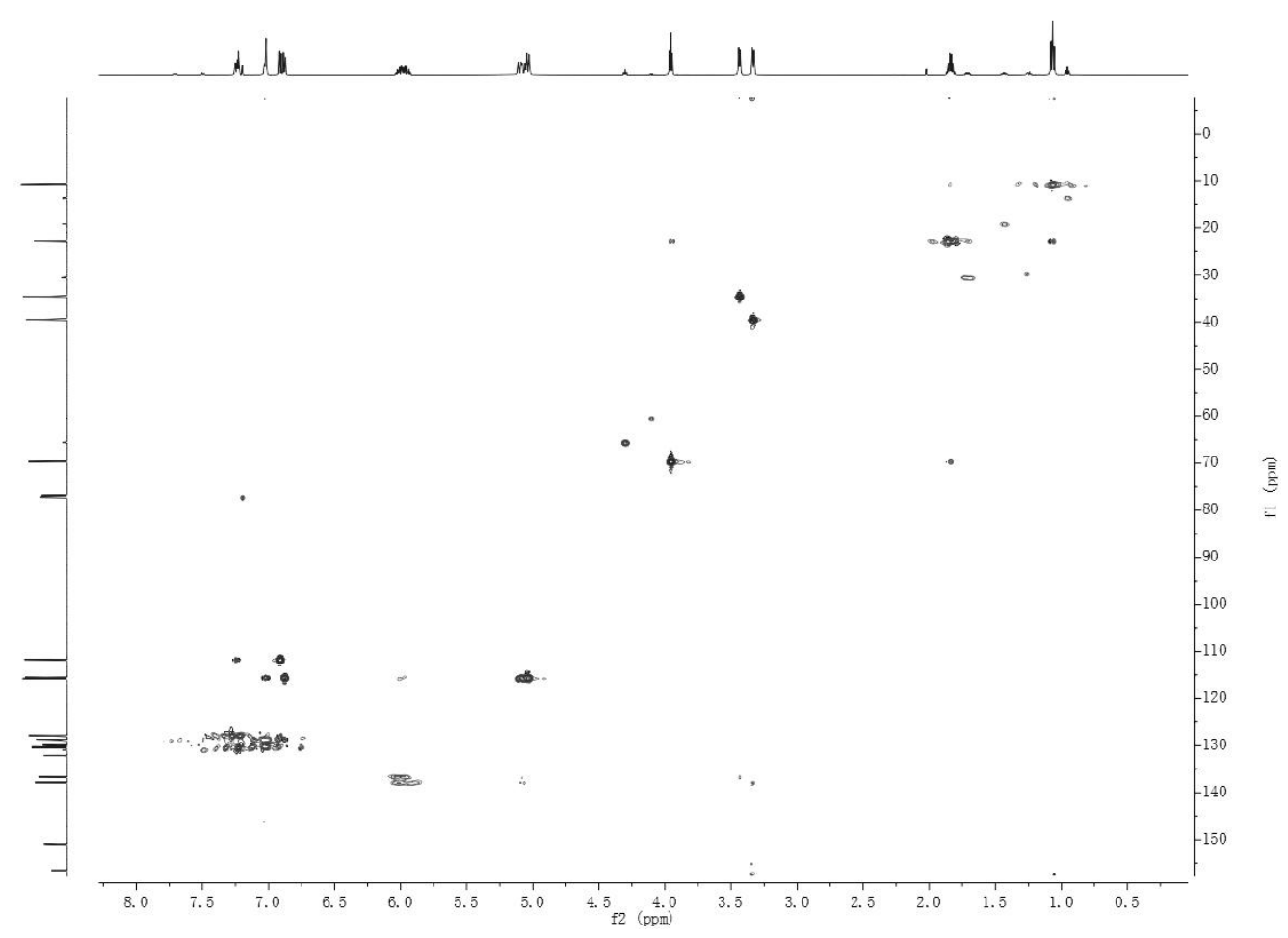

Figure S21. HSQC spectrum of $\mathbf{2 d}$ in $\mathrm{CDCl}_{3}$. 


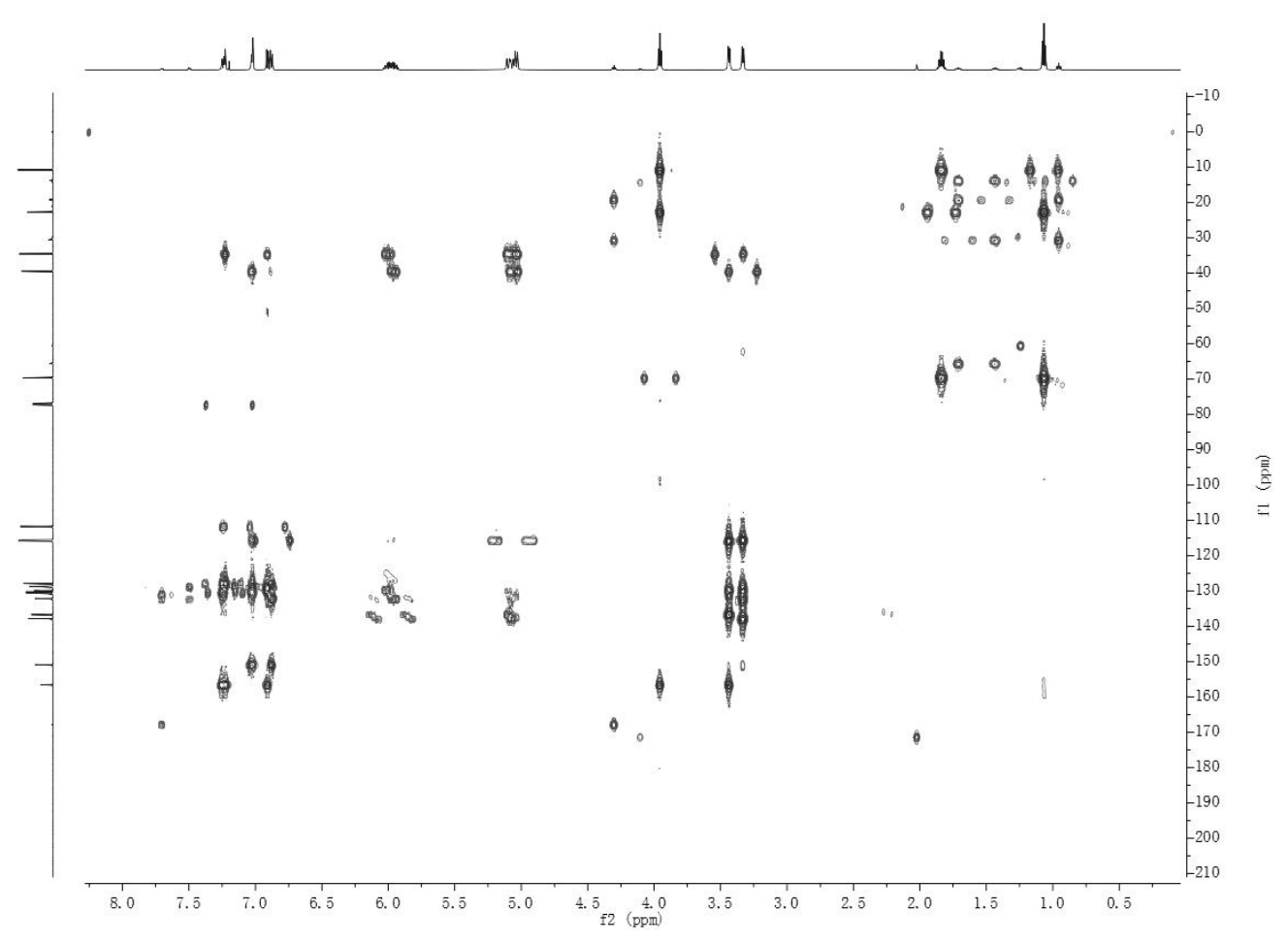

Figure S22. $\mathrm{HMBC}$ spectrum of $\mathbf{2 d}$ in $\mathrm{CDCl}_{3}$.

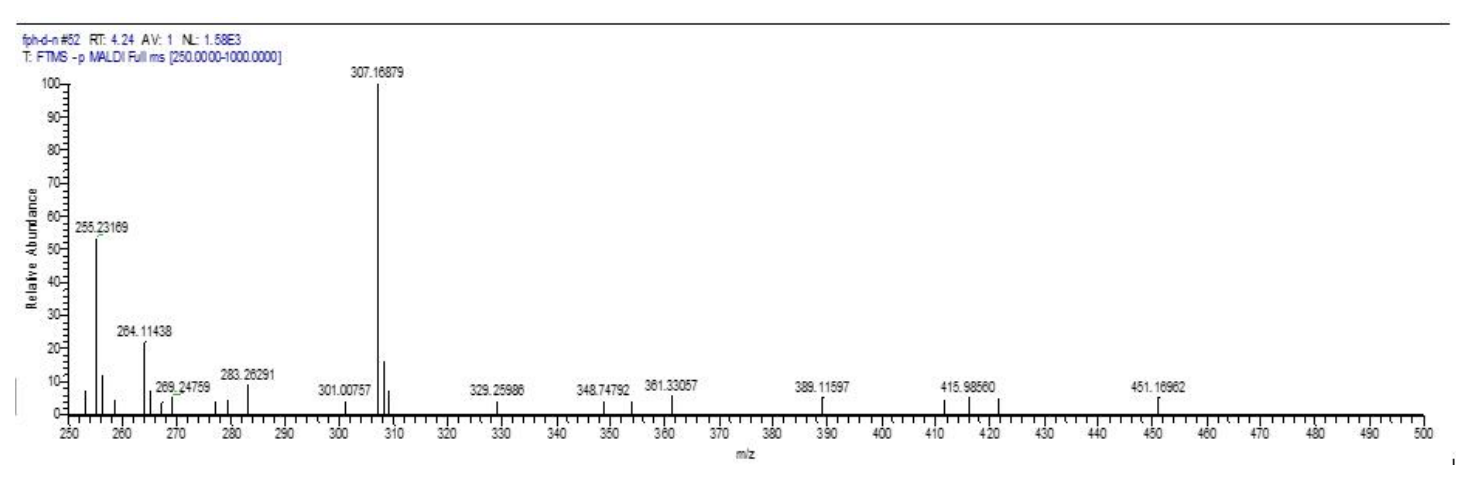

Figure S23. HR-ESI-MS spectrum of $2 d$.

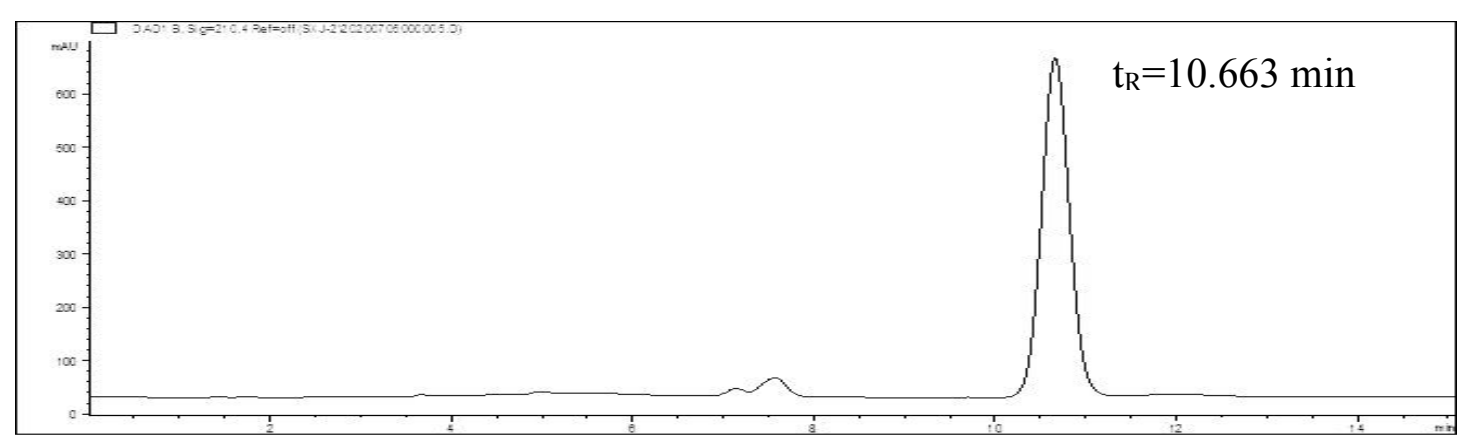


Figure S24. HPLC chromatogram of $2 d$.

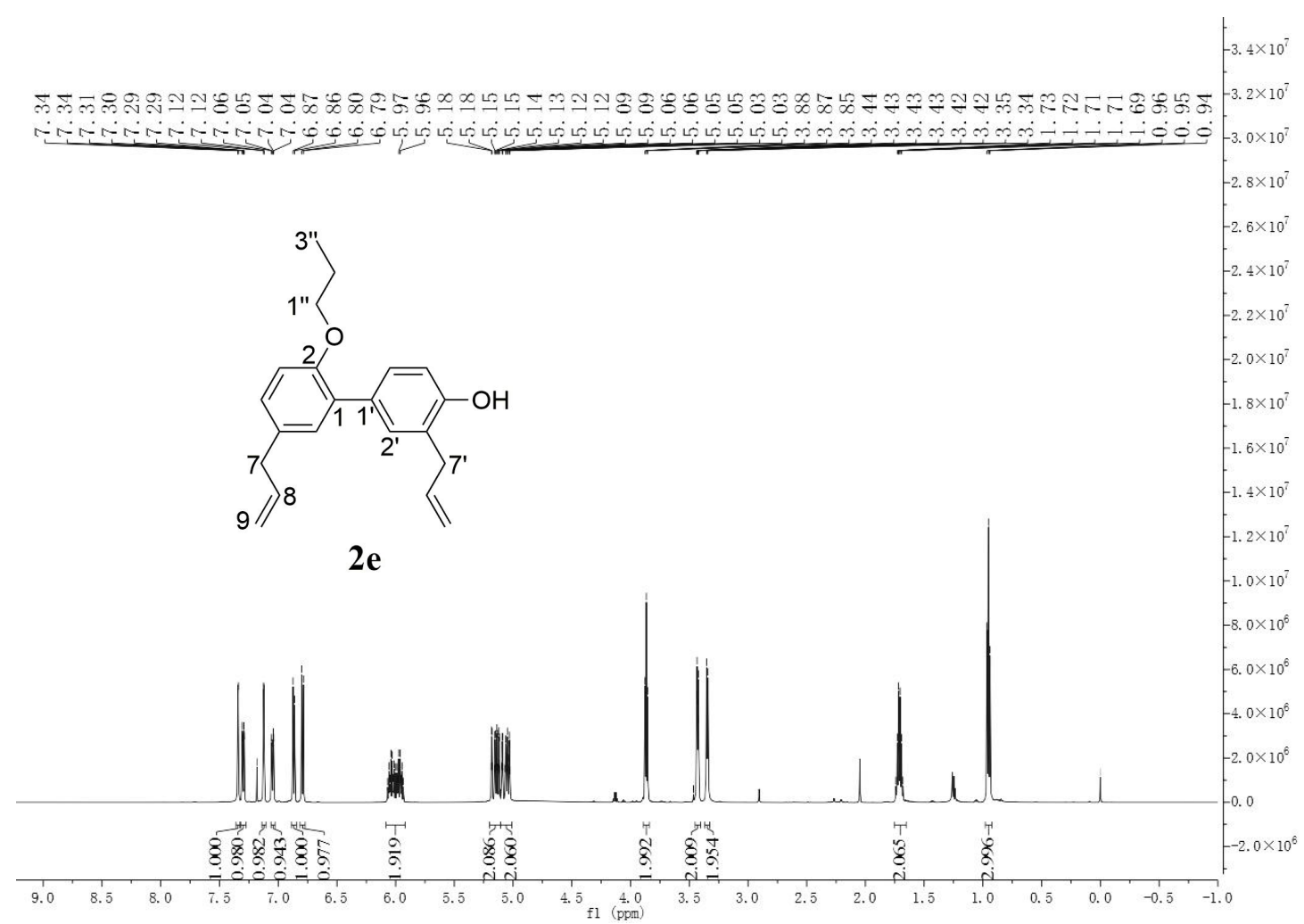

Figure S25. ${ }^{1} \mathrm{H}$ NMR spectrum of $\mathbf{2 e}$ in $\mathrm{CDCl}_{3}$.

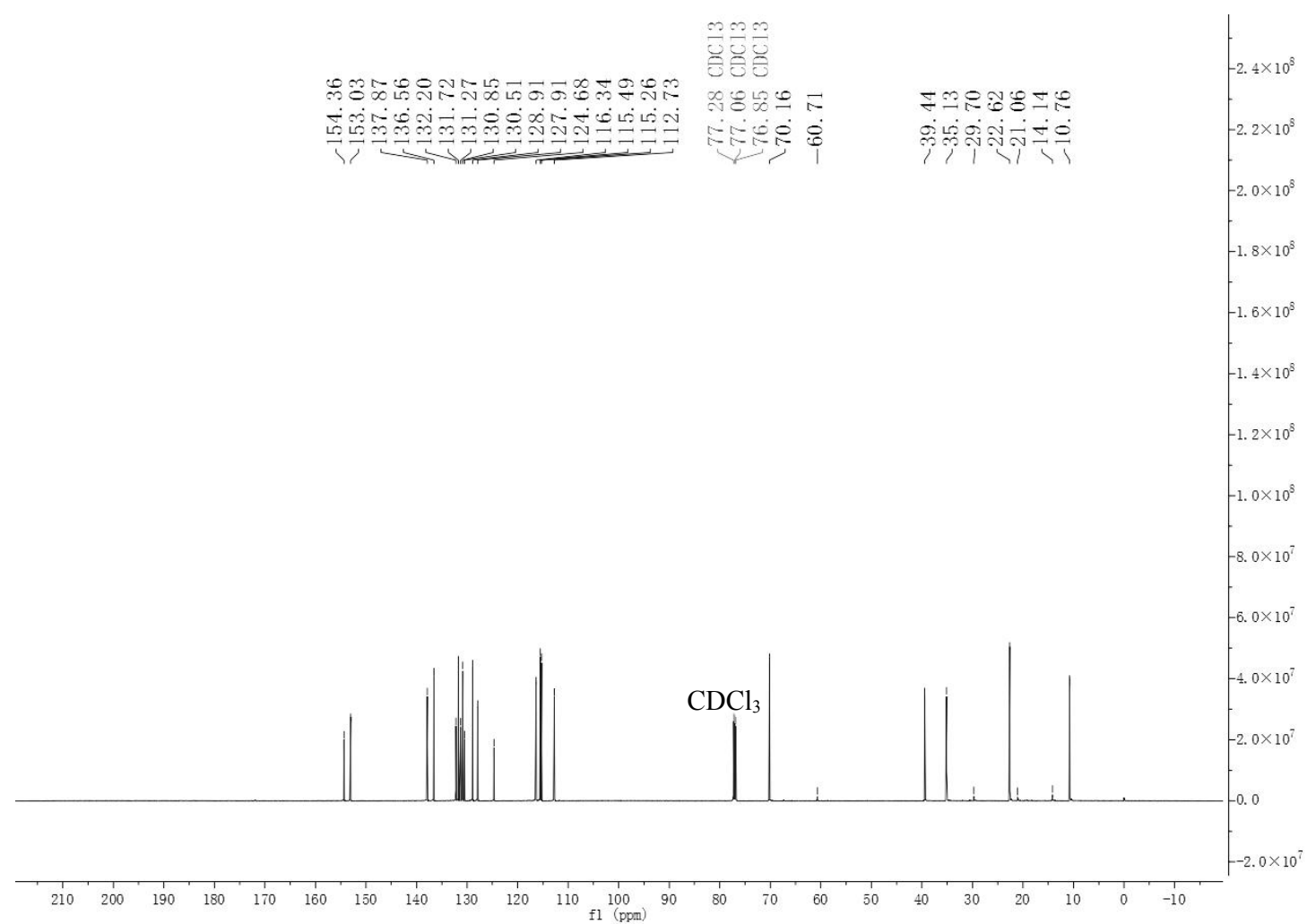


Figure S26. ${ }^{13} \mathrm{C}$ NMR spectrum of $2 \mathbf{e}$ in $\mathrm{CDCl}_{3}$.

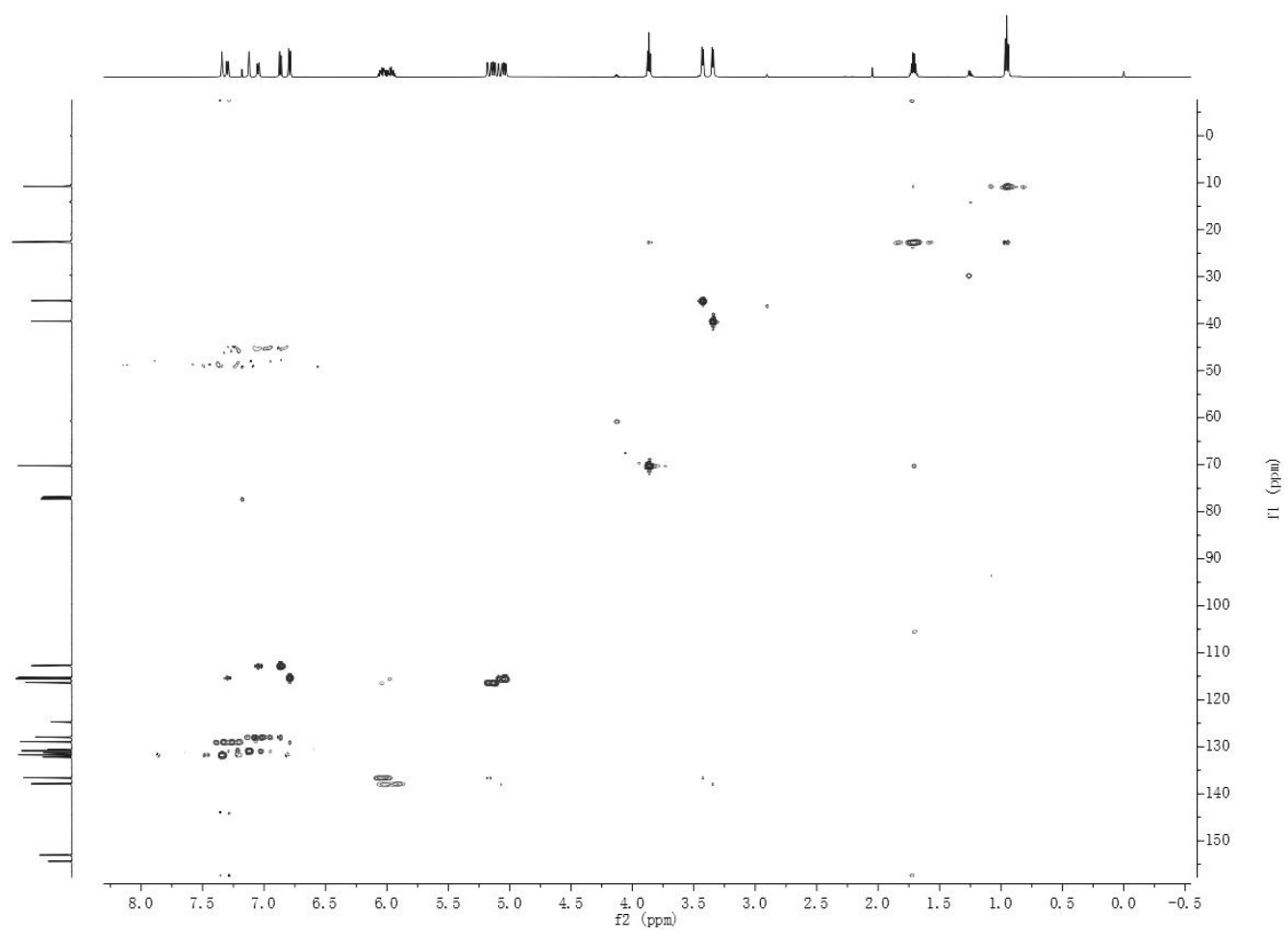

Figure S27. HSQC spectrum of $\mathbf{2 e}$ in $\mathrm{CDCl}_{3}$.

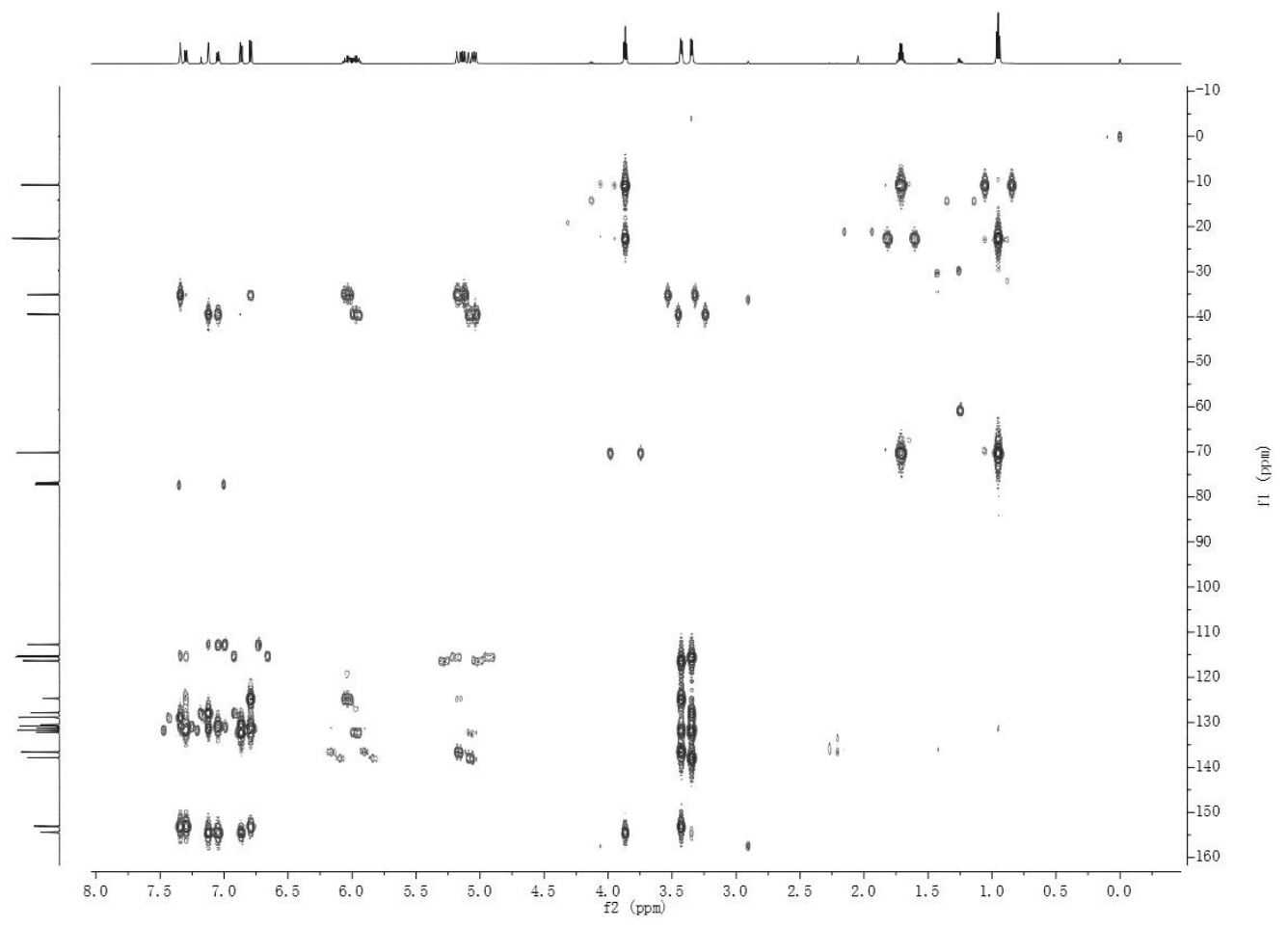

S23 
Figure S28. $\mathrm{HMBC}$ spectrum of $\mathbf{2 e}$ in $\mathrm{CDCl}_{3}$.

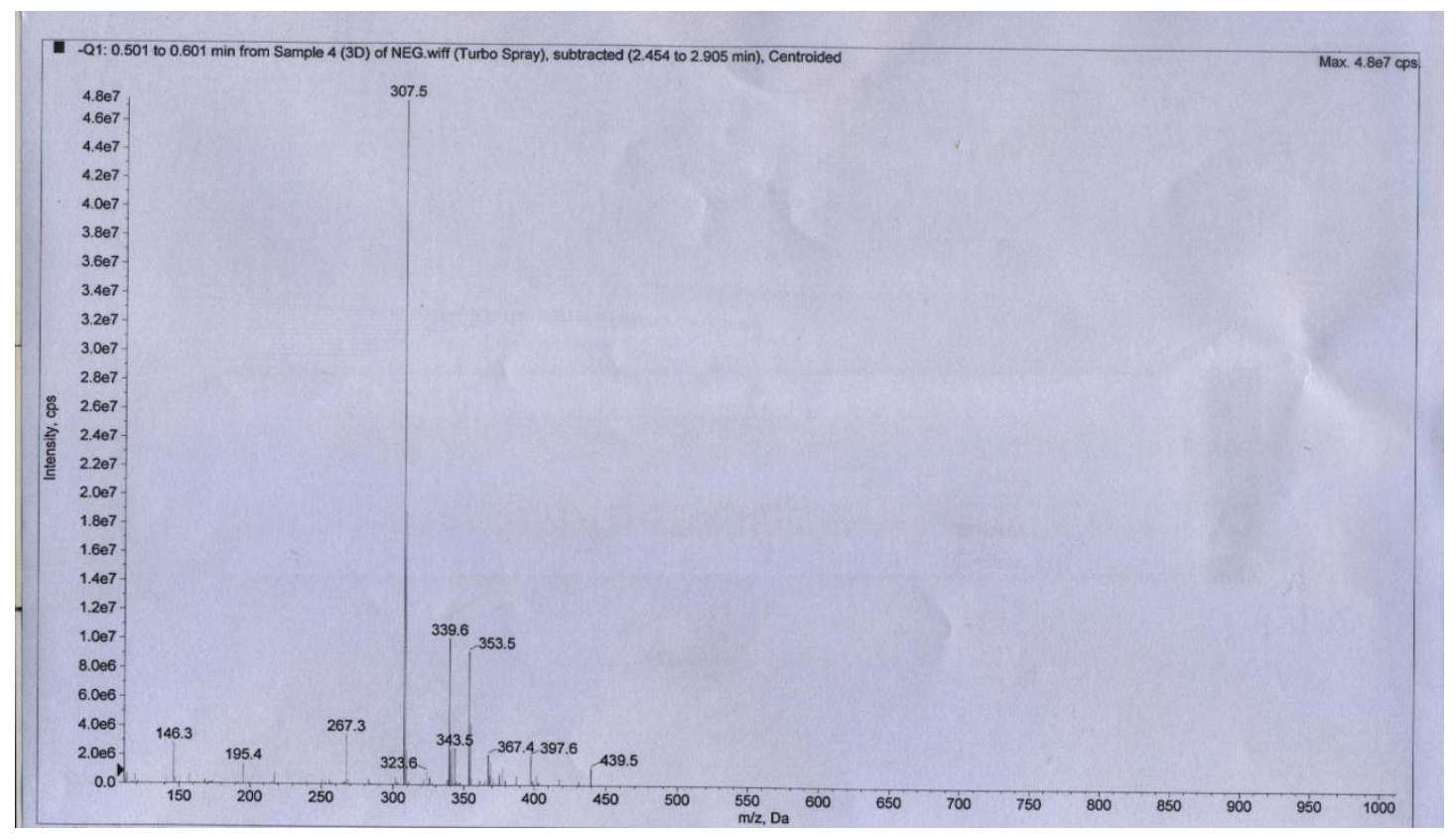

Figure S29. ESI-MS spectrum of $2 \mathbf{e}$.

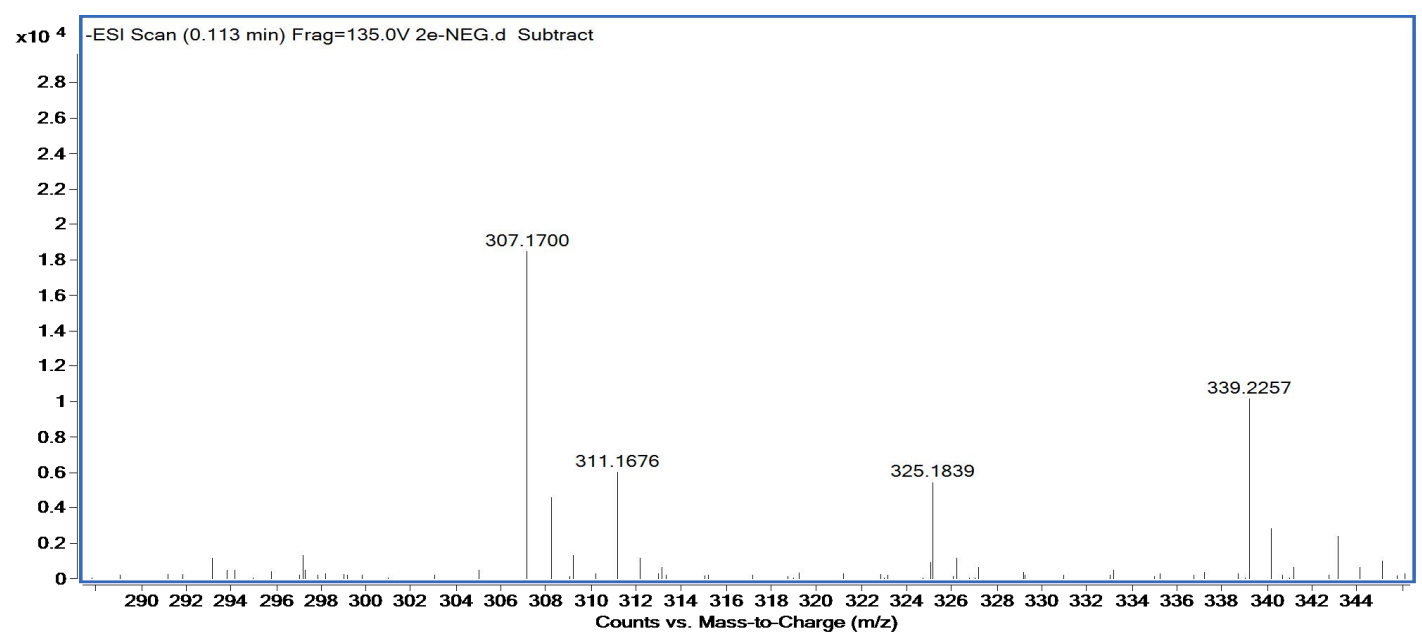

Figure S30. HR-ESI-MS spectrum of $2 \mathbf{e}$. 


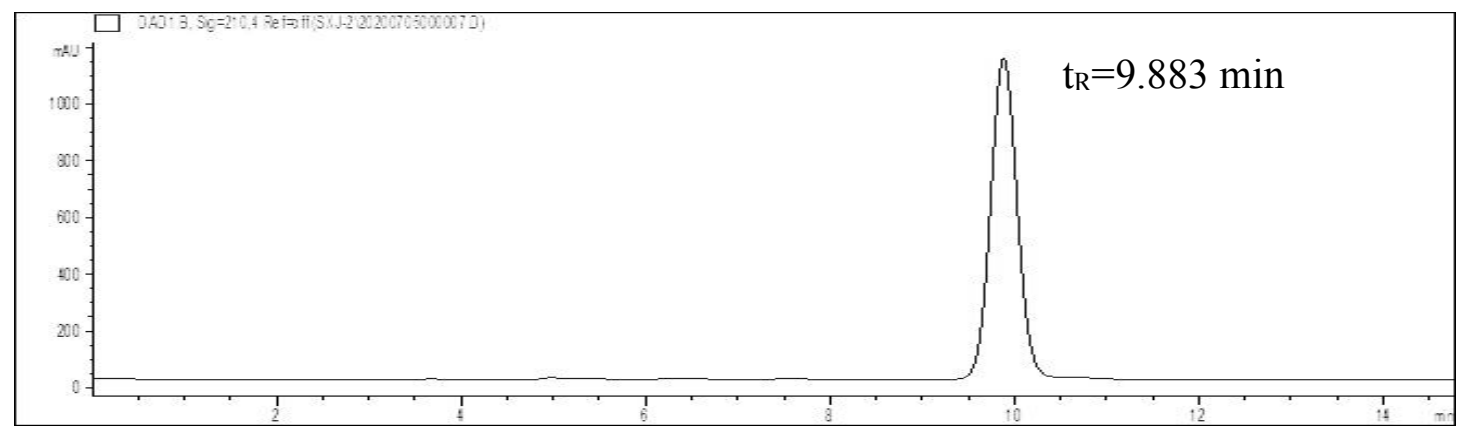

Figure S31. HPLC chromatogram of $2 \mathbf{e}$.

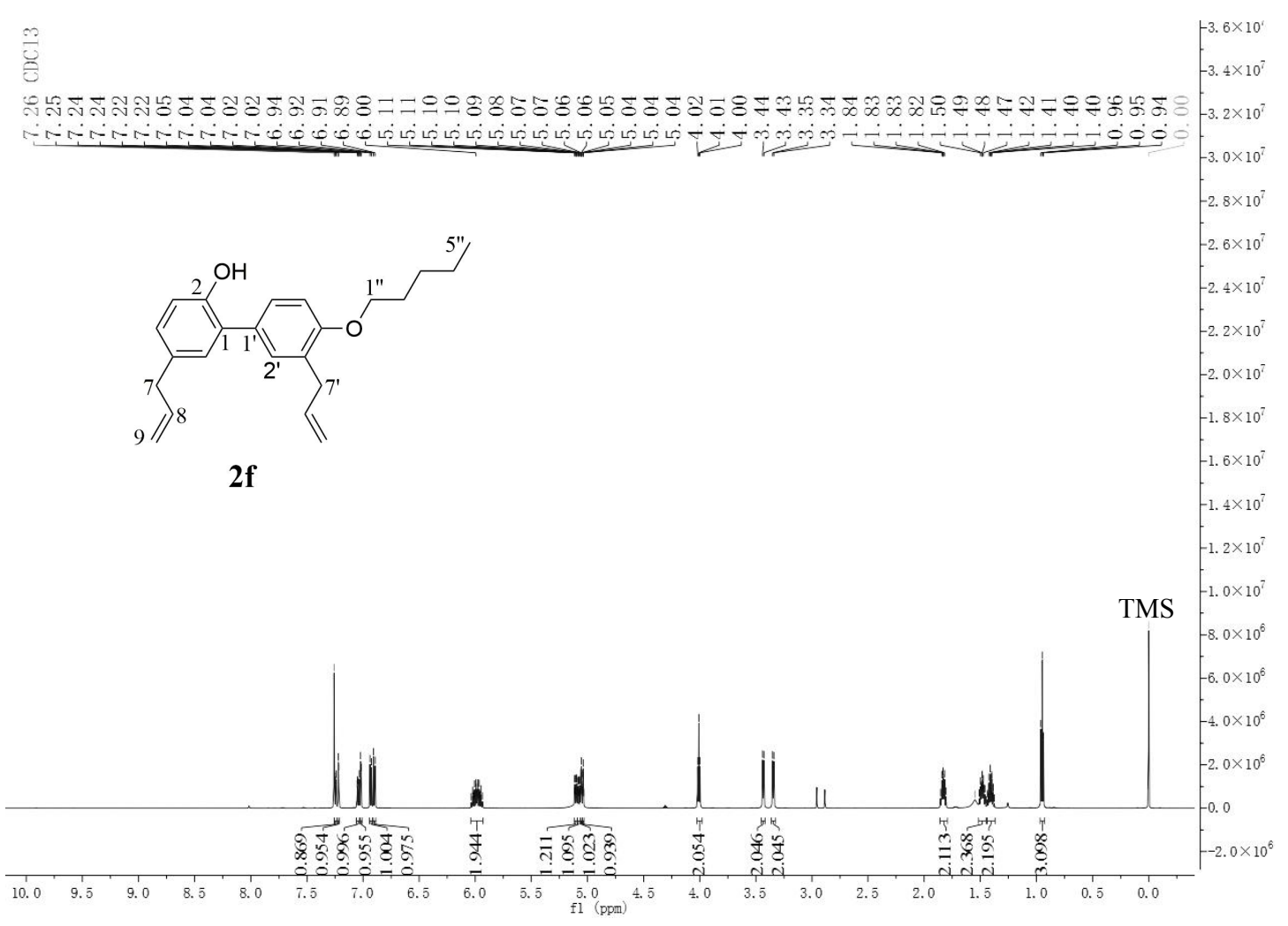

Figure S32. ${ }^{1} \mathrm{H}$ NMR spectrum of $2 \mathbf{f}$ in $\mathrm{CDCl}_{3}$. 


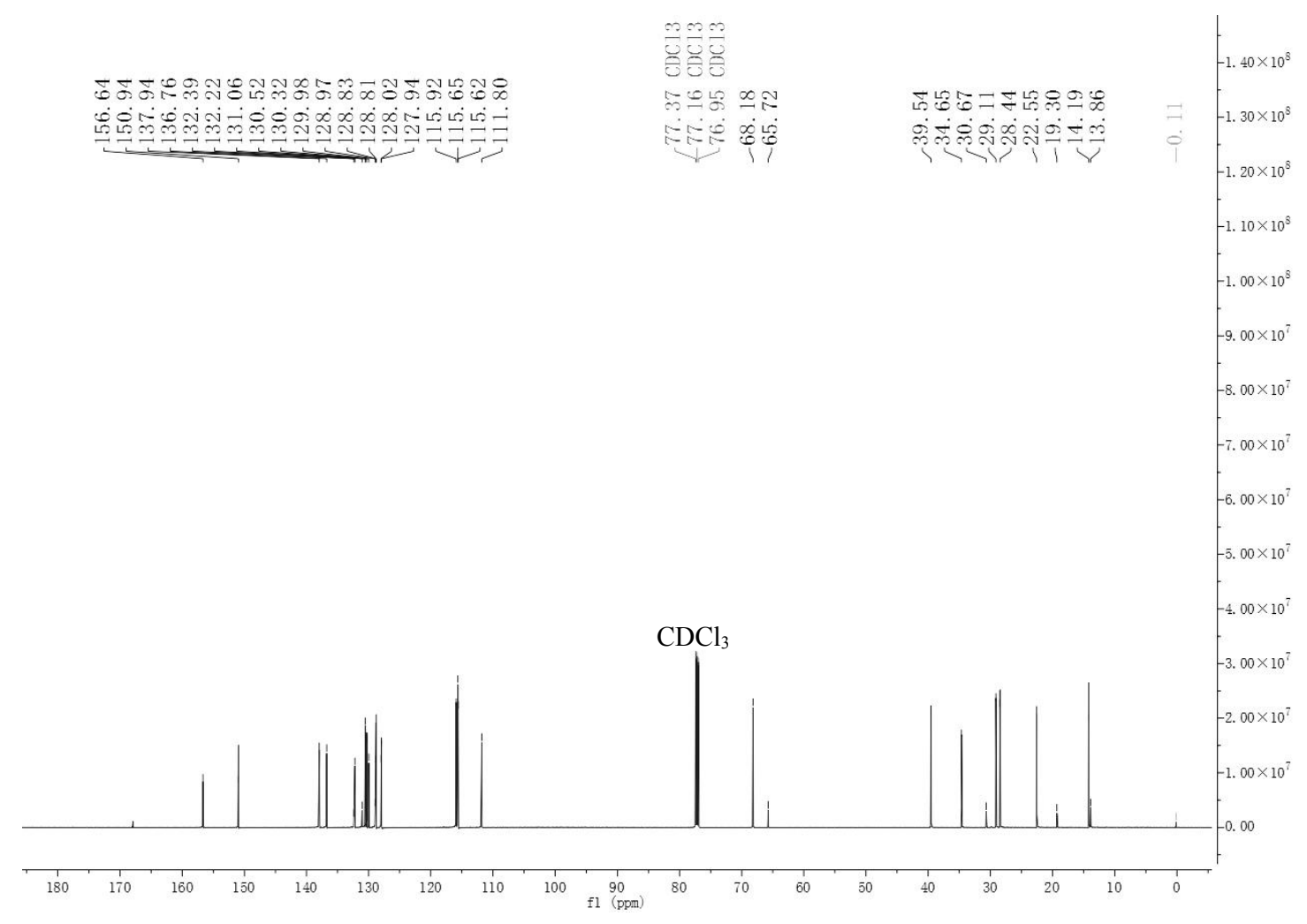

Figure S33. ${ }^{13} \mathrm{C}$ NMR spectrum of $2 \mathrm{f}$ in $\mathrm{CDCl}_{3}$.

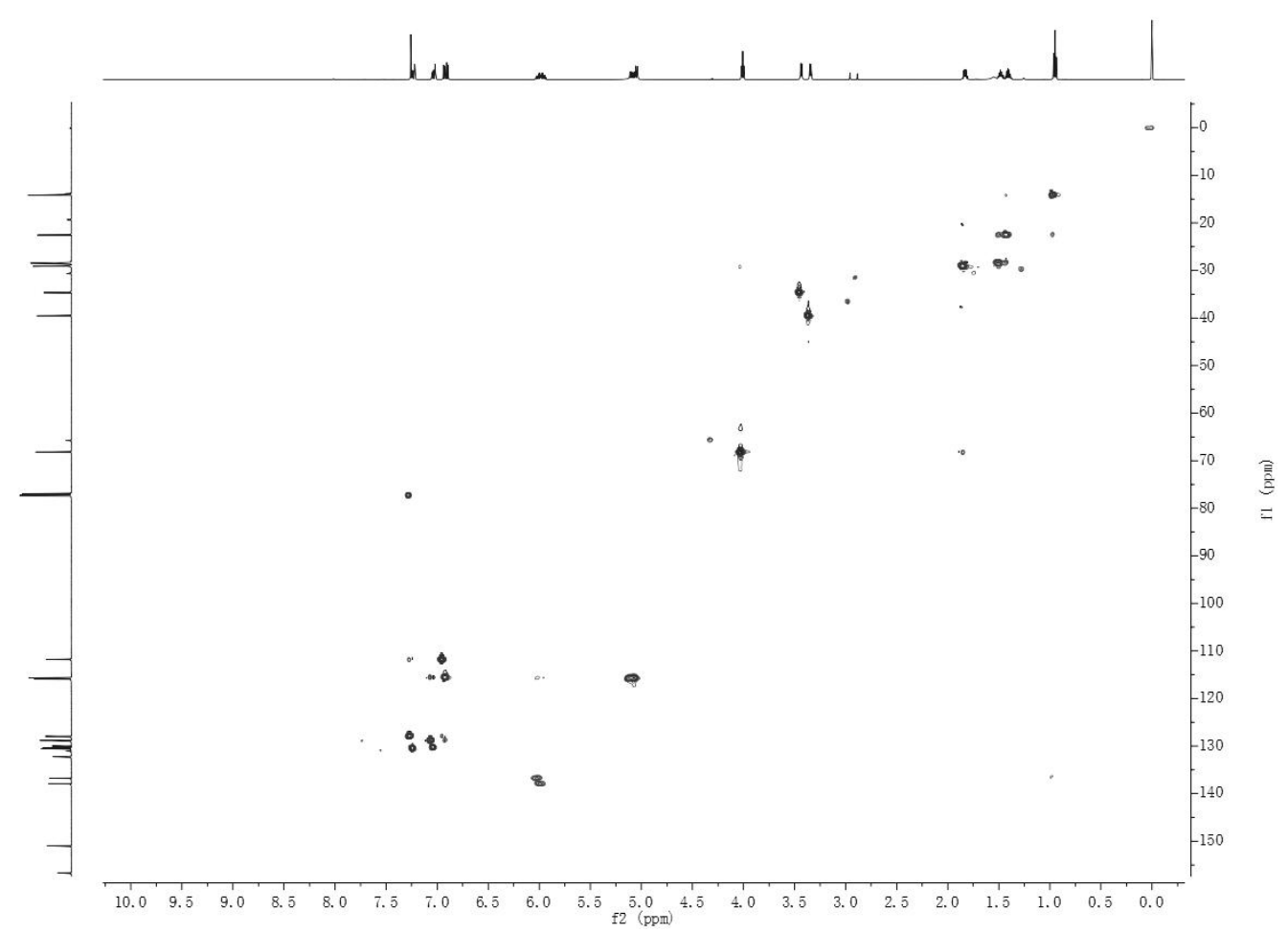

Figure S34. HSQC spectrum of $\mathbf{2} \mathbf{f}$ in $\mathrm{CDCl}_{3}$. 


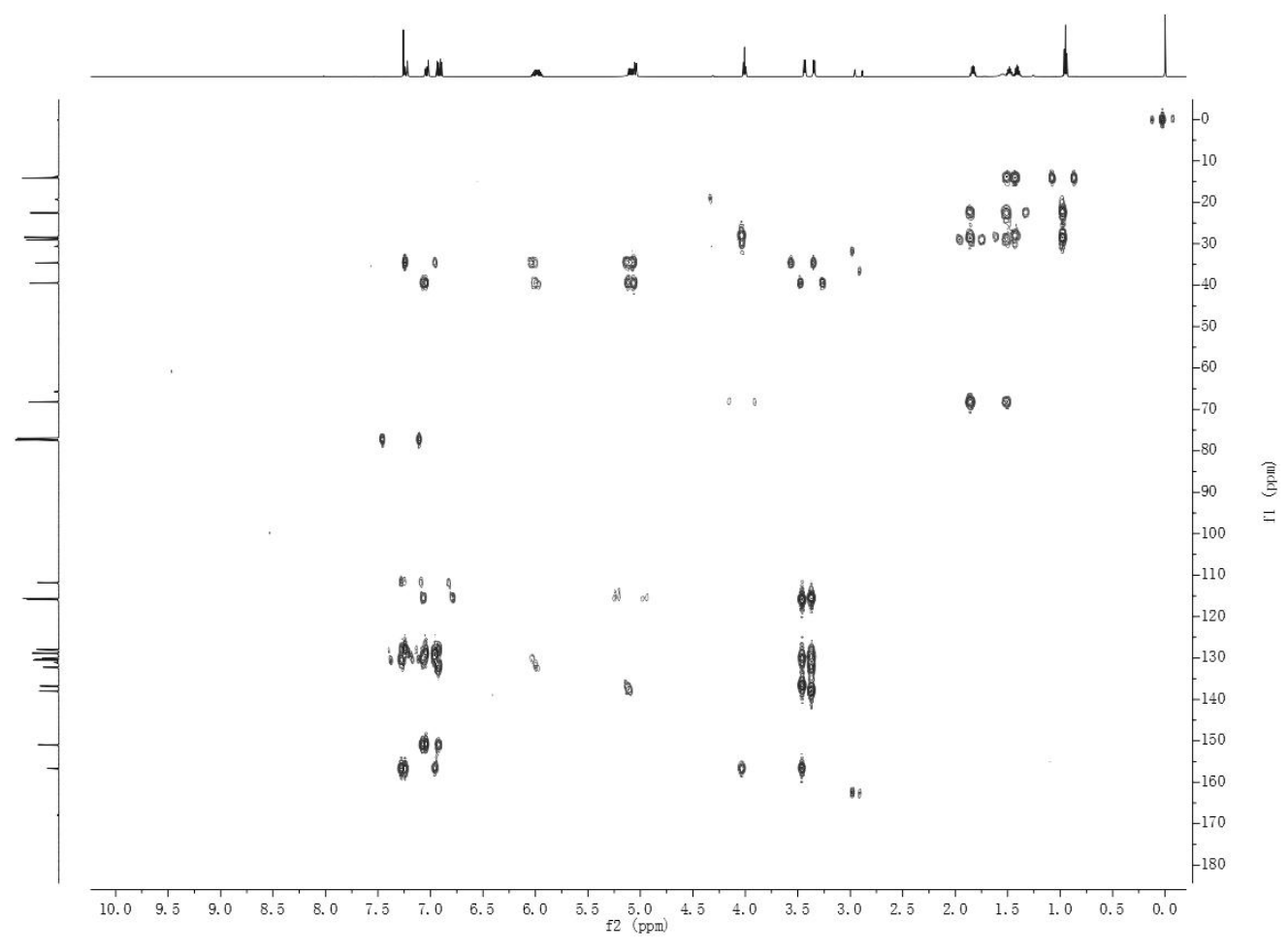

Figure S35. $\mathrm{HMBC}$ spectrum of $\mathbf{2} \mathbf{f}$ in $\mathrm{CDCl}_{3}$.

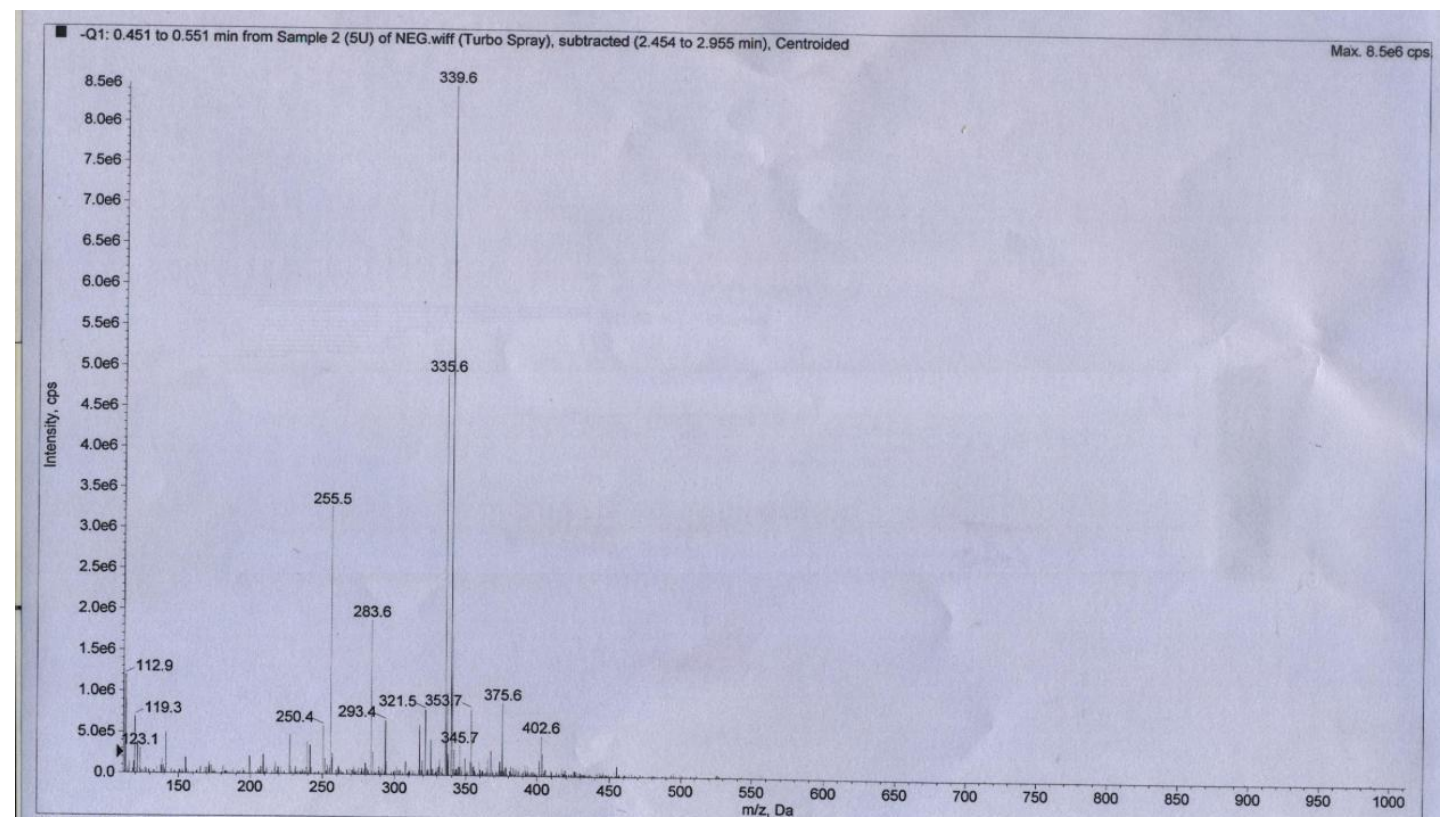

Figure S36. ESI-MS spectrum of $2 \mathbf{f}$. 


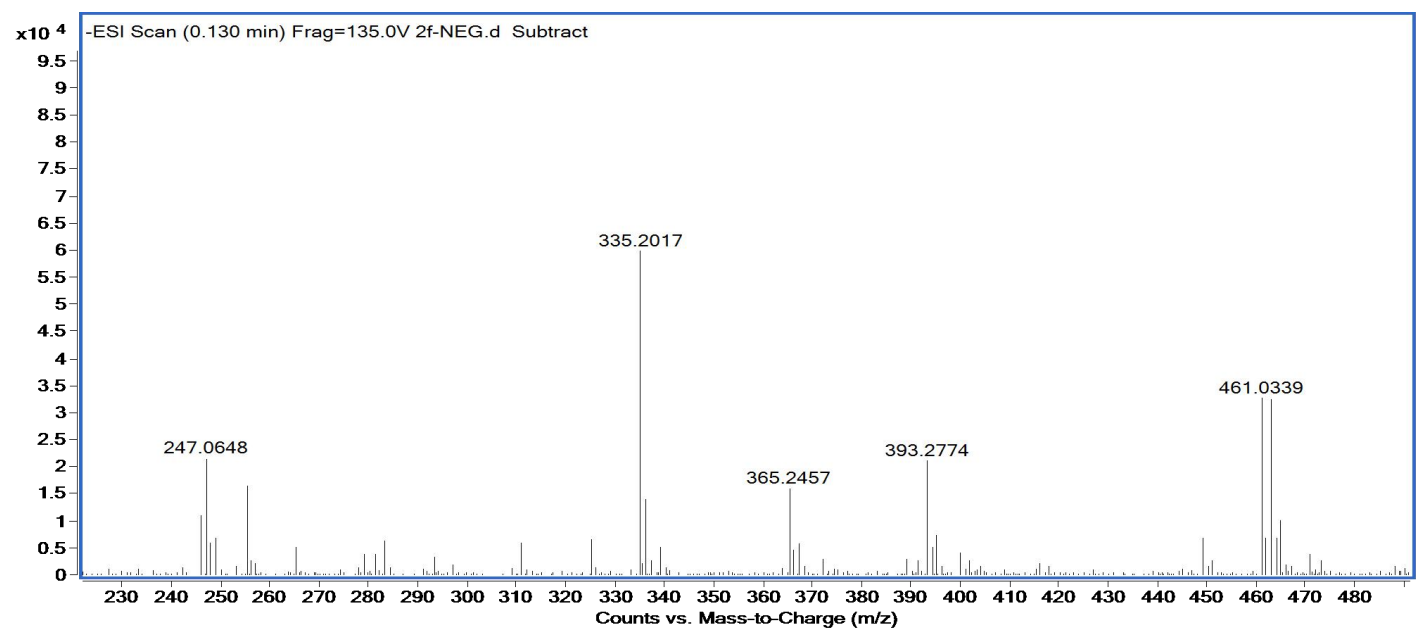

Figure S37. HR-ESI-MS spectrum of $\mathbf{2 f}$.

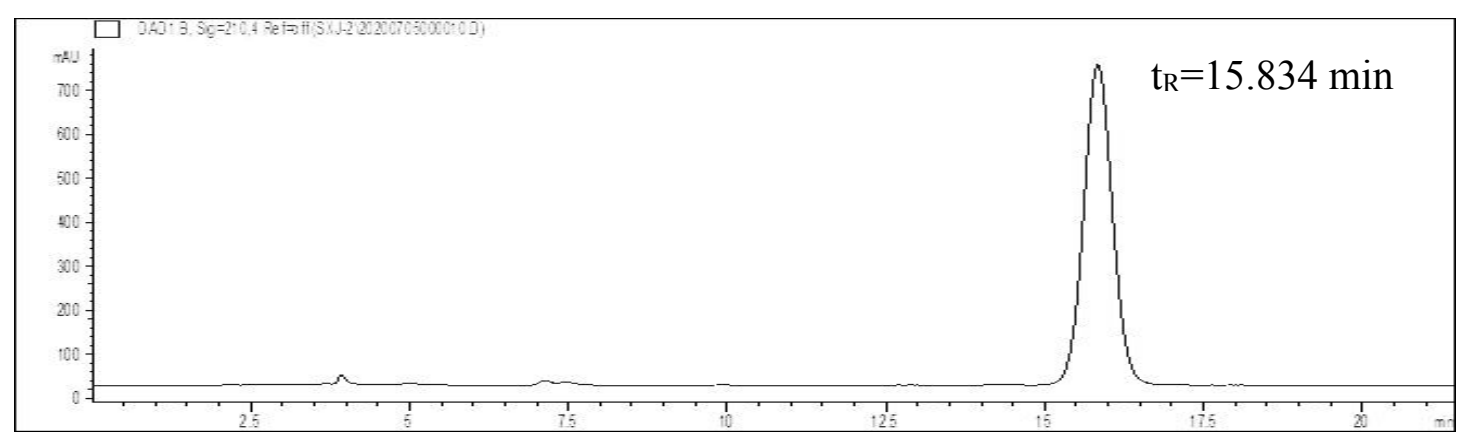

Figure S38. HPLC chromatogram of $2 \mathbf{f}$. 


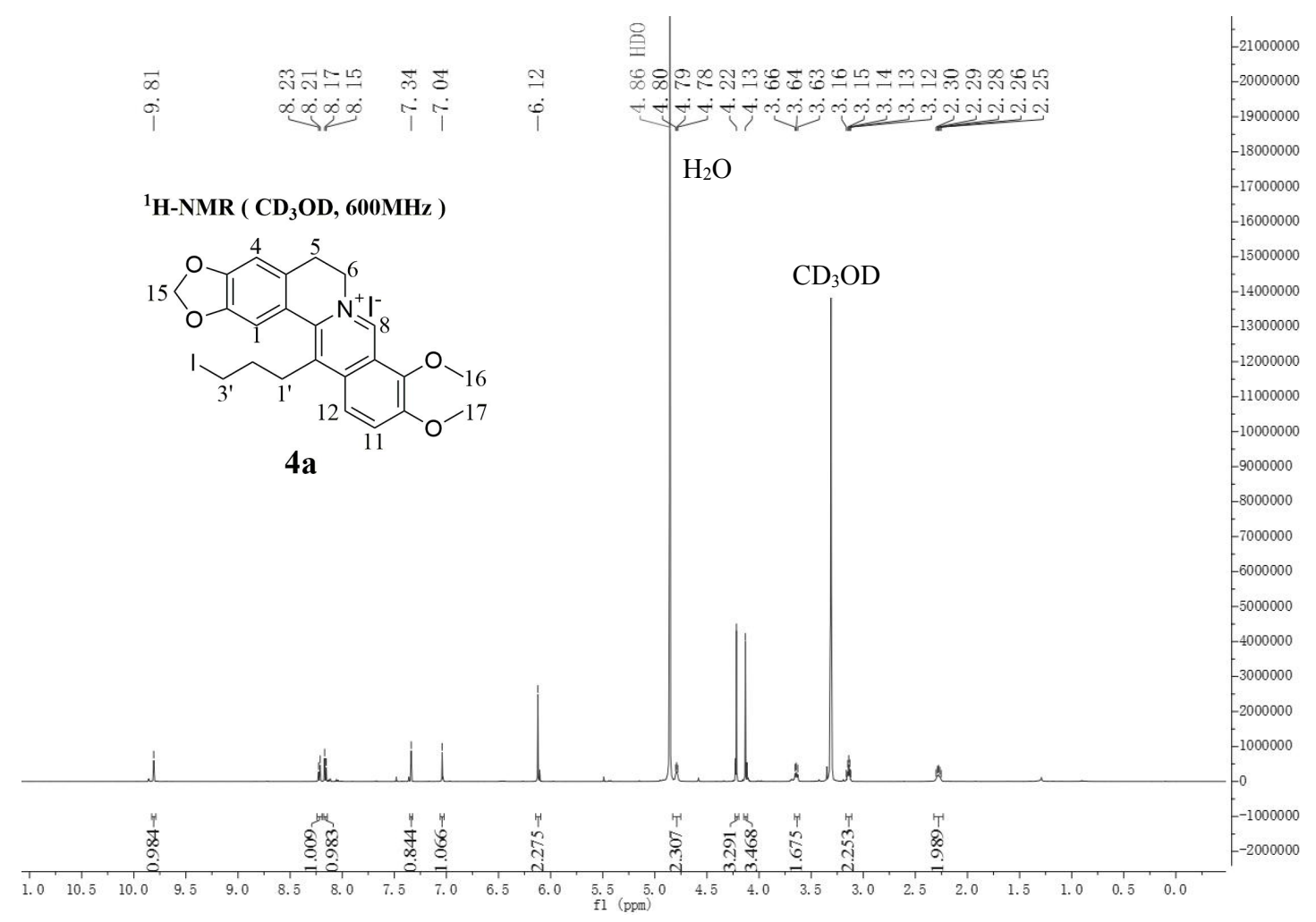

Figure S39. ${ }^{1} \mathrm{H}-\mathrm{NMR}$ spectrum of $\mathbf{4 a}$ in $\mathrm{CD}_{3} \mathrm{OD}$.

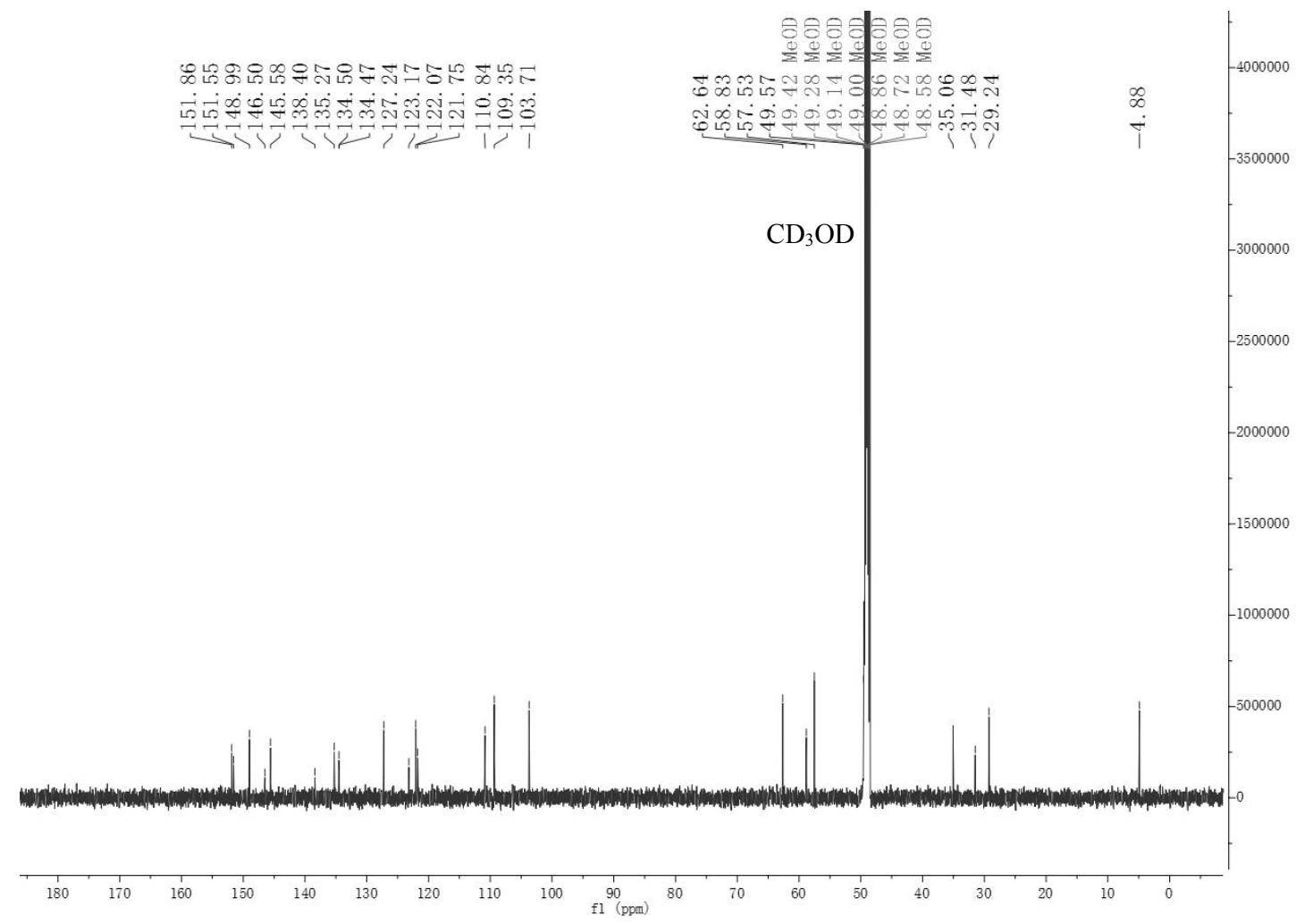

Figure S40. ${ }^{13} \mathrm{C}-\mathrm{NMR}$ spectrum of $\mathbf{4 a}$ in $\mathrm{CD}_{3} \mathrm{OD}$. 


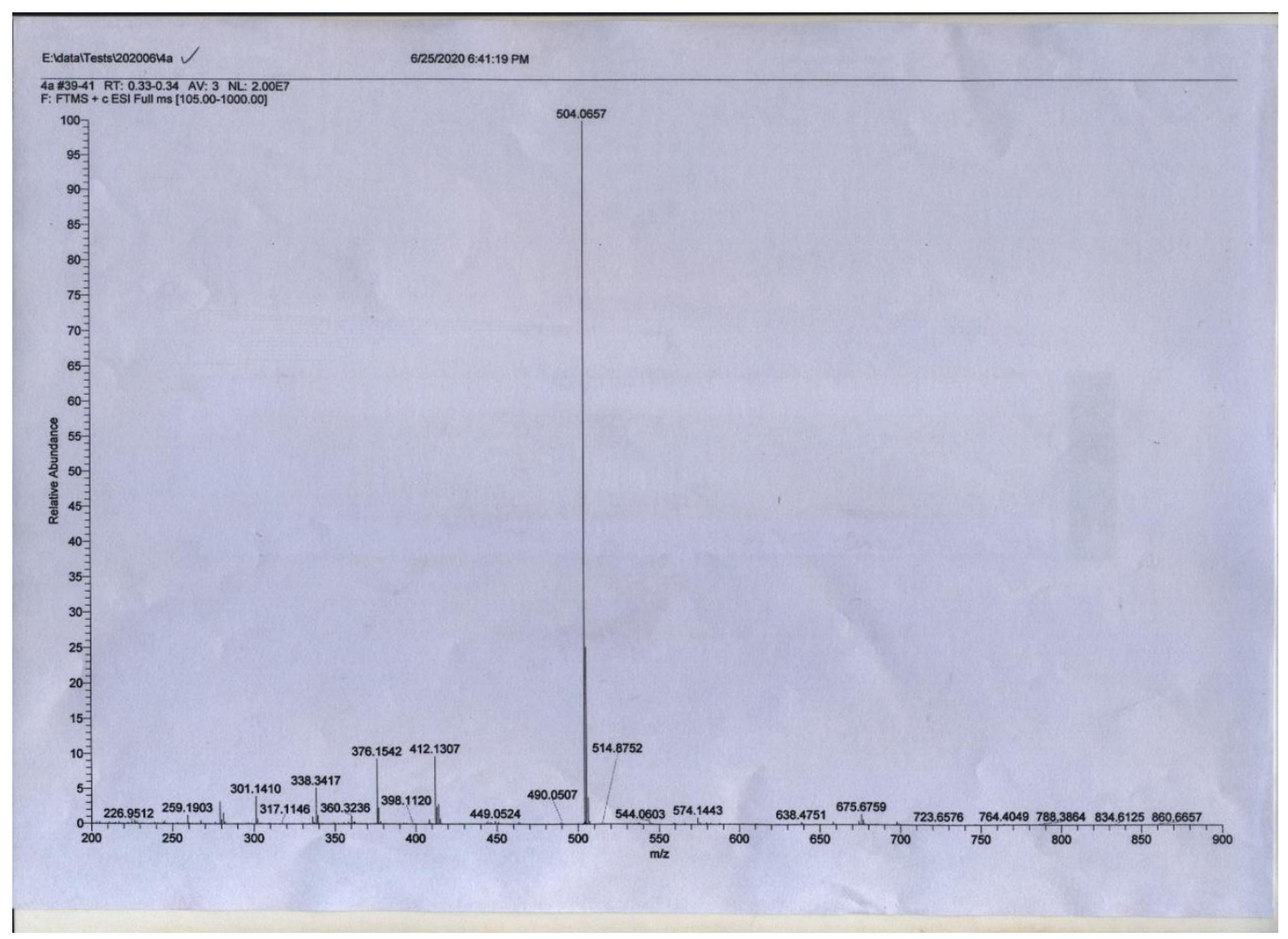

Figure S41. HR-ESI-MS spectrum of 4a.

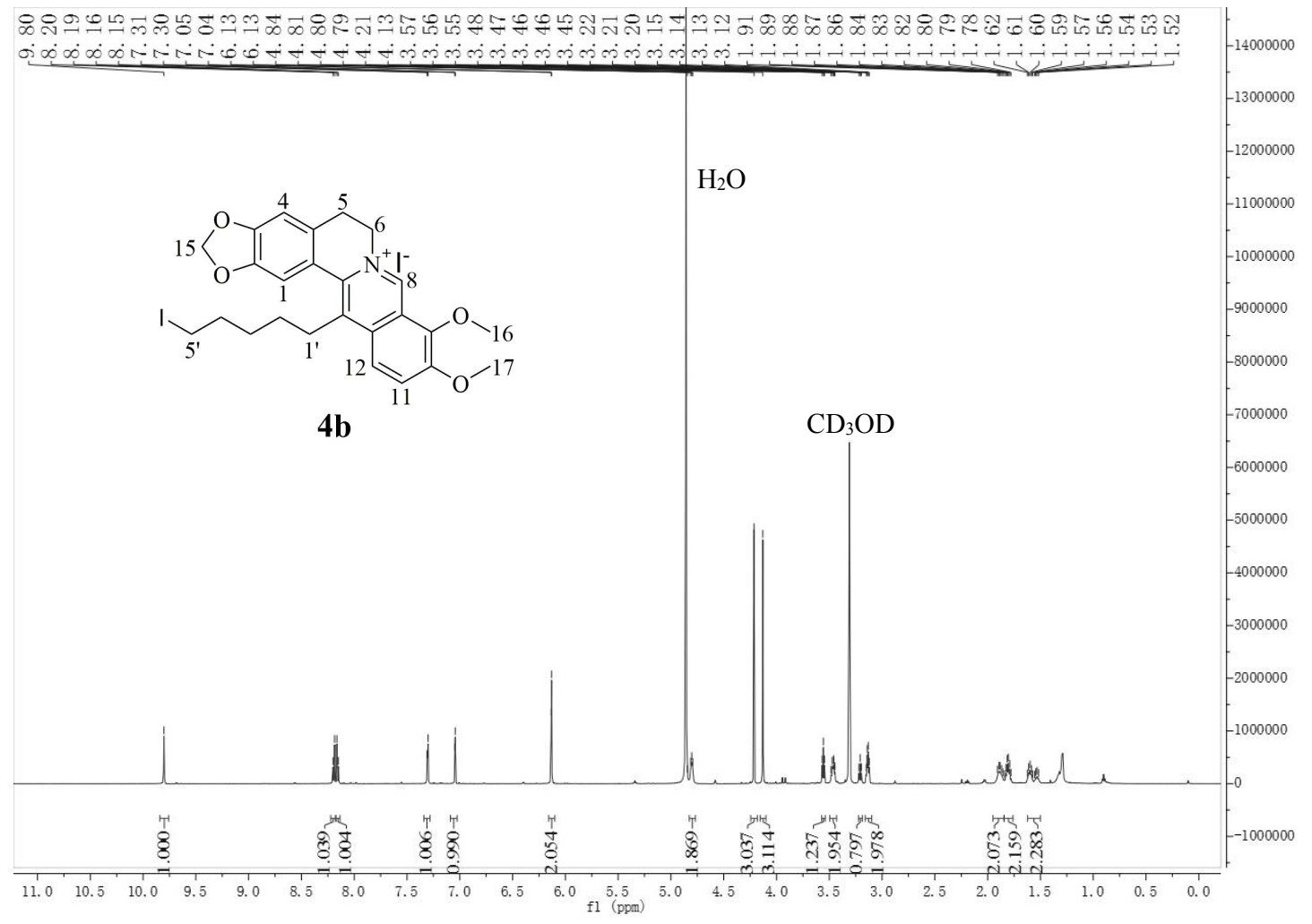

Figure S42. ${ }^{1} \mathrm{H}-\mathrm{NMR}$ spectrum of $\mathbf{4 b}$ in $\mathrm{CD}_{3} \mathrm{OD}$. 


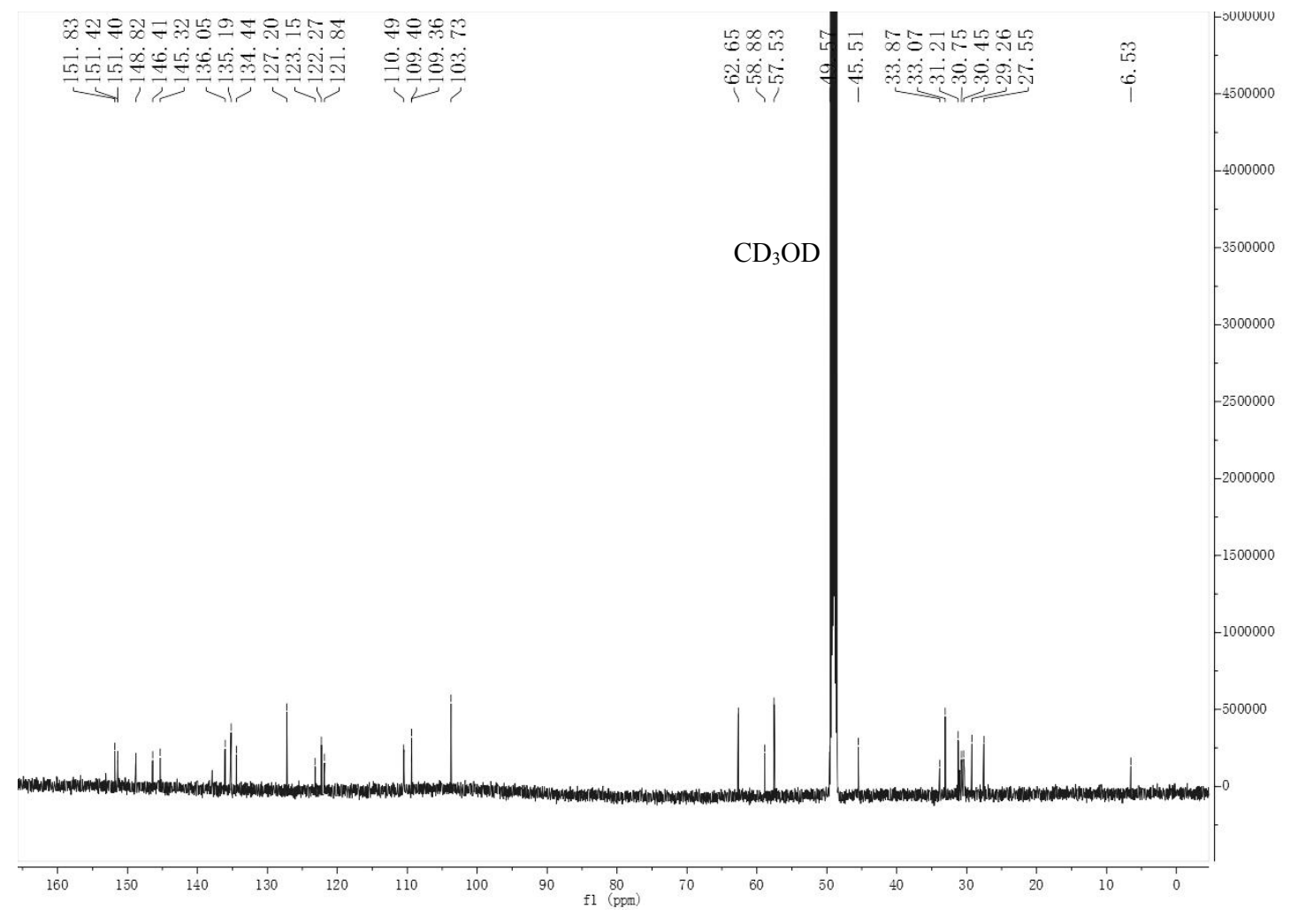

Figure S43. ${ }^{13} \mathrm{C}-\mathrm{NMR}$ spectrum of $\mathbf{4 b}$ in $\mathrm{CD}_{3} \mathrm{OD}$.

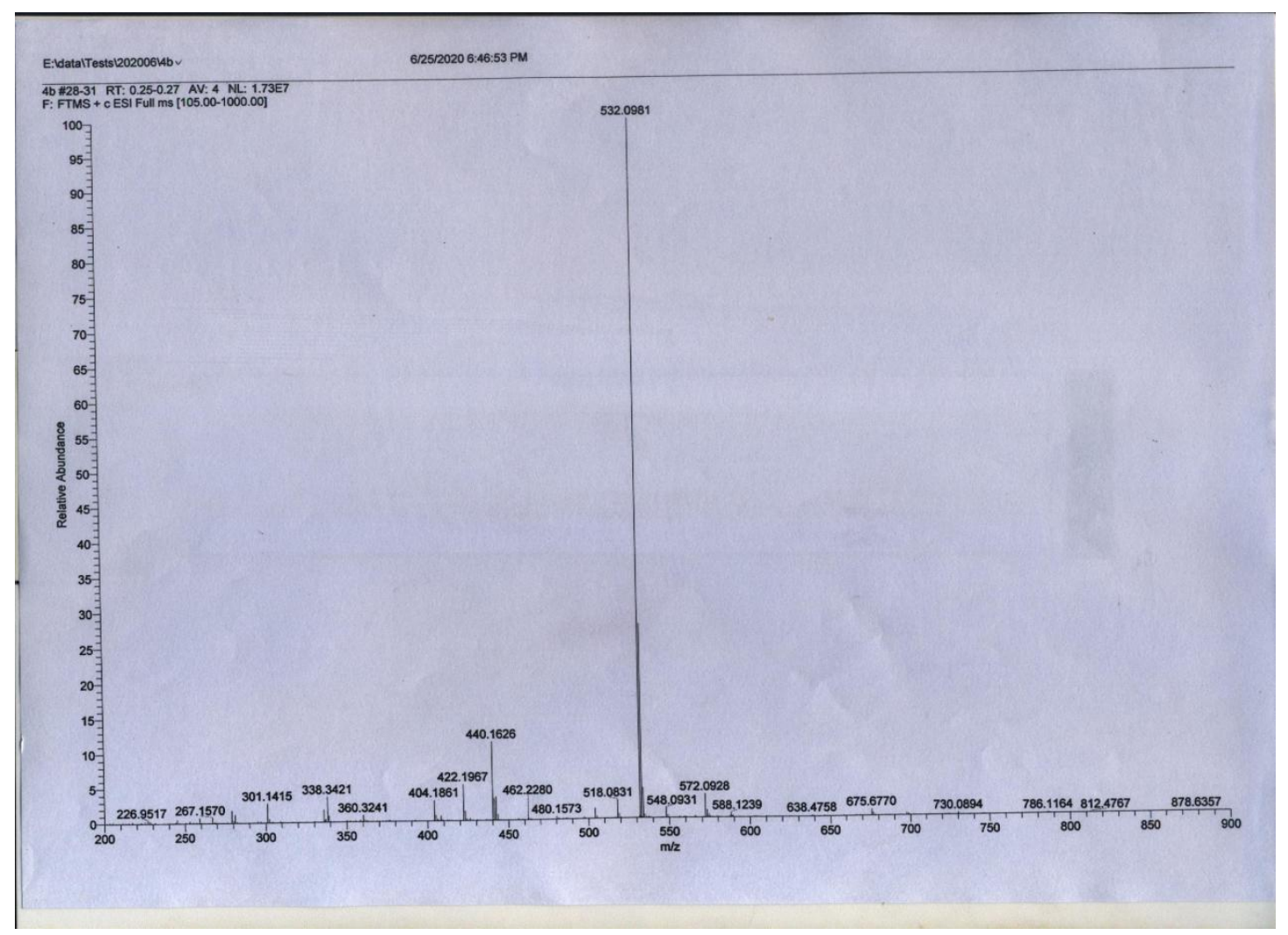

Figure S44. HR-ESI-MS spectrum of $\mathbf{4 b}$. 


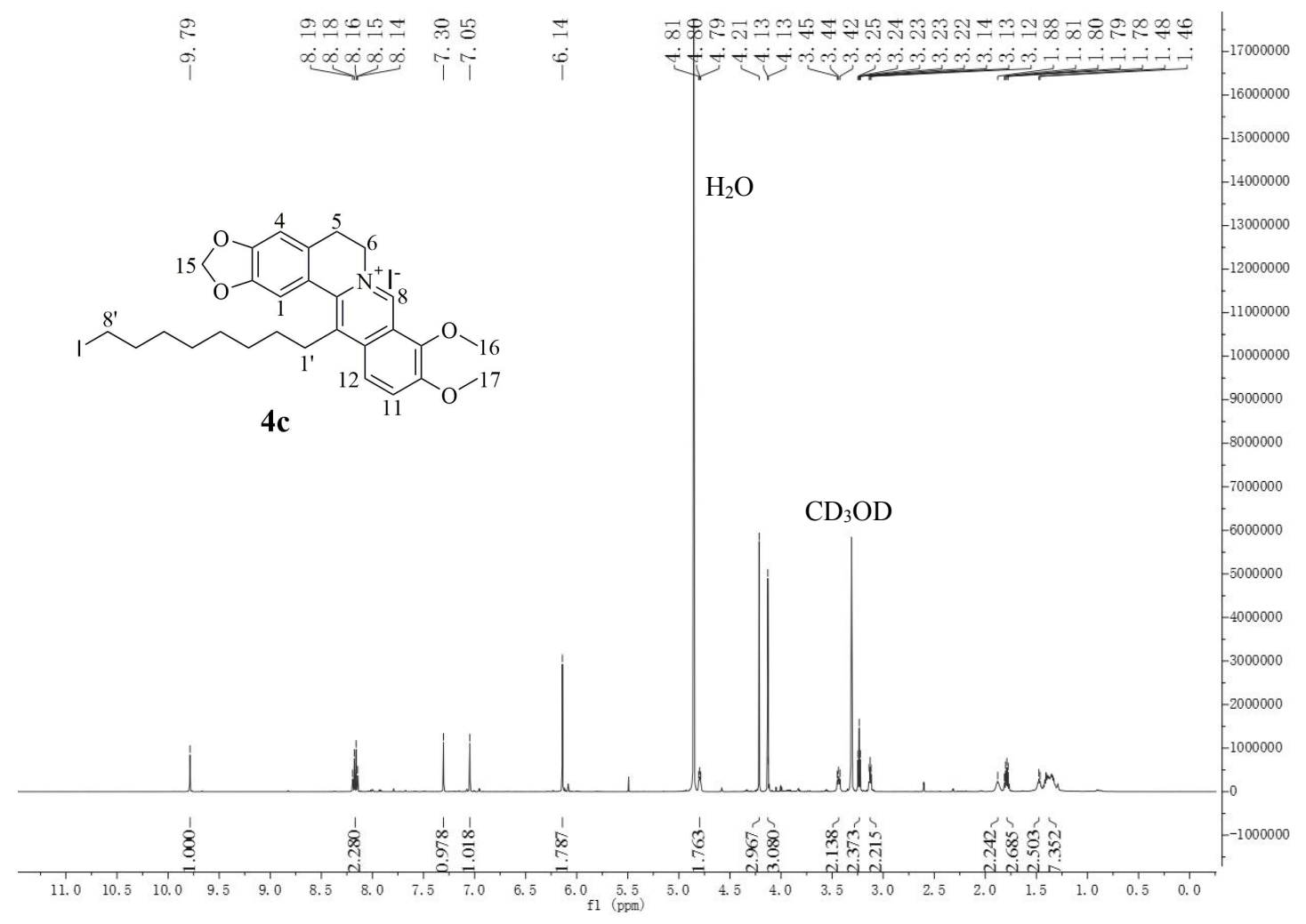

Figure S45. ${ }^{1} \mathrm{H}$ NMR spectrum of $\mathbf{4 c}$ in $\mathrm{CD}_{3} \mathrm{OD}$.

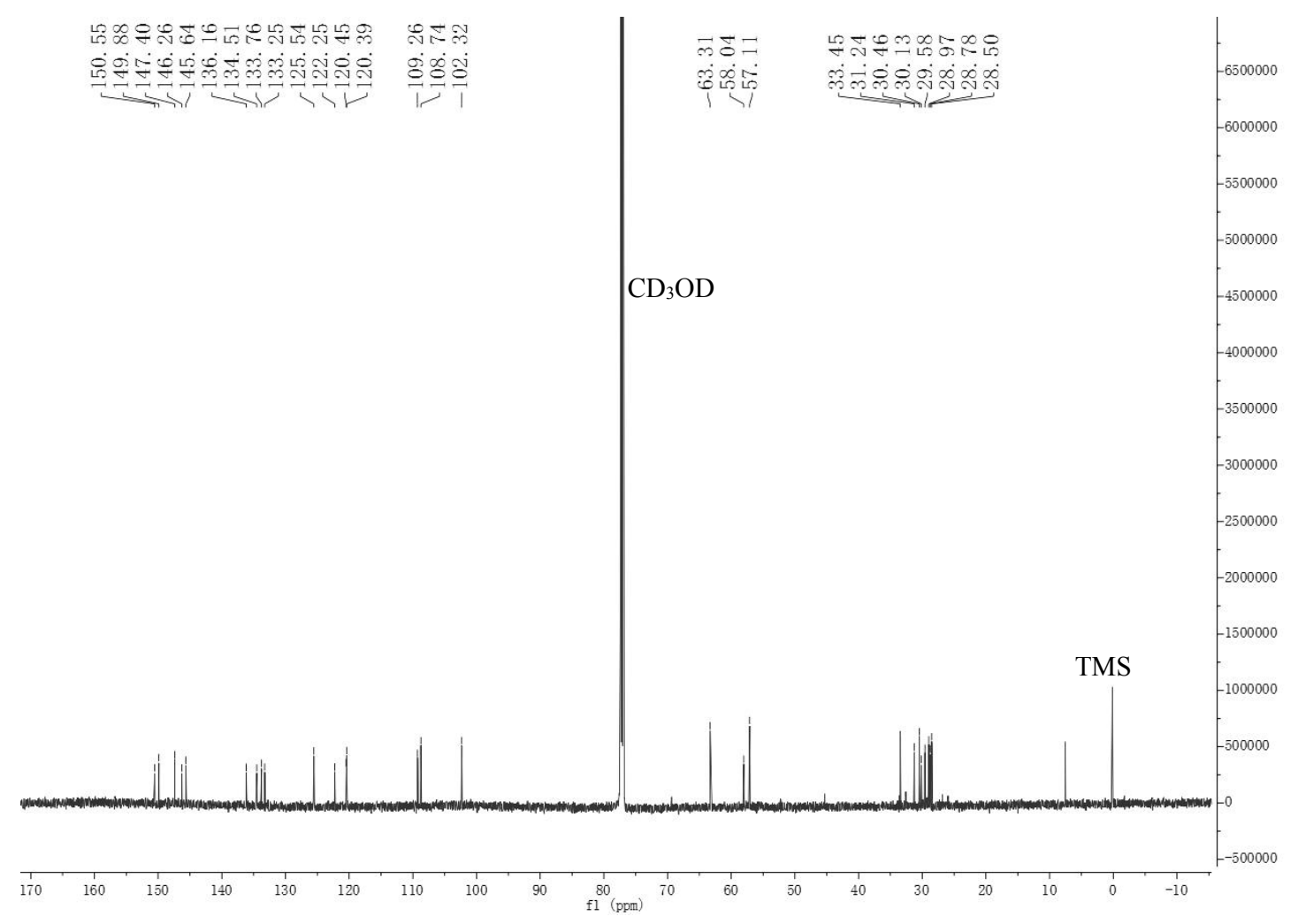

Figure S46. ${ }^{13} \mathrm{C}$ NMR spectrum of $4 \mathbf{c}$ in $\mathrm{CD}_{3} \mathrm{OD}$. 


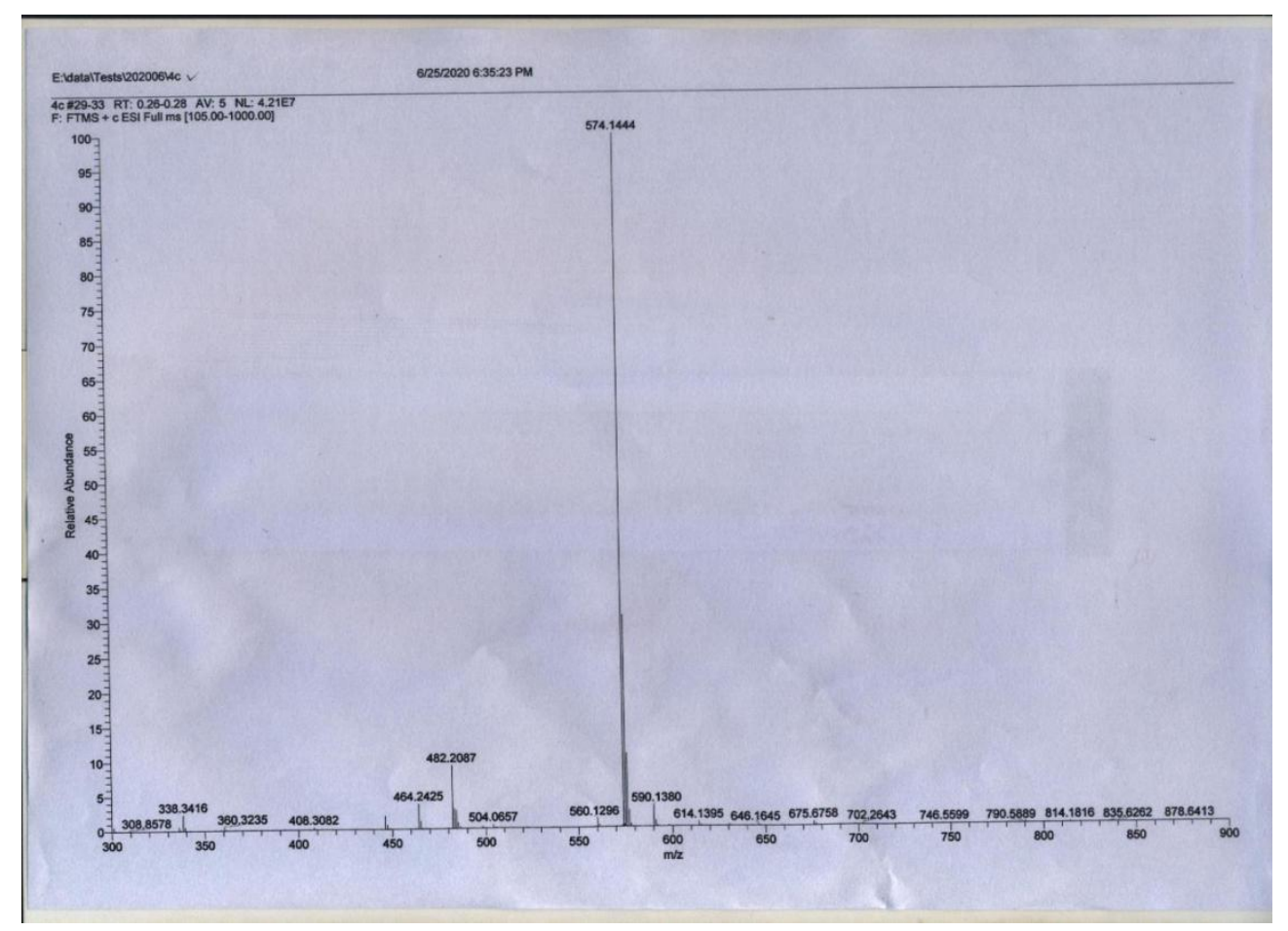

Figure S47. HR-ESI-MS spectrum of 4c.

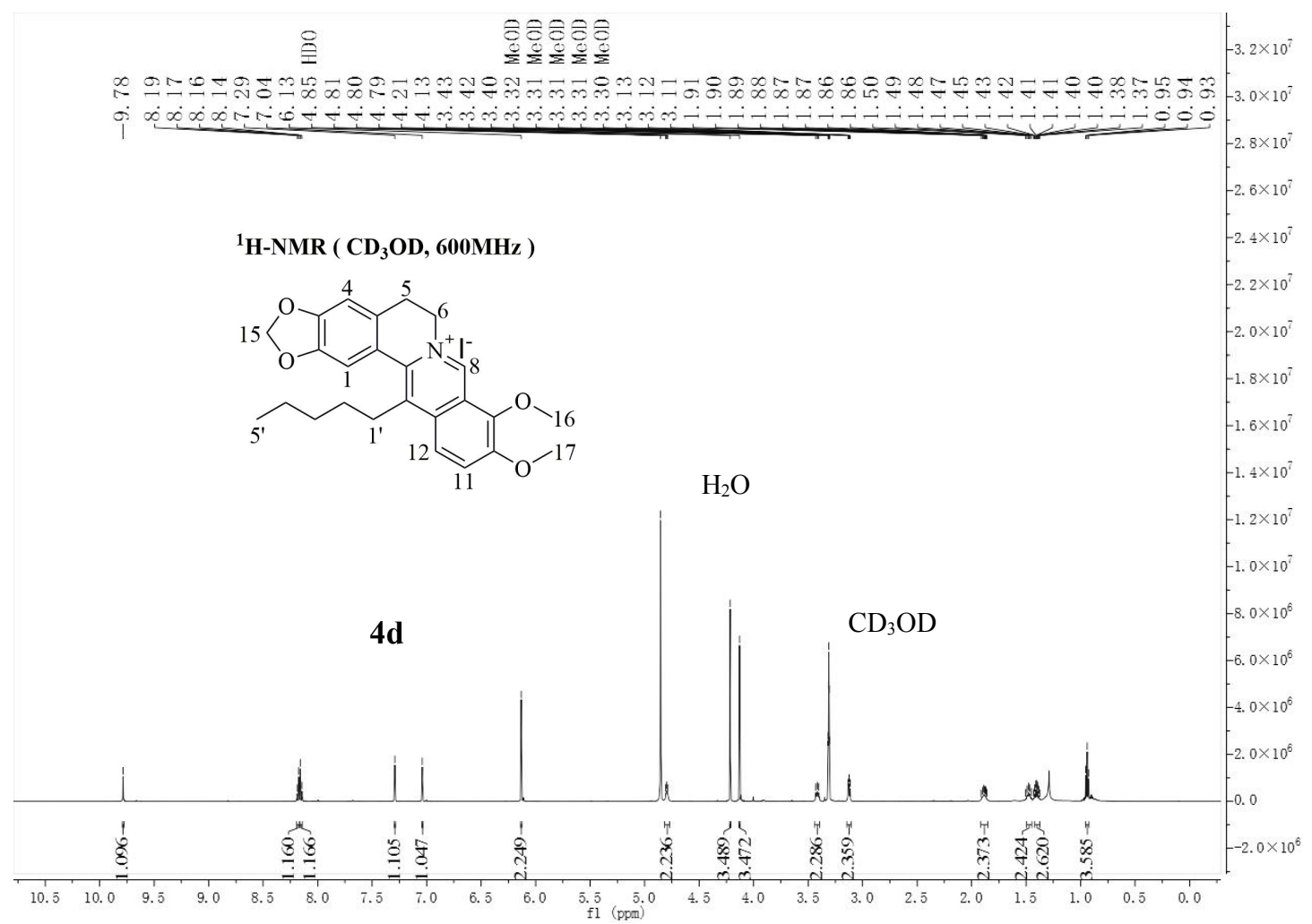

Figure S48. ${ }^{1} \mathrm{H}$ NMR spectrum of $\mathbf{4 d}$ in $\mathrm{CD}_{3} \mathrm{OD}$. 


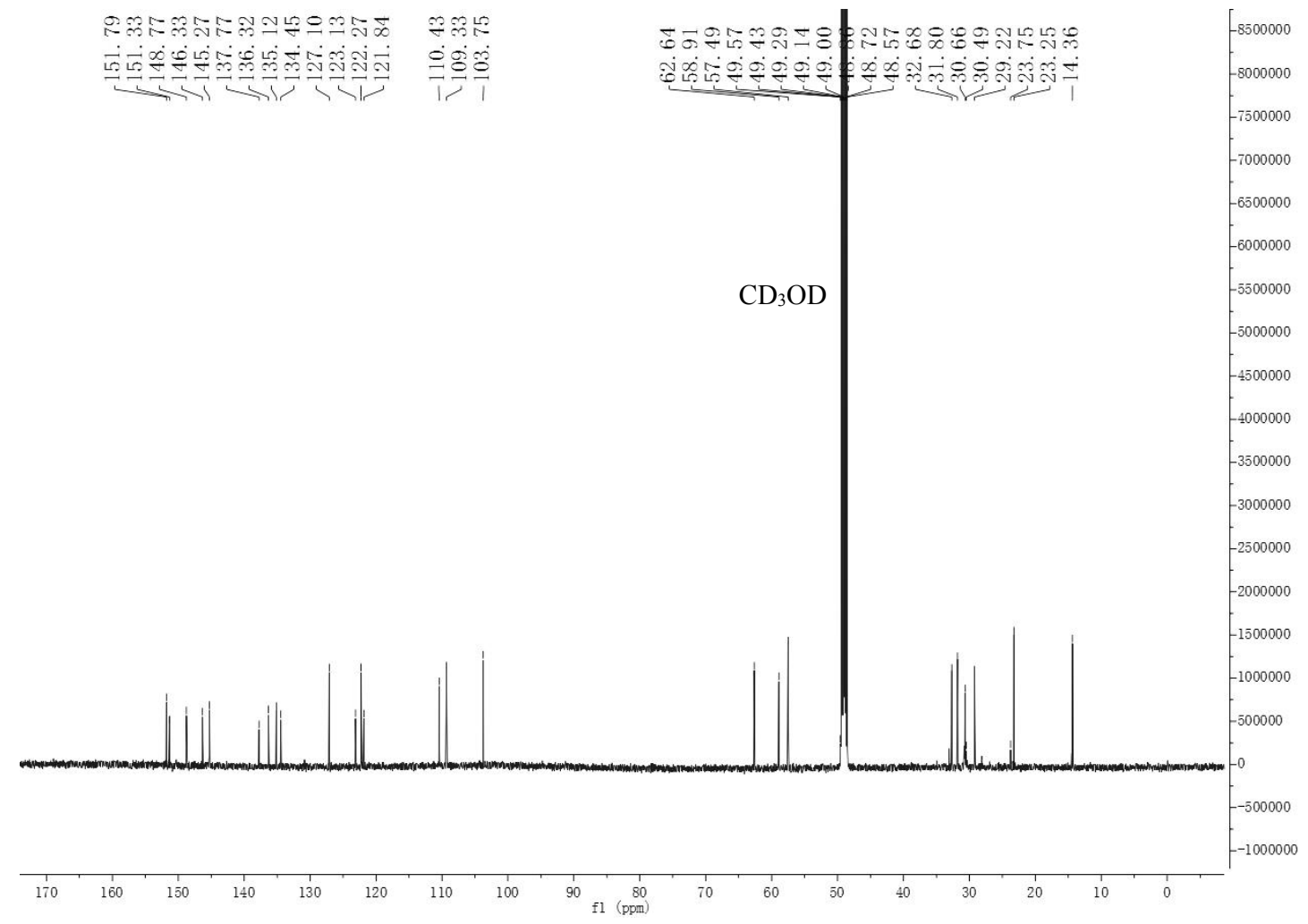

Figure $\mathbf{S 4 9} .{ }^{13} \mathrm{C}$ NMR spectrum of $\mathbf{4 d}$ in $\mathrm{CD}_{3} \mathrm{OD}$.

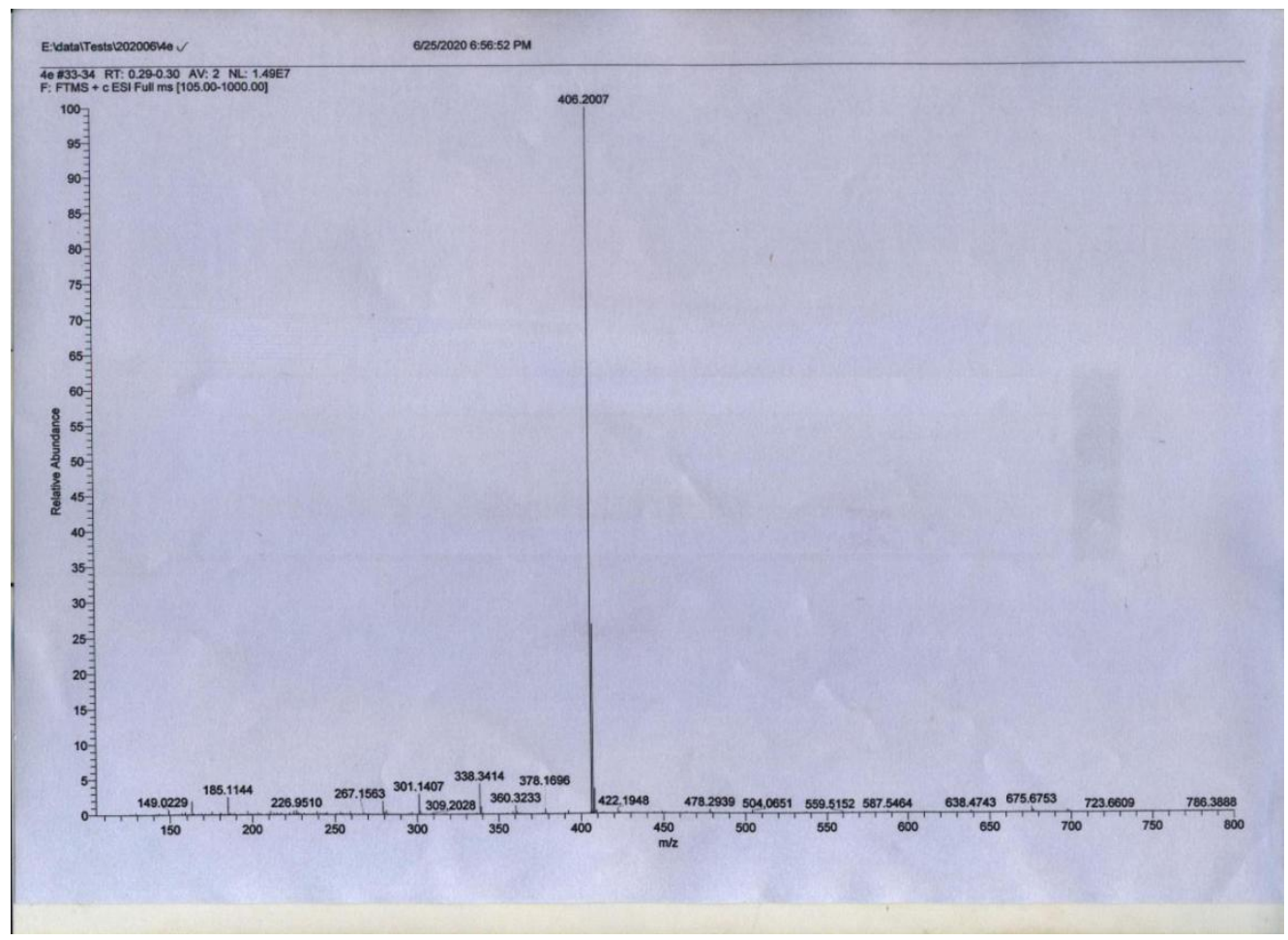

Figure S50. HR-ESI-MS spectrum of $\mathbf{4 d}$. 


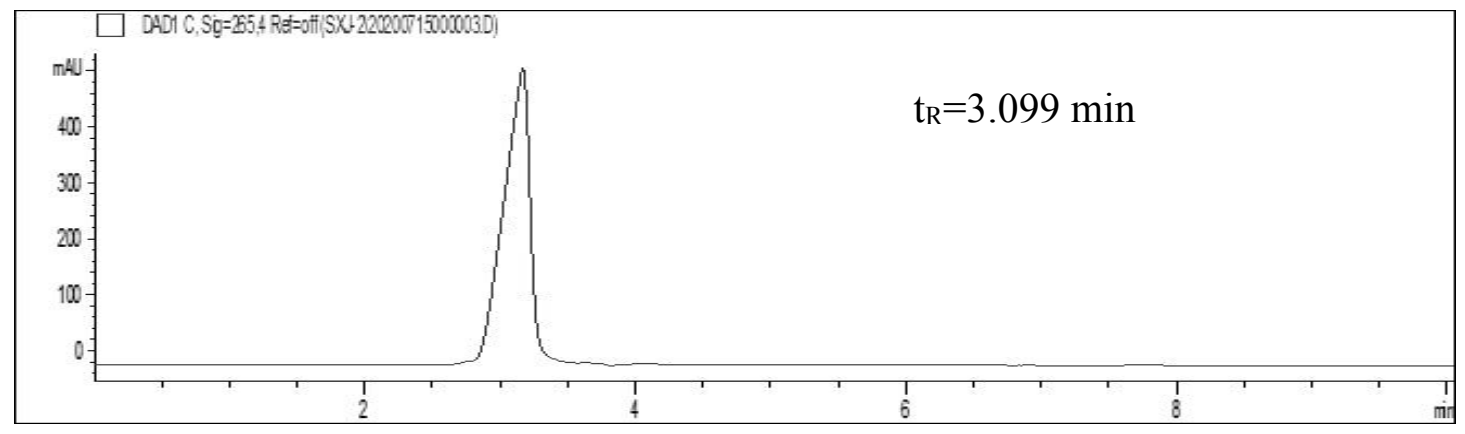

Figure S51. HPLC chromatogram of 4d.

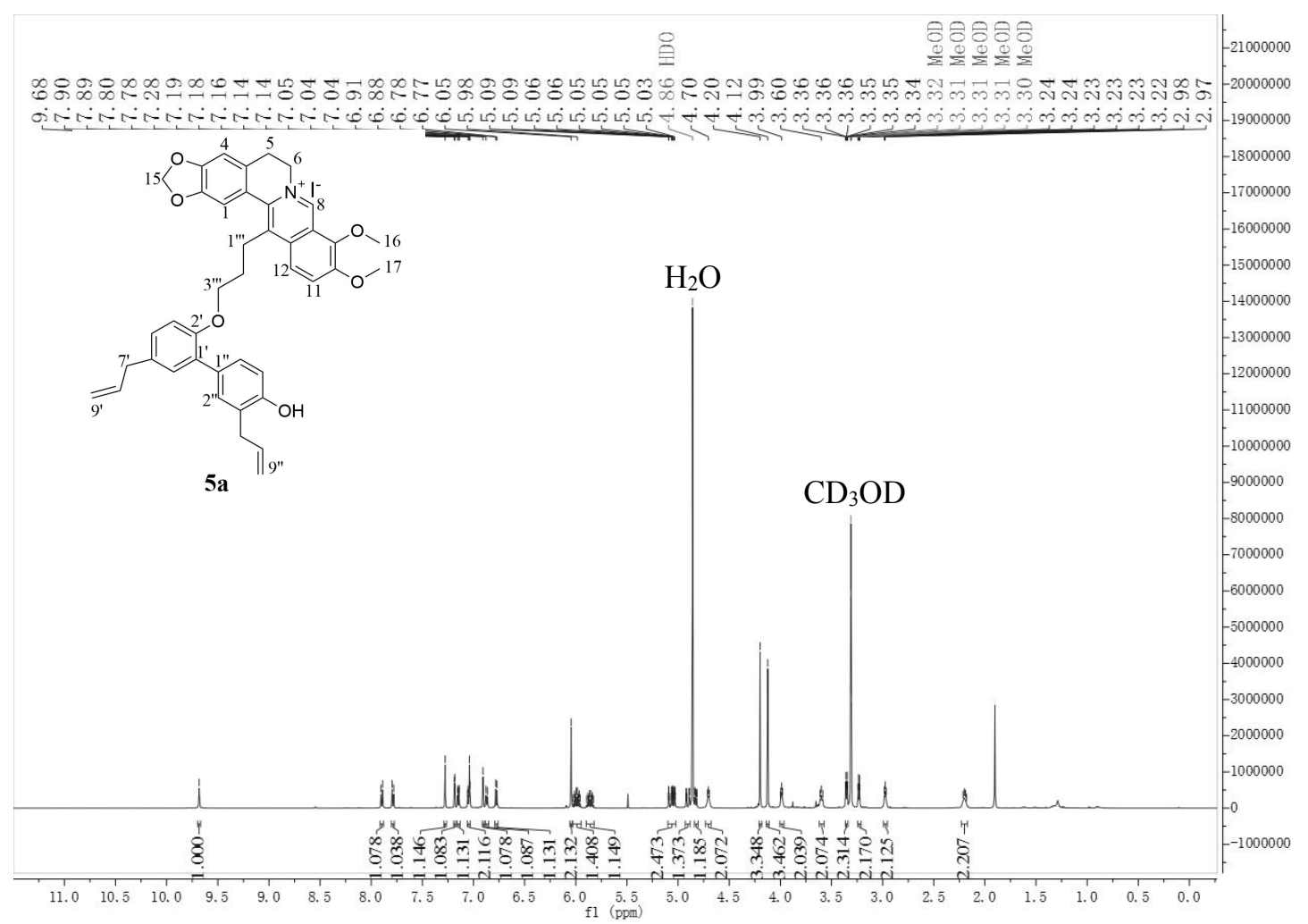

Figure S52. ${ }^{1} \mathrm{H}$ NMR spectrum of 5a in $\mathrm{CD}_{3} \mathrm{OD}$. 


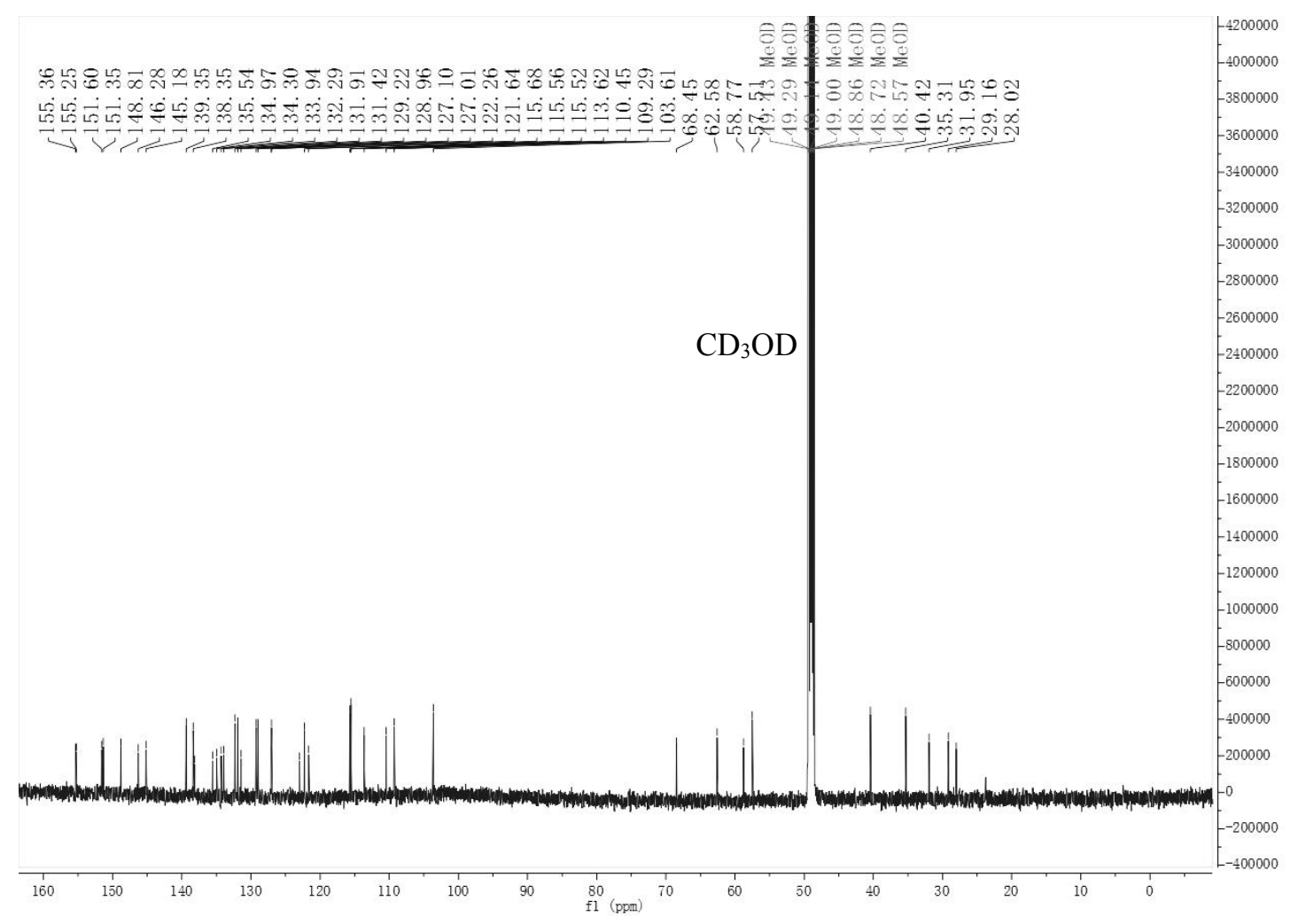

Figure S53. ${ }^{13} \mathrm{C}$ NMR spectrum of $5 \mathbf{a}$ in $\mathrm{CD}_{3} \mathrm{OD}$.

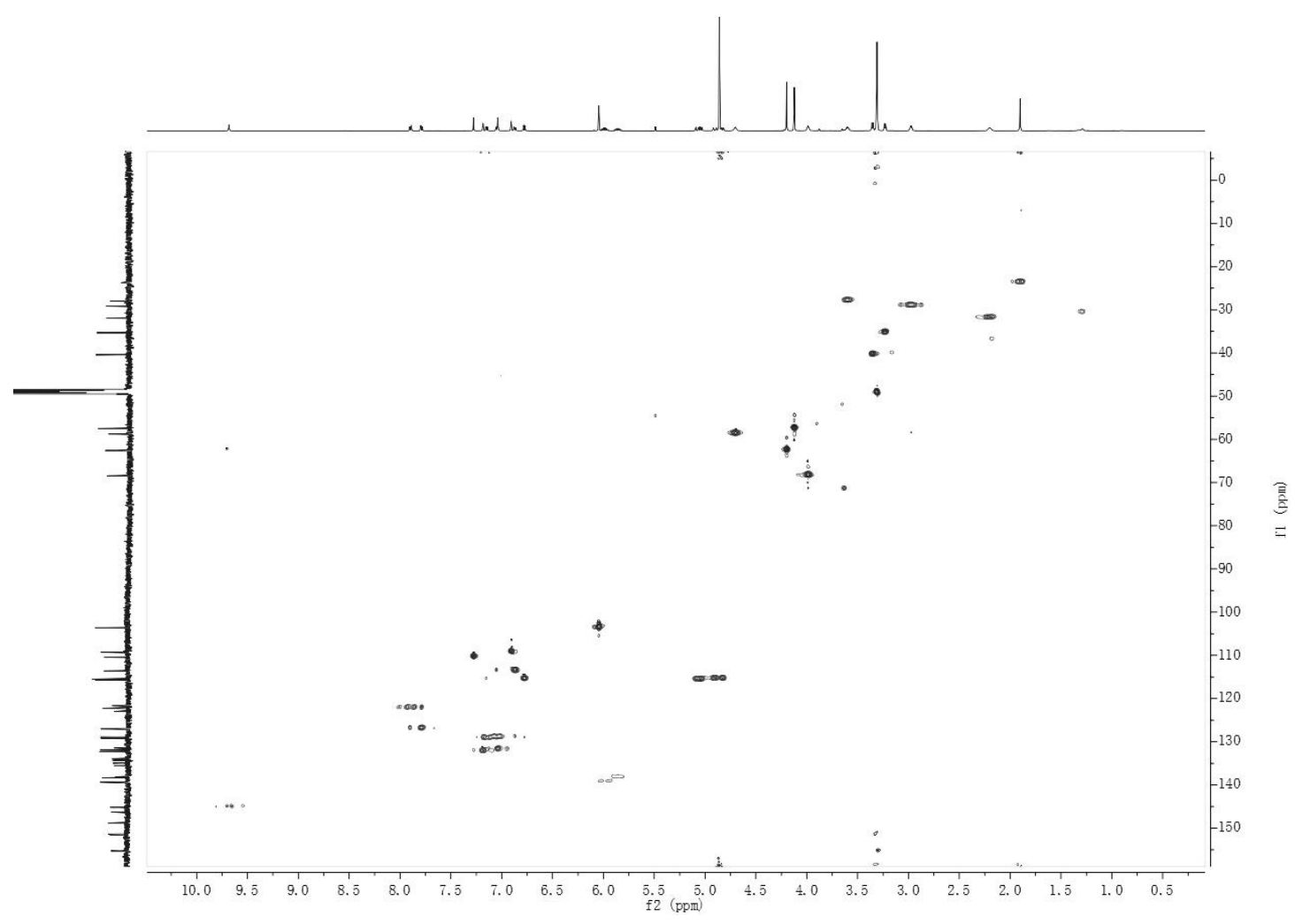

Figure S54. HSQC spectrum of $\mathbf{5 a}$ in $\mathrm{CD}_{3} \mathrm{OD}$. 


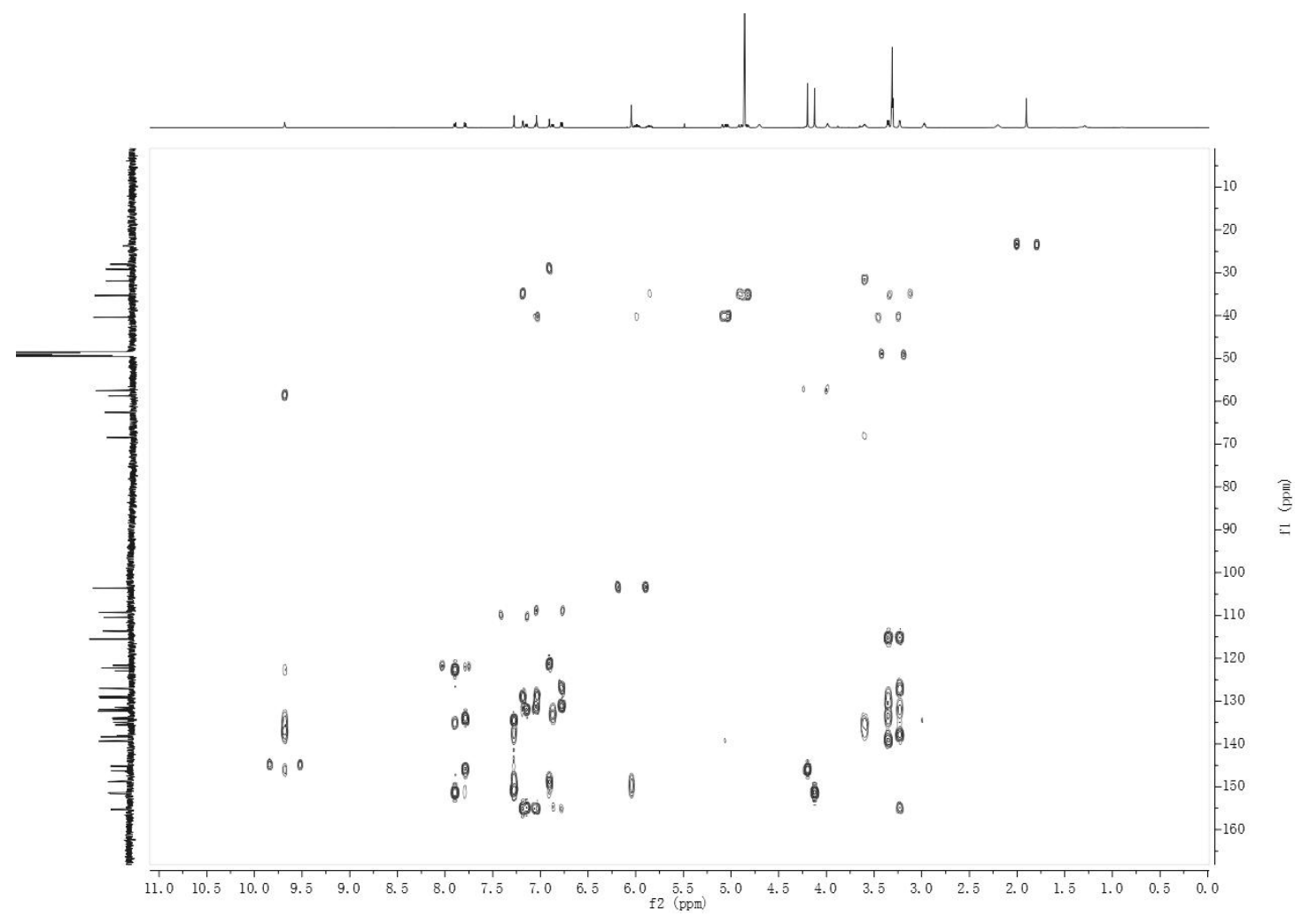

Figure S55. $\mathrm{HMBC}$ spectrum of $\mathbf{5 a}$ in $\mathrm{CD}_{3} \mathrm{OD}$.

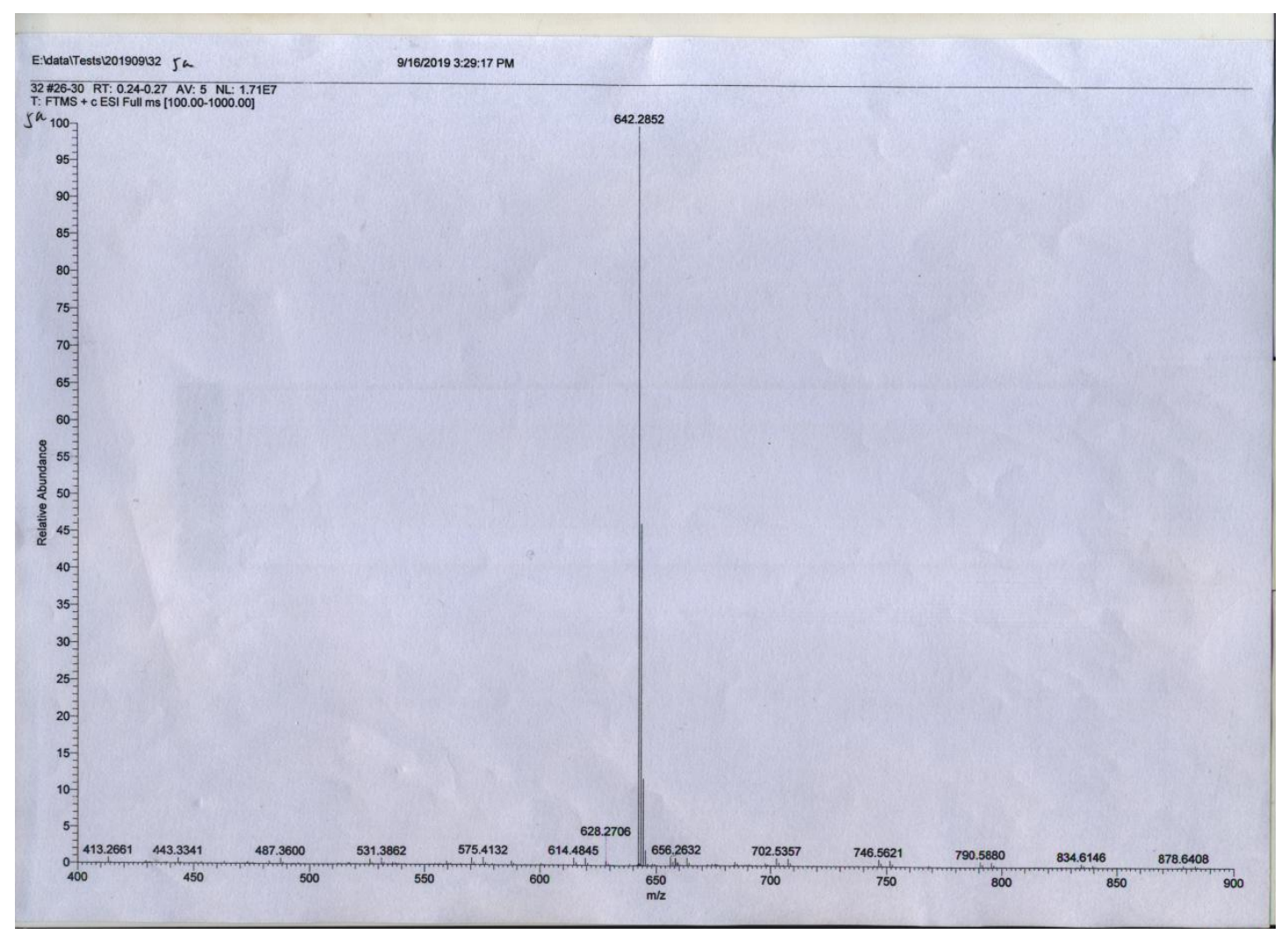

Figure S56. HR-ESI-MS spectrum of $\mathbf{5 a}$. 


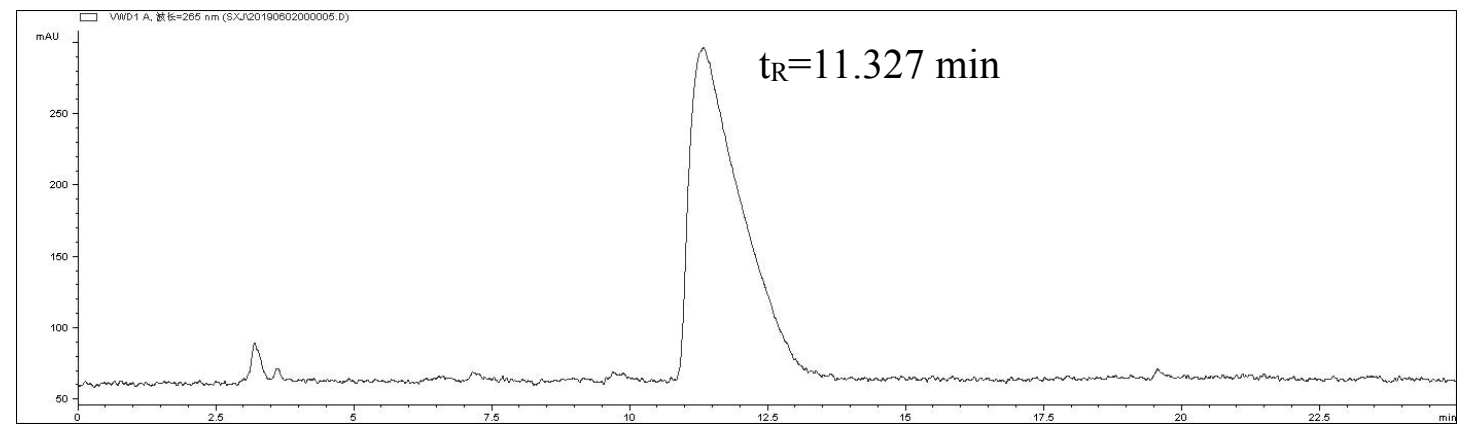

Figure S57. HPLC chromatogram of $\mathbf{5 a}$.

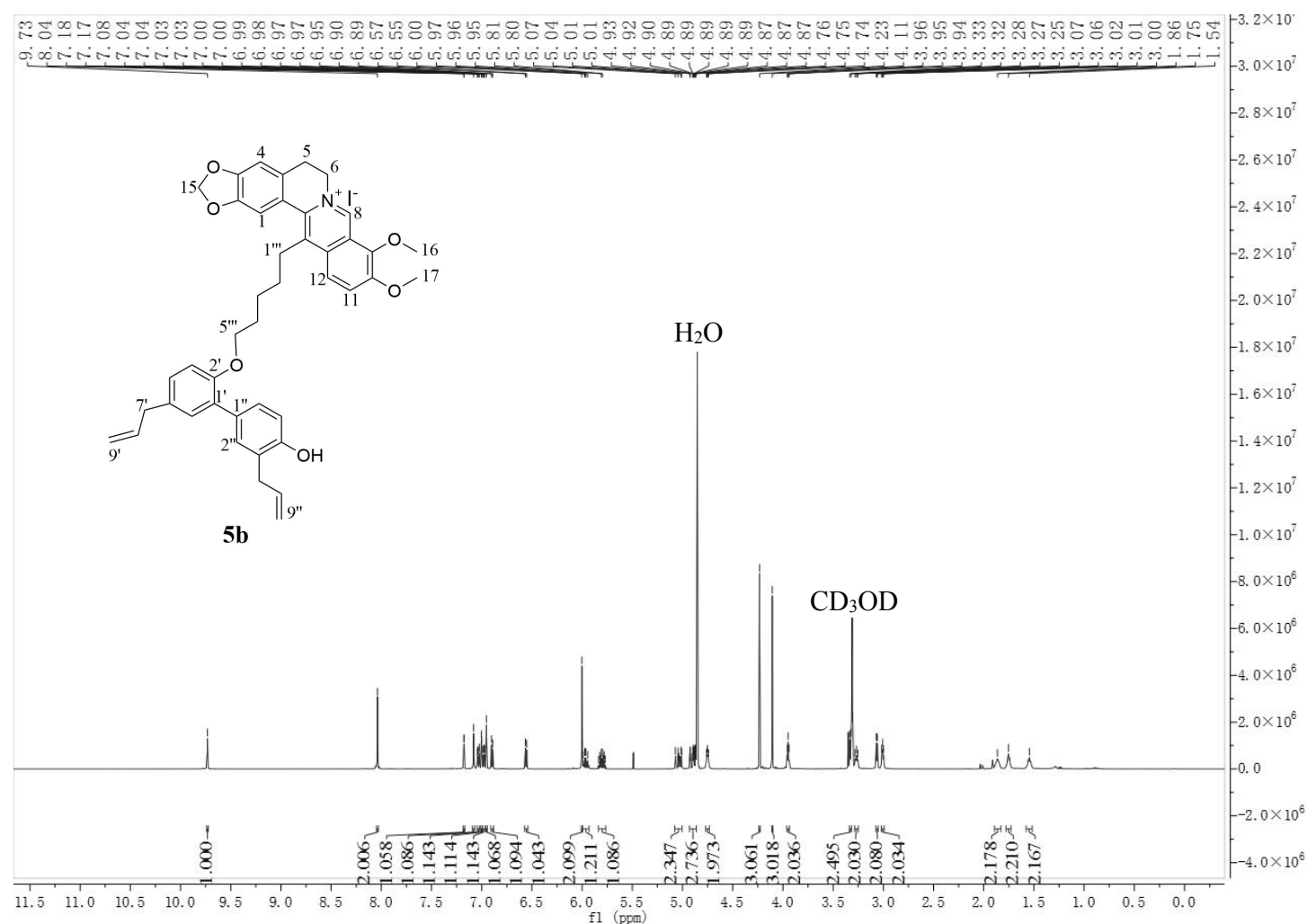

Figure S58. ${ }^{1} \mathrm{H}$ NMR spectrum of $\mathbf{5 b}$ in $\mathrm{CD}_{3} \mathrm{OD}$. 


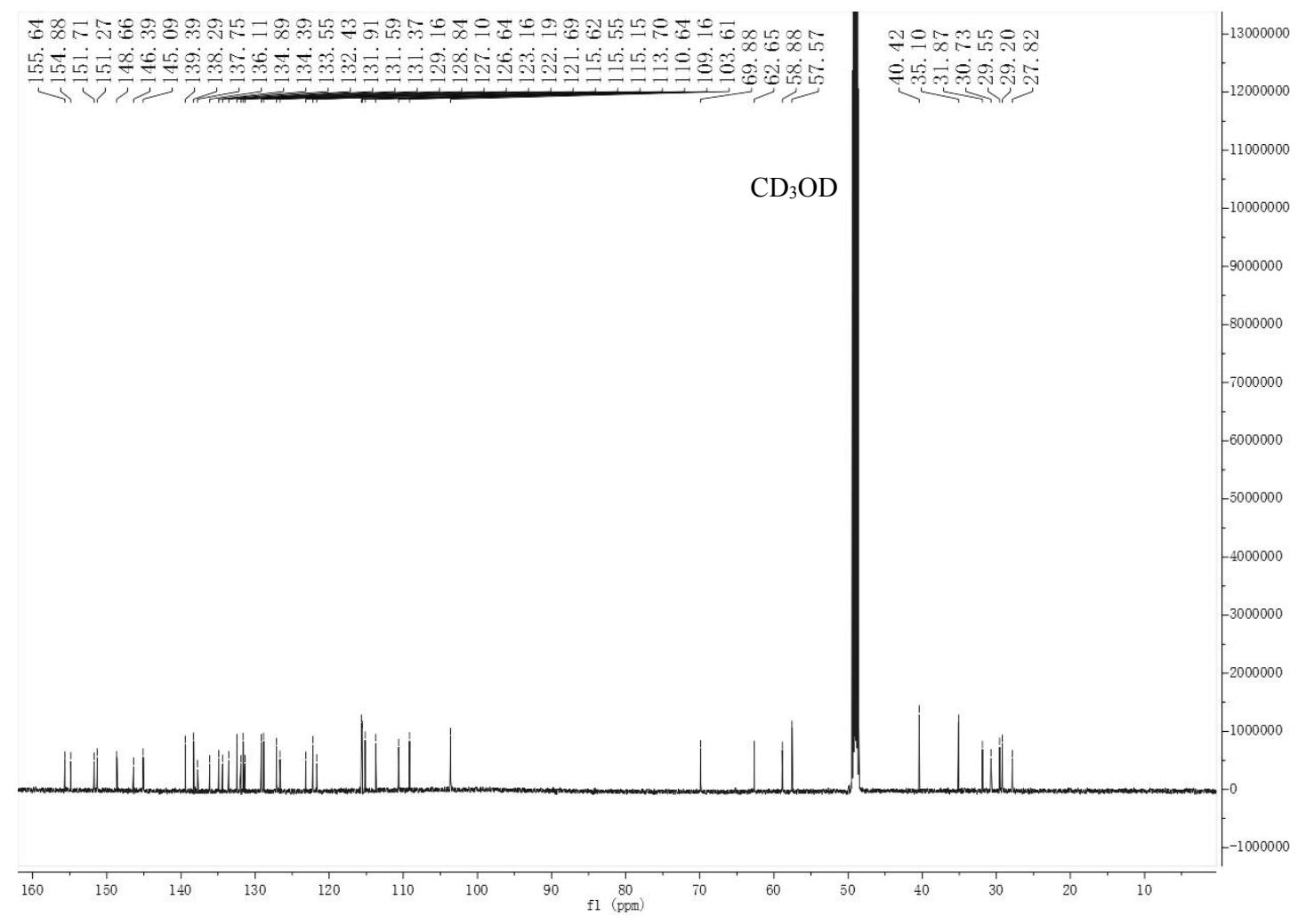

Figure S59. ${ }^{13} \mathrm{C}$ NMR spectrum of $\mathbf{5 b}$ in $\mathrm{CD}_{3} \mathrm{OD}$.

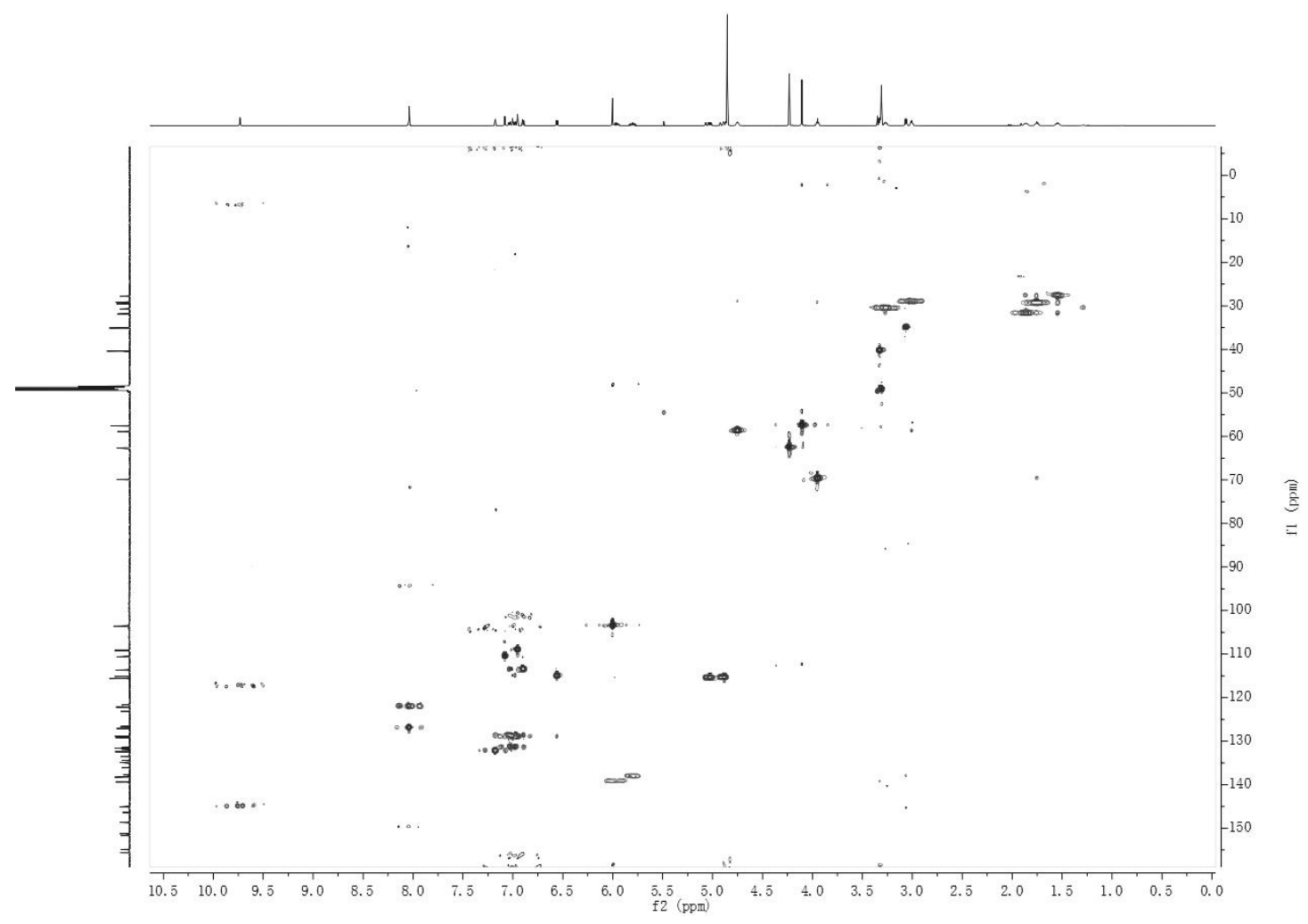

Figure S60. HSQC spectrum of $\mathbf{5 b}$ in $\mathrm{CD}_{3} \mathrm{OD}$. 


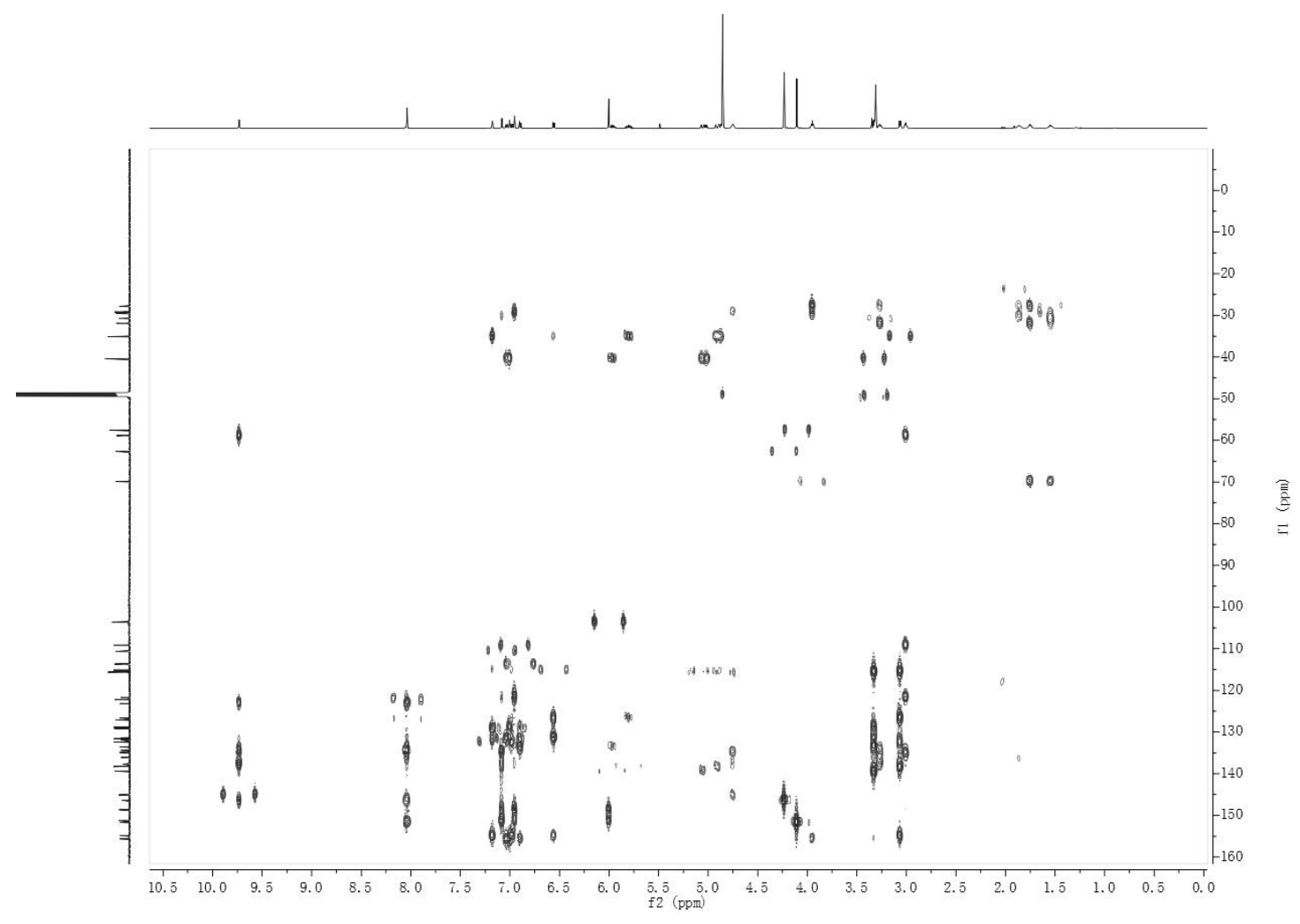

Figure S61. $\mathrm{HMBC}$ spectrum of $\mathbf{5 b}$ in $\mathrm{CD}_{3} \mathrm{OD}$.

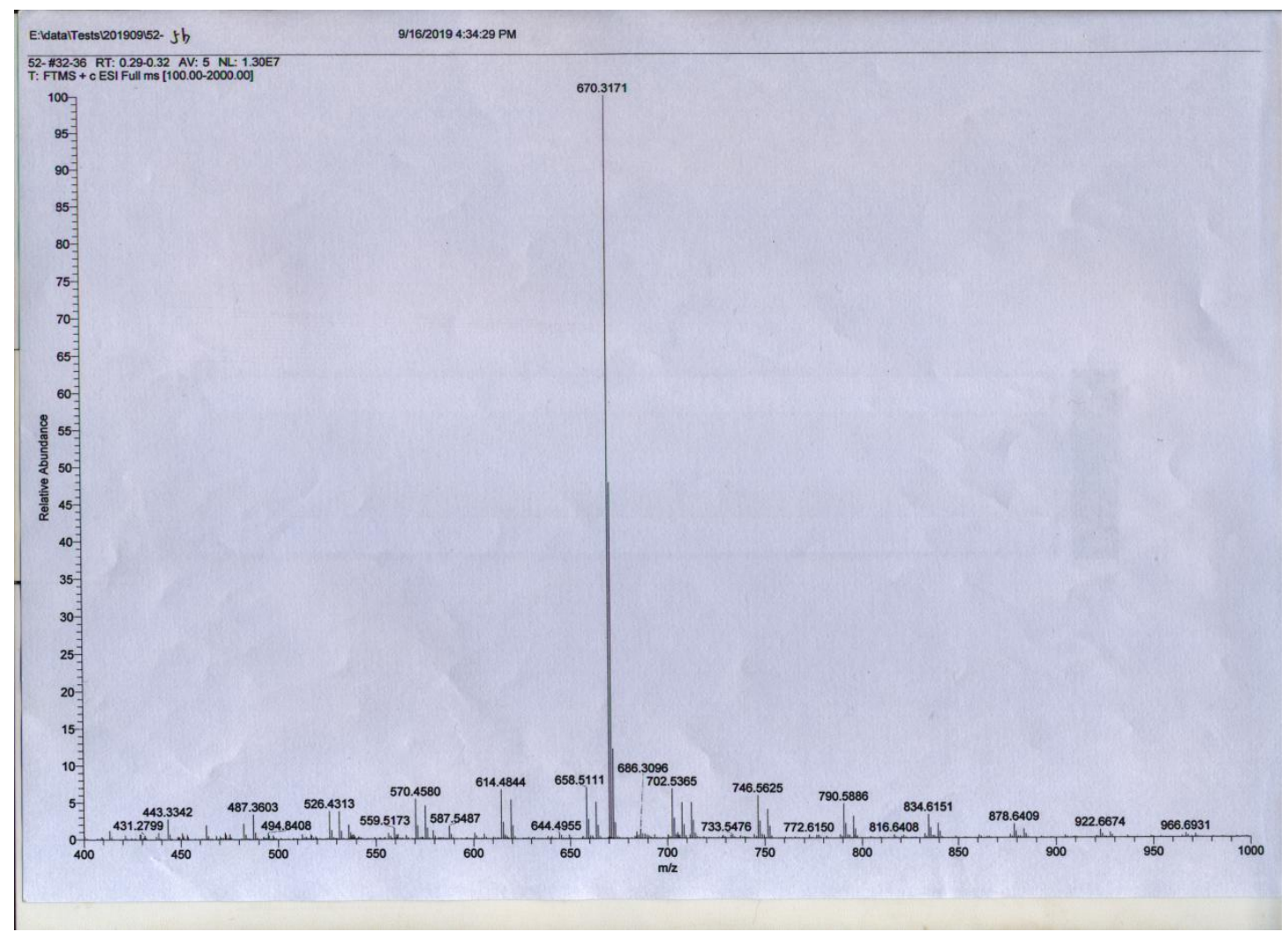

Figure S62. HR-ESI-MS spectrum of $\mathbf{5 b}$. 


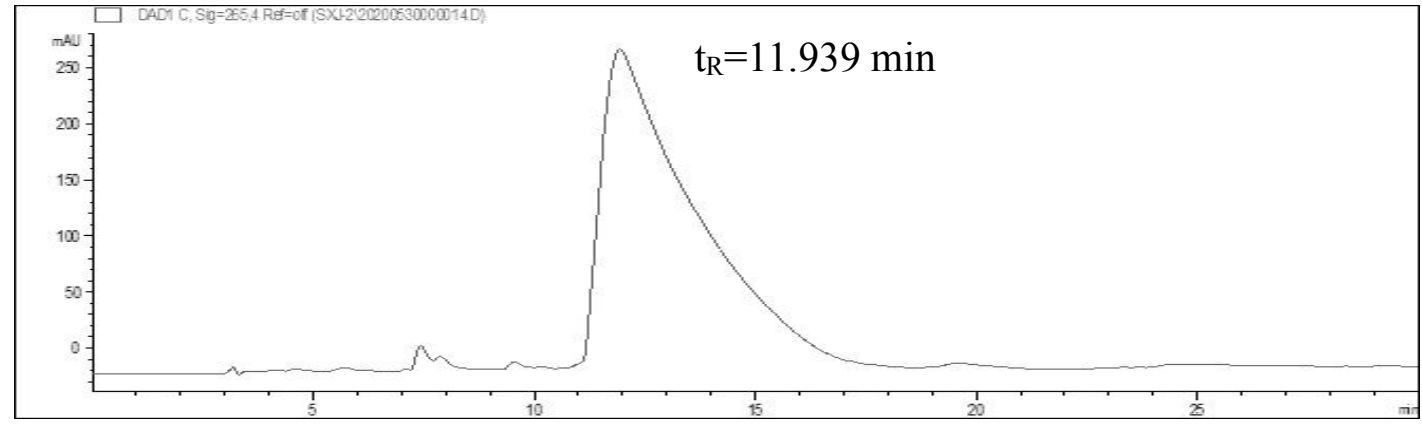

Figure S63. HPLC chromatogram of $\mathbf{5 b}$.

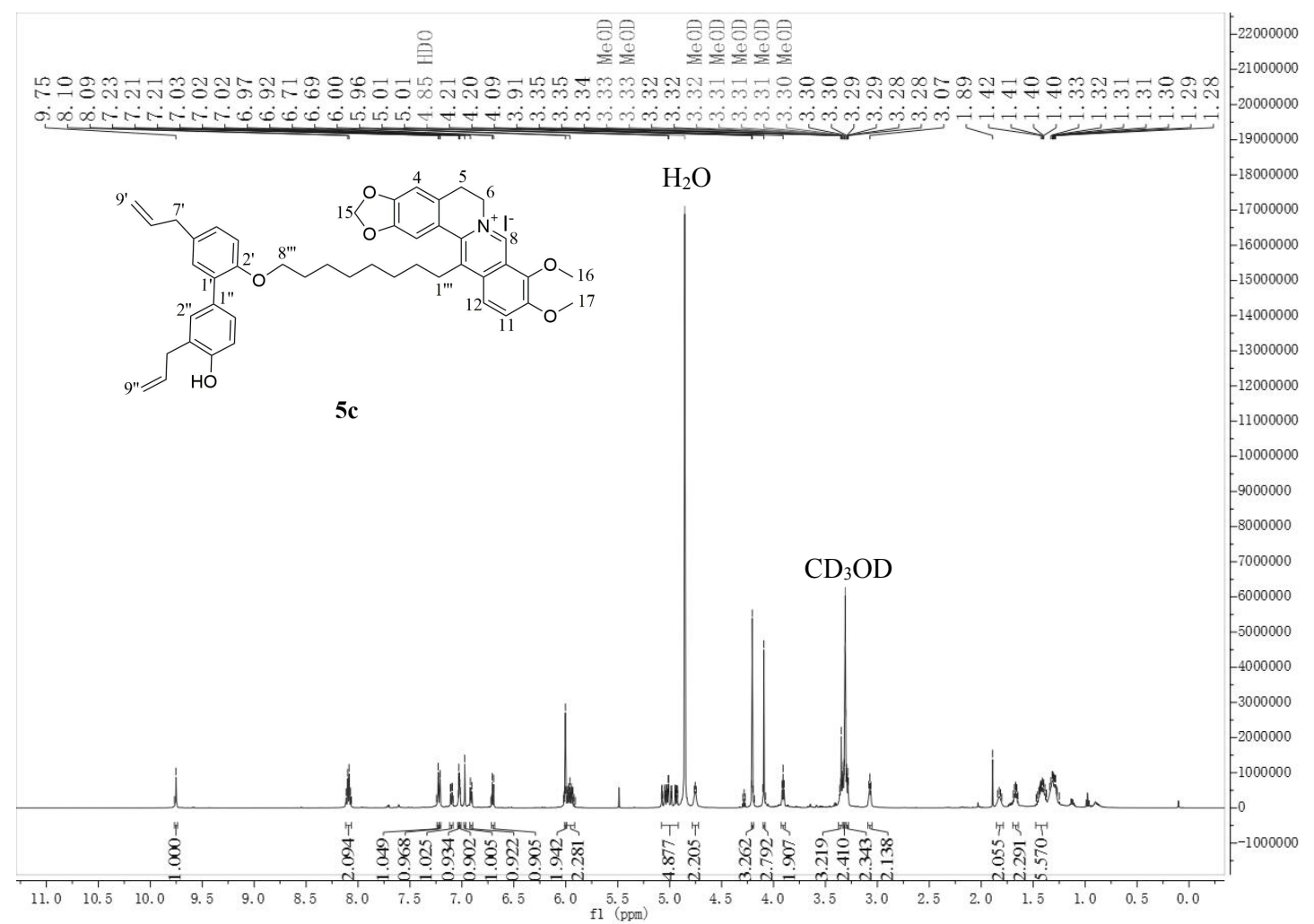

Figure S64. ${ }^{1} \mathrm{H}$ NMR spectrum of $5 \mathrm{c}$ in $\mathrm{CD}_{3} \mathrm{OD}$. 


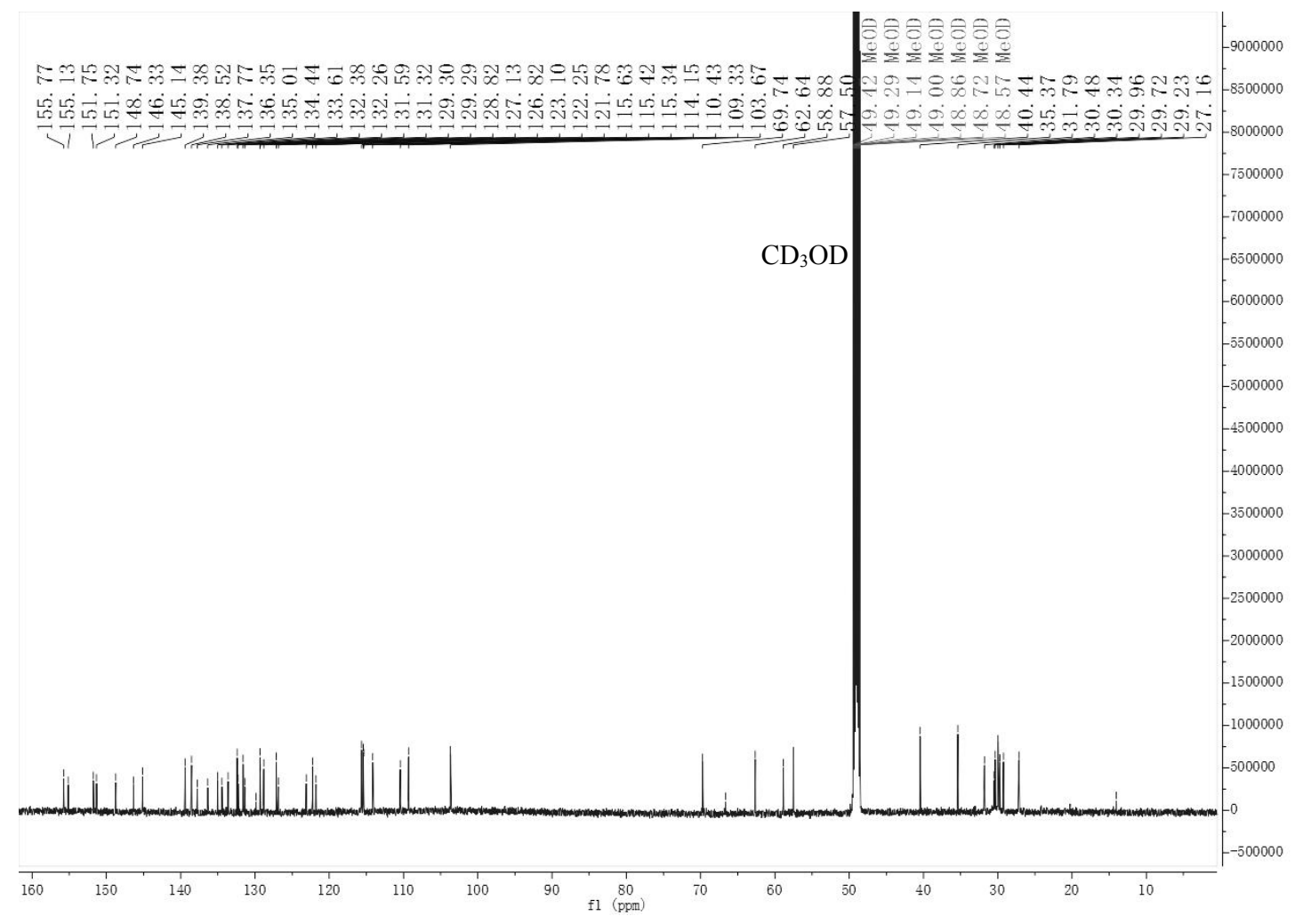

Figure S65. ${ }^{13} \mathrm{C}$ NMR spectrum of $\mathbf{5 c}$ in $\mathrm{CD}_{3} \mathrm{OD}$.

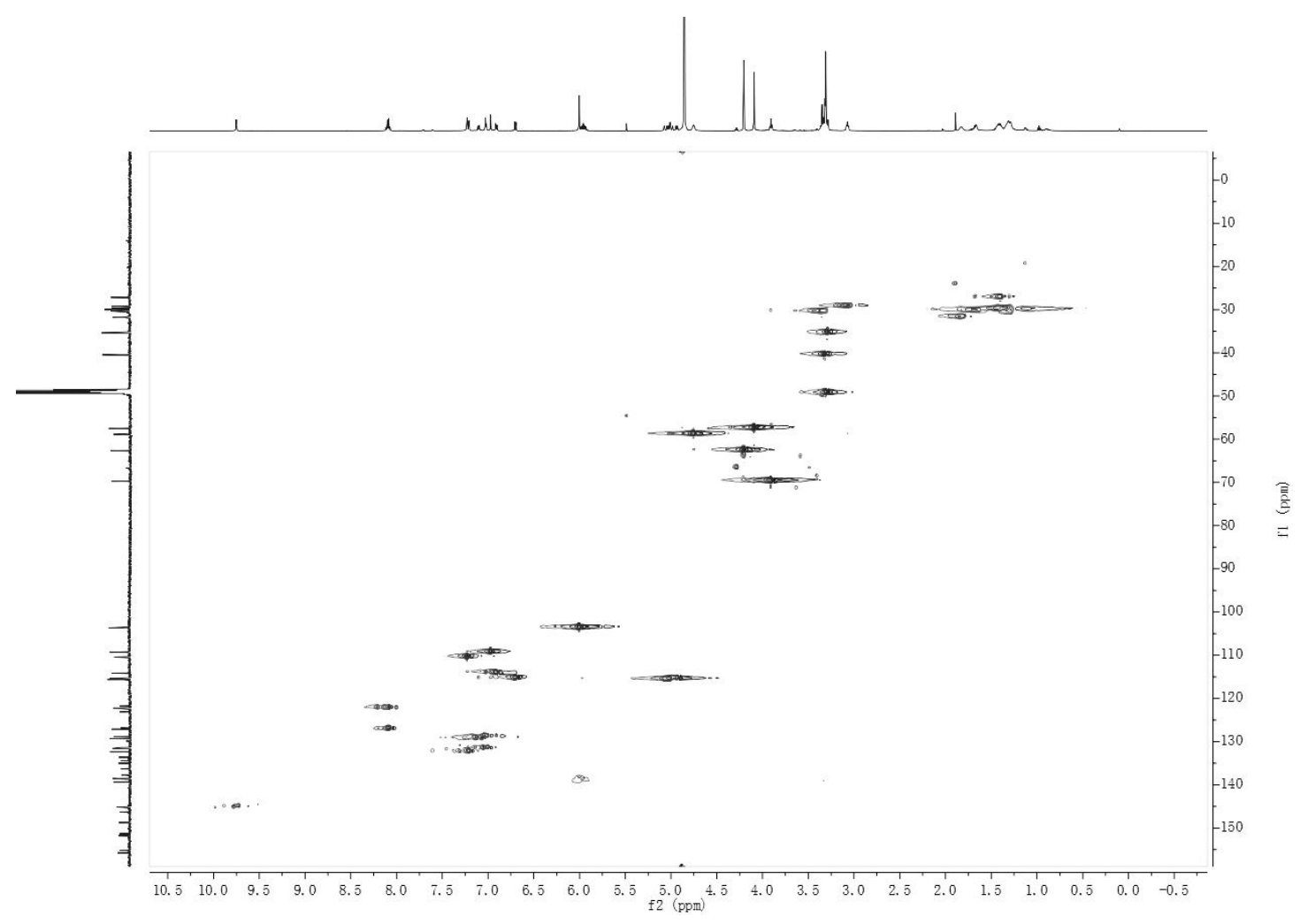

Figure S66. HSQC spectrum of $\mathbf{5 c}$ in $\mathrm{CD}_{3} \mathrm{OD}$. 


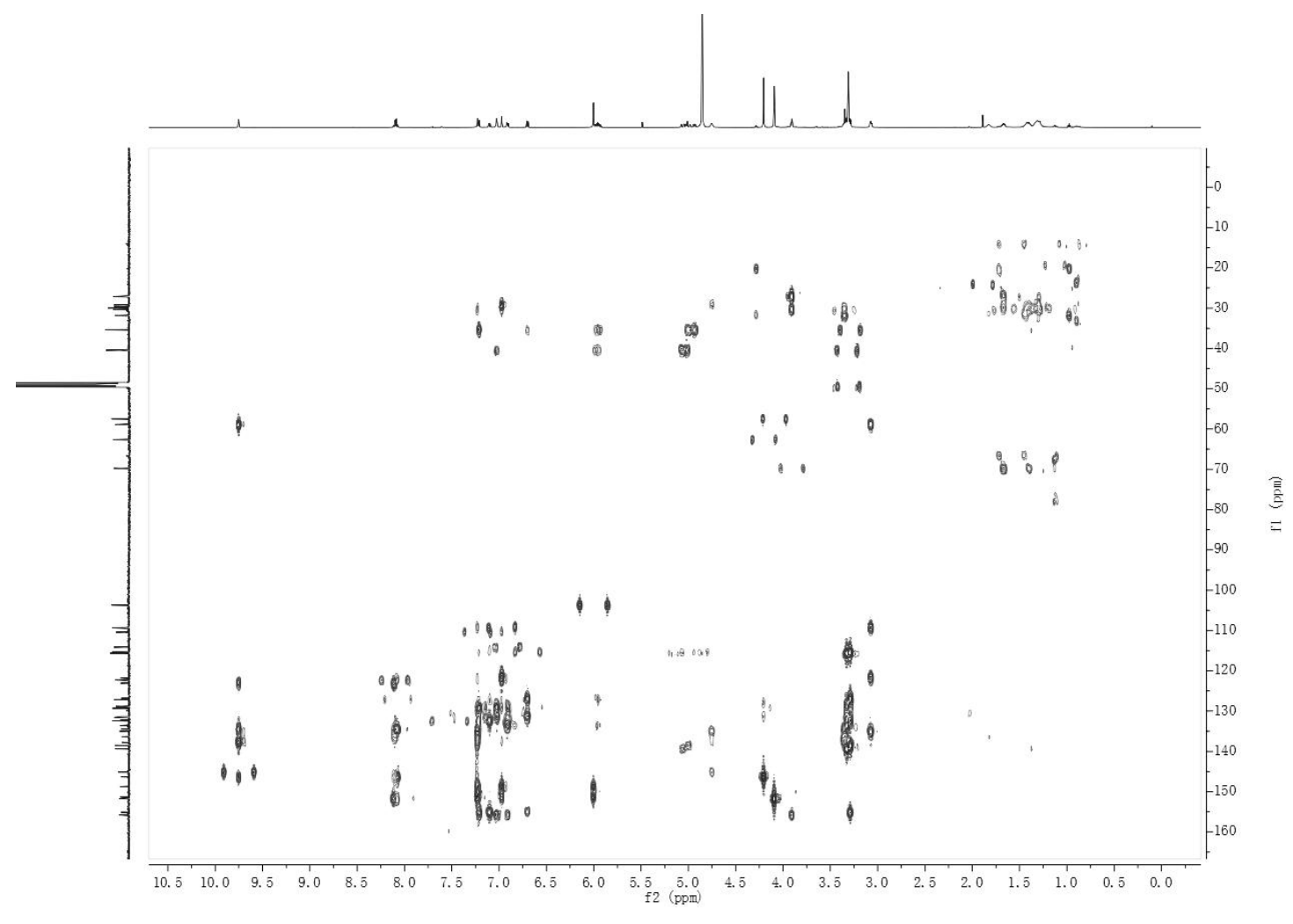

Figure S67. HMBC spectrum of $\mathbf{5 c}$ in $\mathrm{CD}_{3} \mathrm{OD}$.

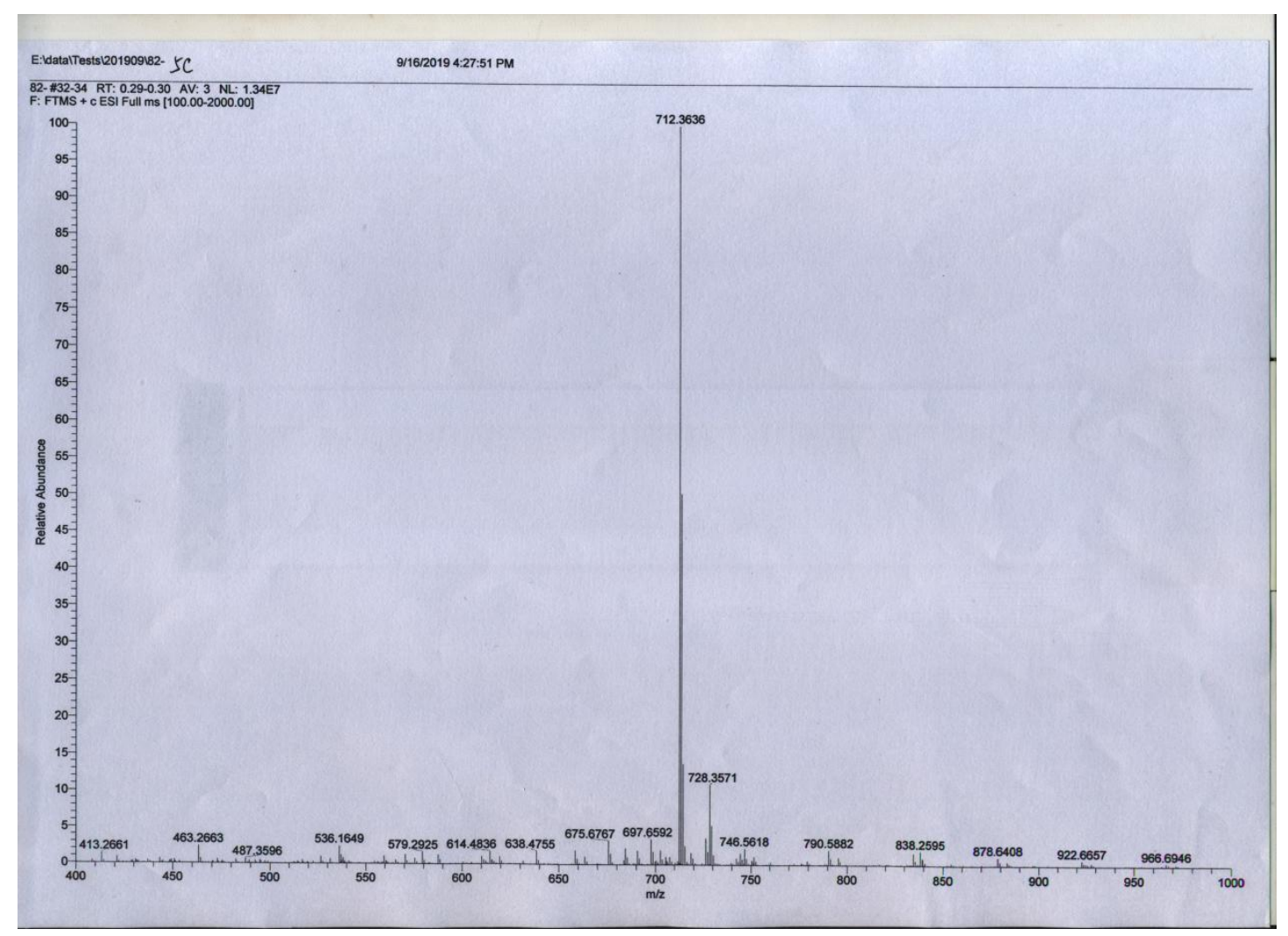

Figure S68. HR-ESI-MS spectrum of 5c. 


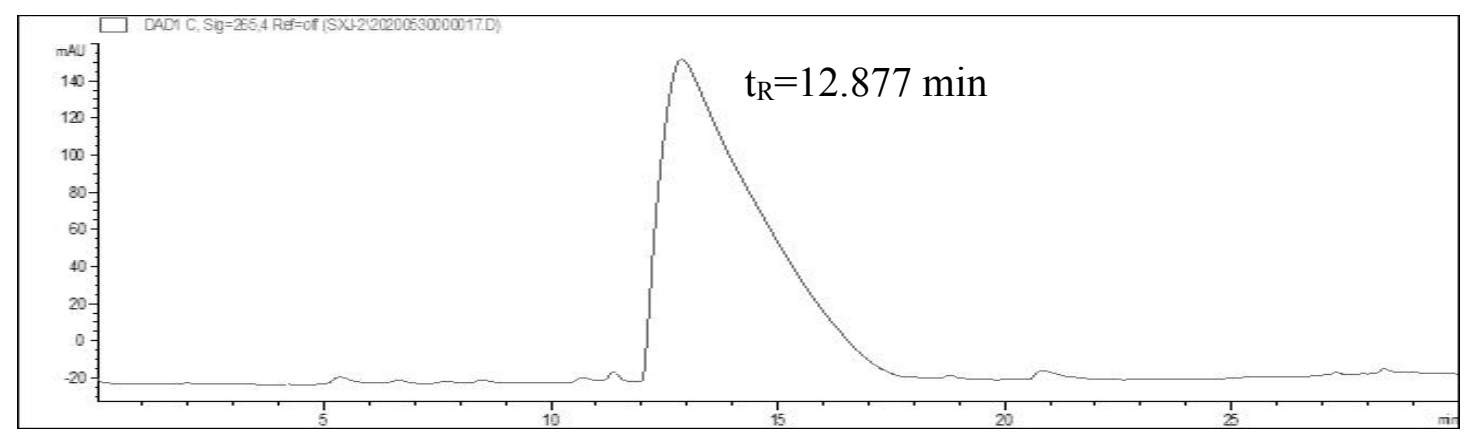

Figure S69. HPLC chromatogram of 5c.

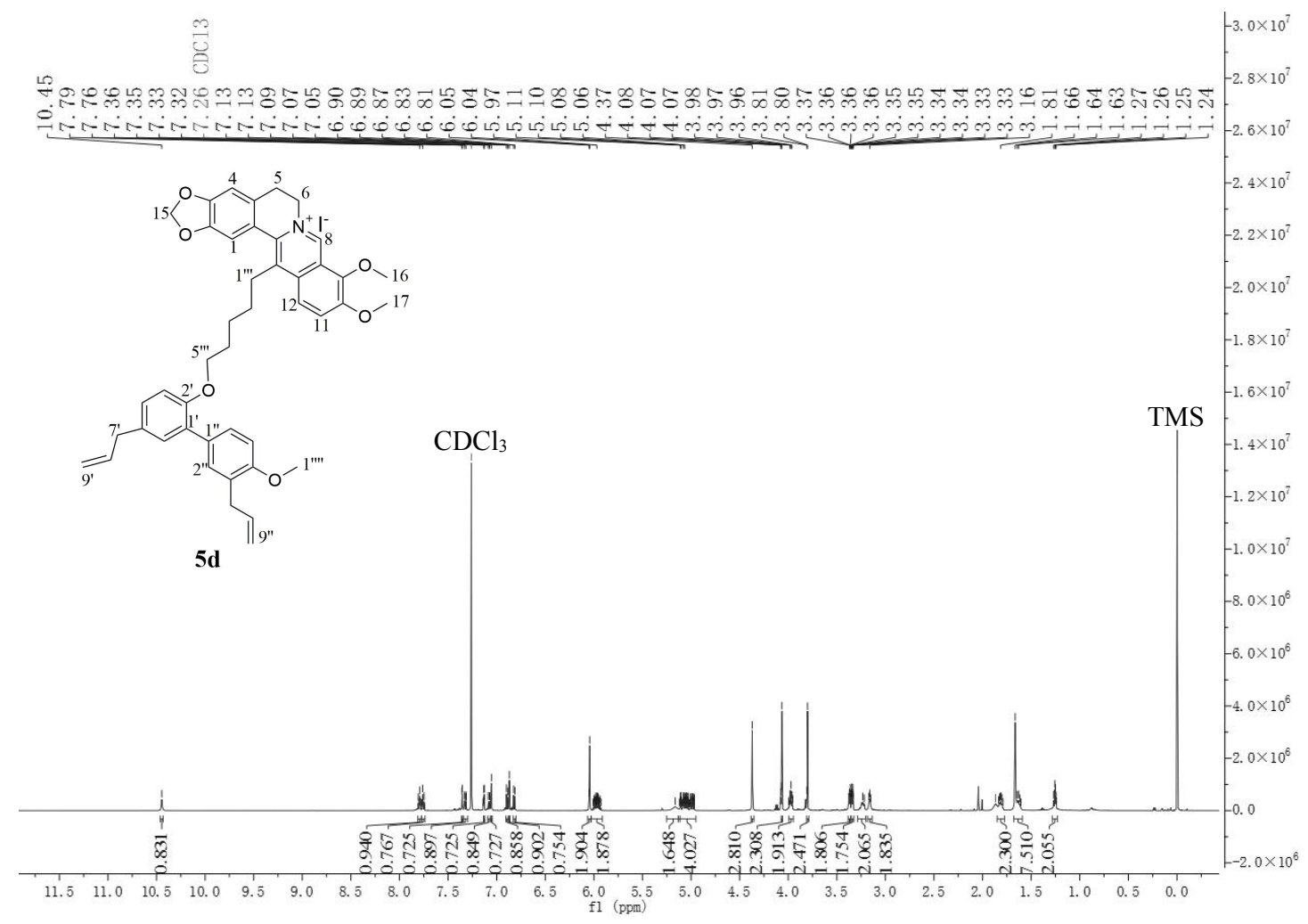

Figure S70. ${ }^{1} \mathrm{H}$ NMR spectrum of $\mathbf{5 d}$ in $\mathrm{CDCl}_{3}$. 


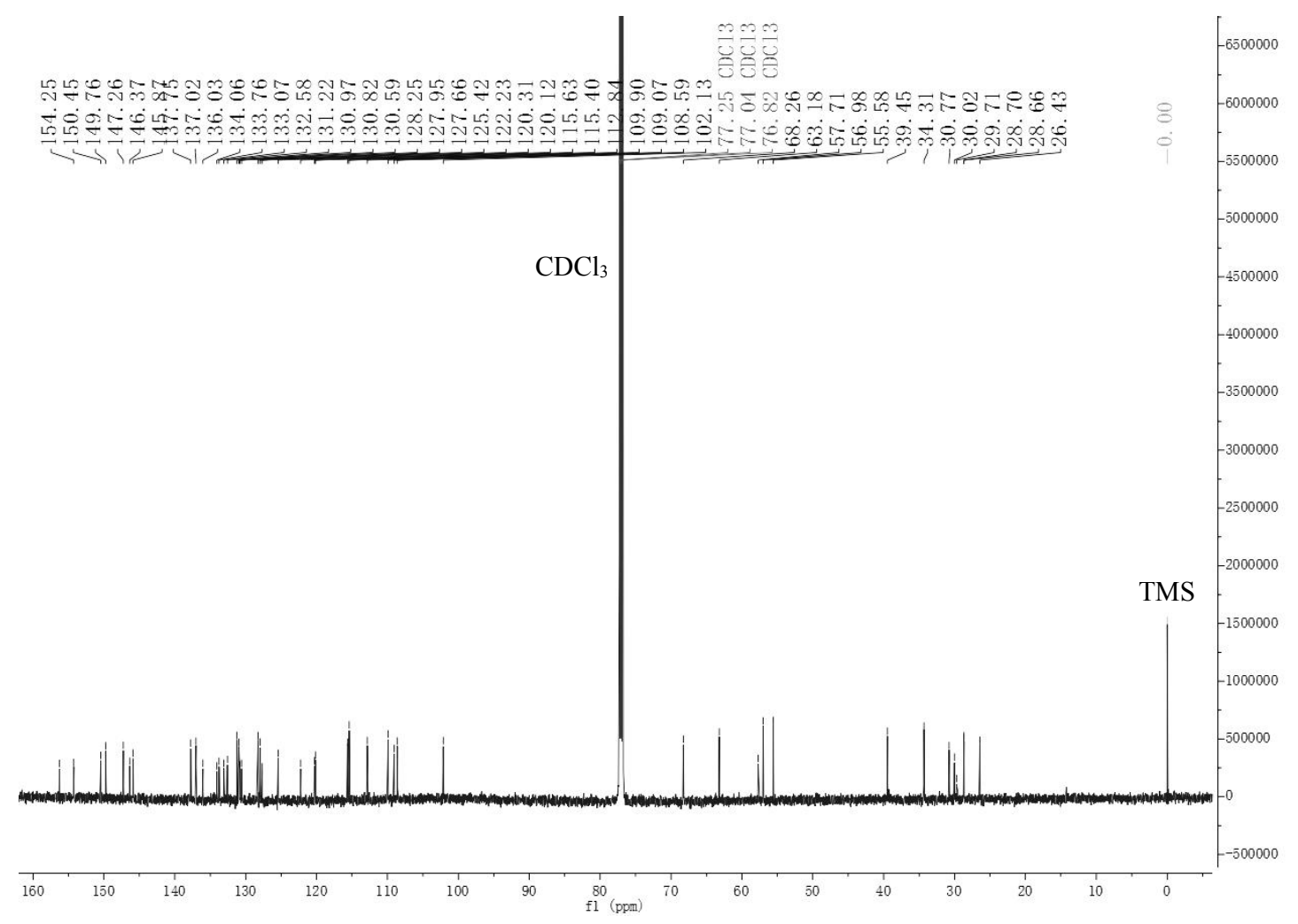

Figure S71. ${ }^{13} \mathrm{C}$ NMR spectrum of $\mathbf{5 d}$ in $\mathrm{CDCl}_{3}$.

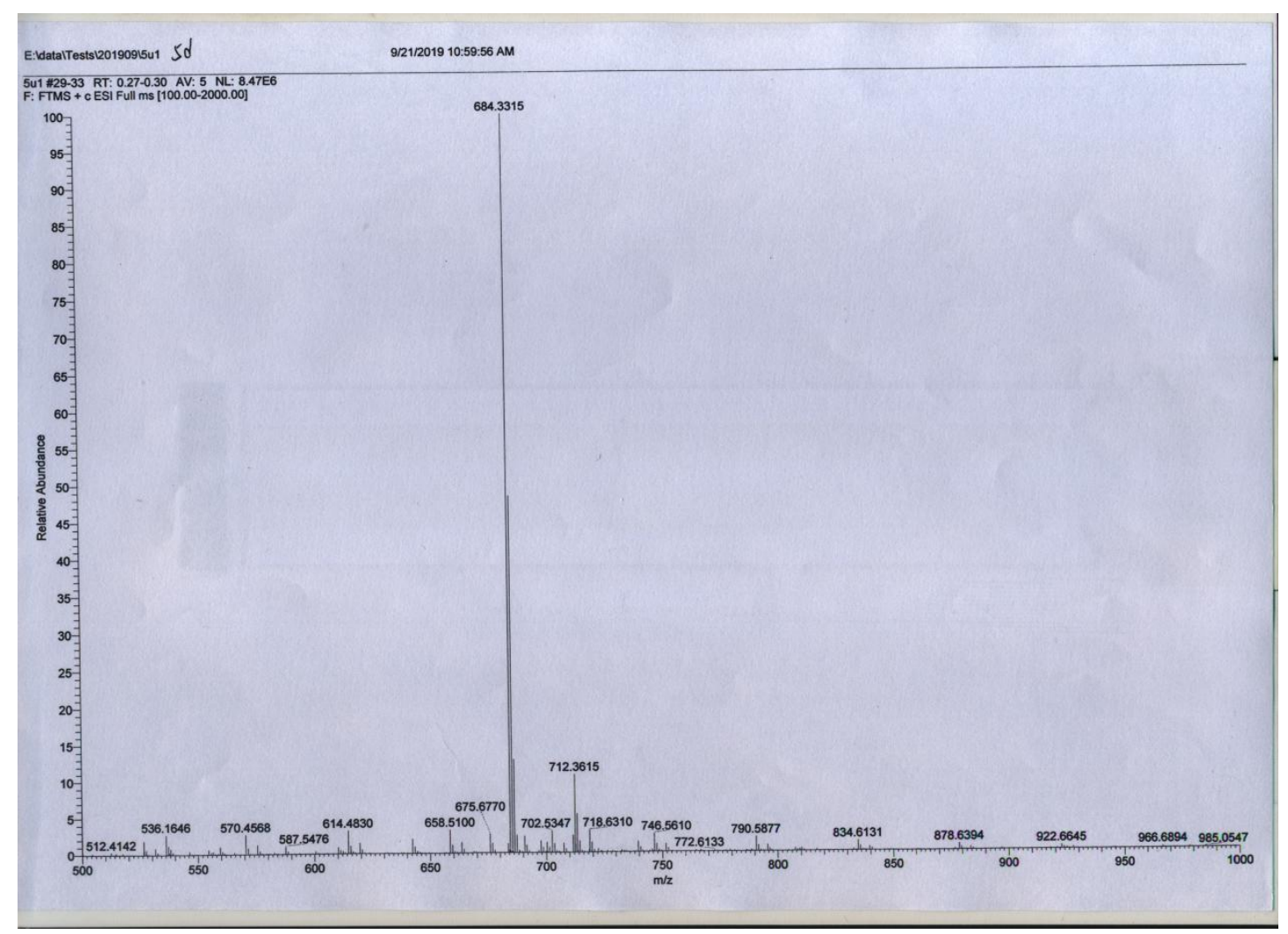

Figure S72. HR-ESI-MS spectrum of $\mathbf{5 d}$. 


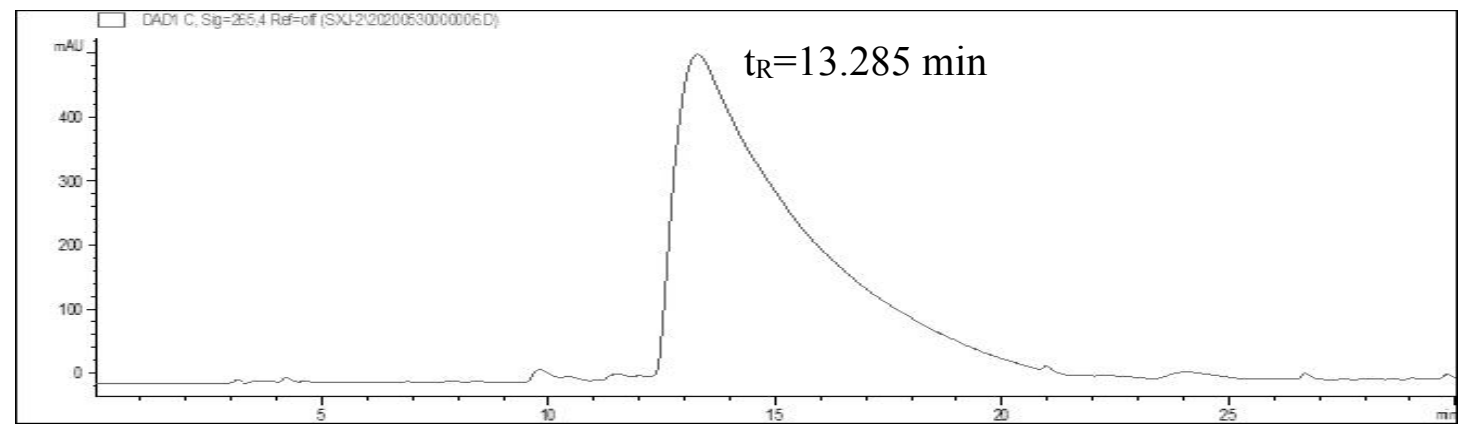

Figure S73. HPLC chromatogram of $\mathbf{5 d}$.

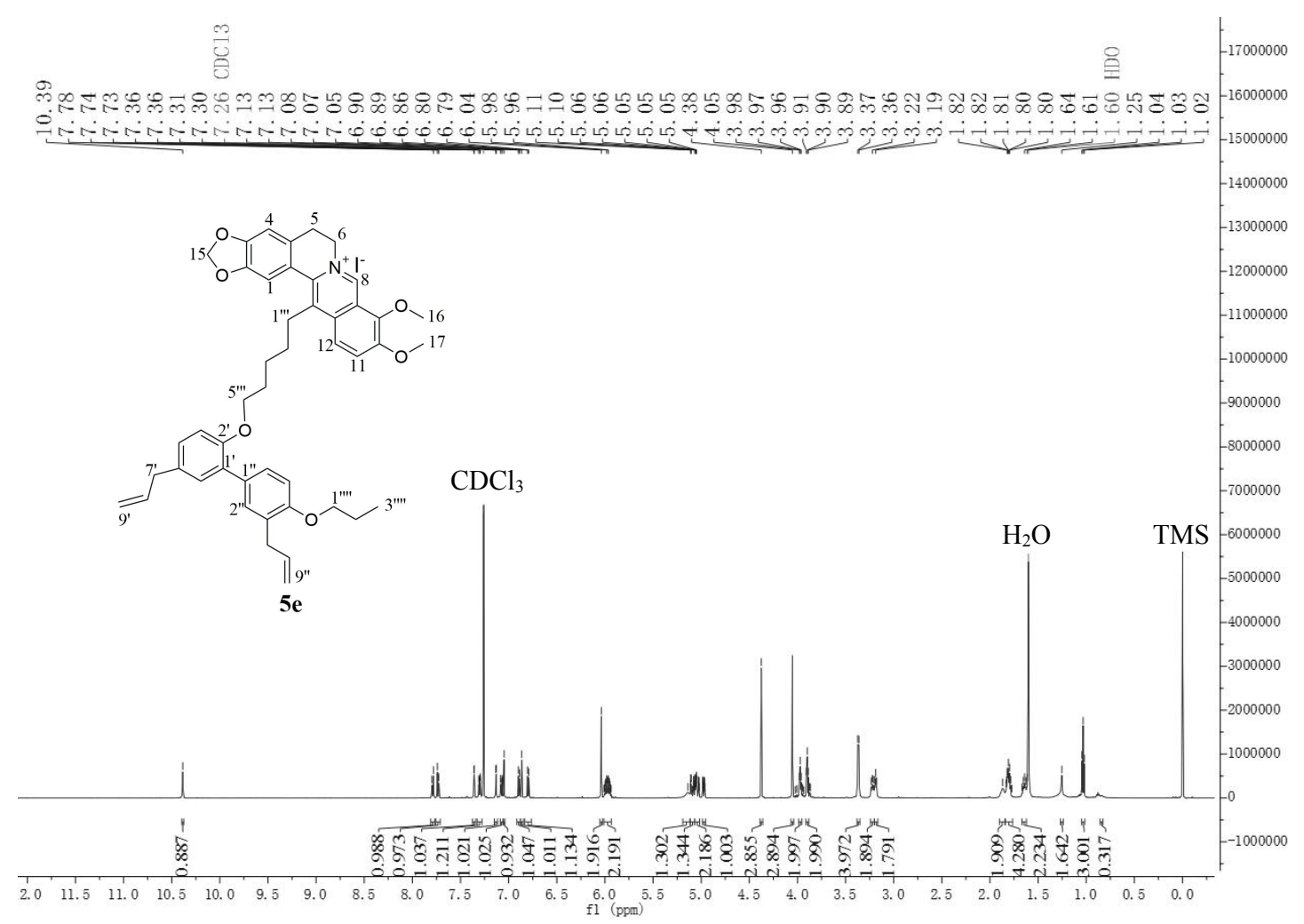

Figure $\mathbf{S 7 4} .{ }^{1} \mathrm{H}$ NMR spectrum of $\mathbf{5 e}$ in $\mathrm{CDCl}_{3}$. 


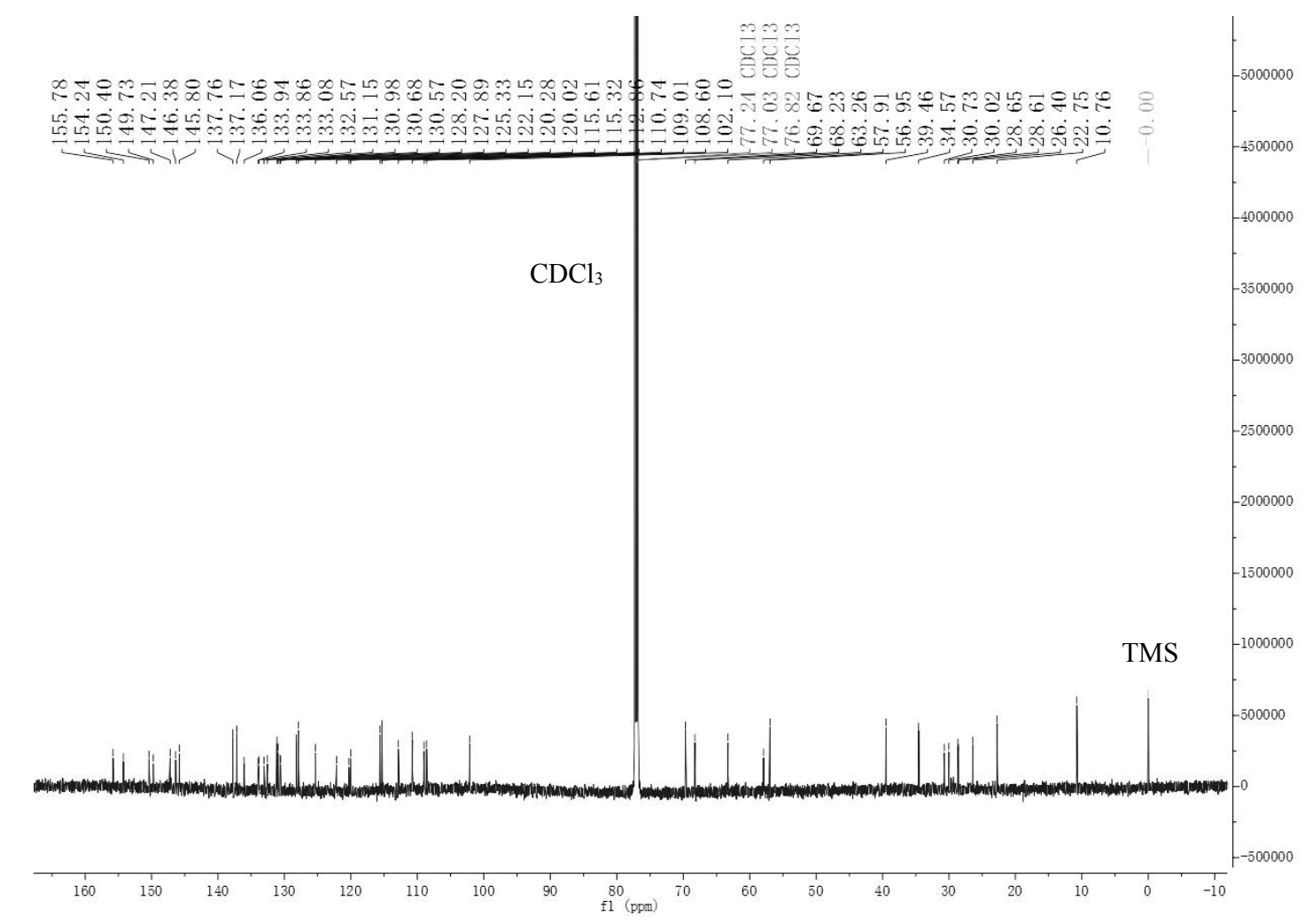

Figure S75. ${ }^{13} \mathrm{C}$ NMR spectrum of $5 e$ in $\mathrm{CDCl}_{3}$.

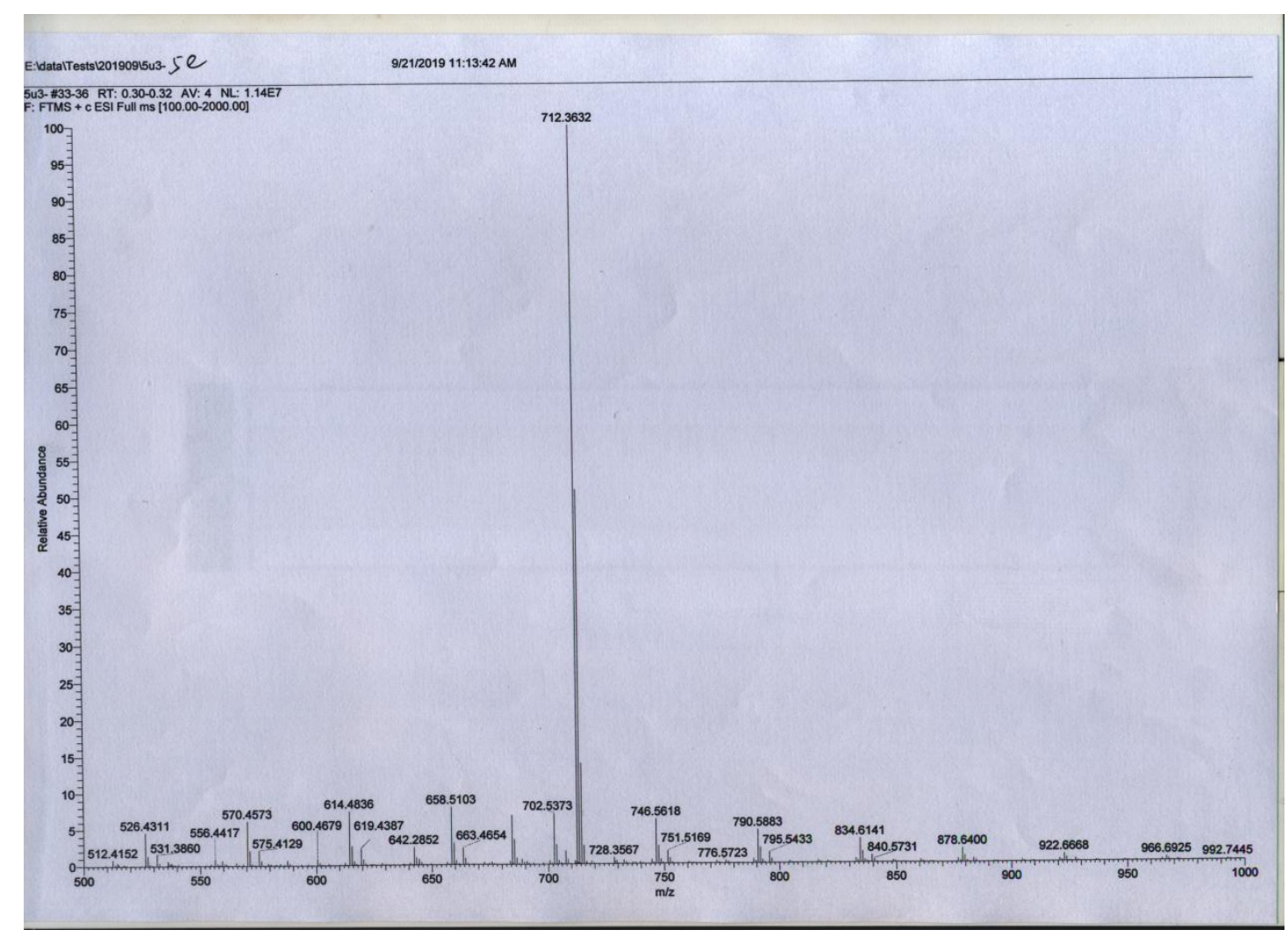

Figure S76. HR-ESI-MS spectrum of 5e. 


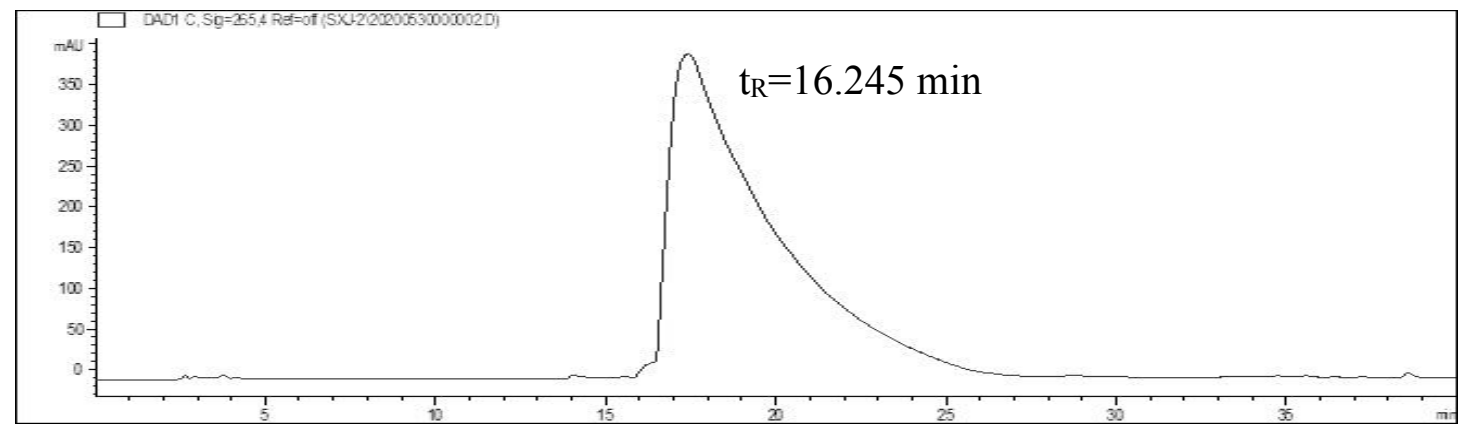

Figure S77. HPLC chromatogram of 5e.

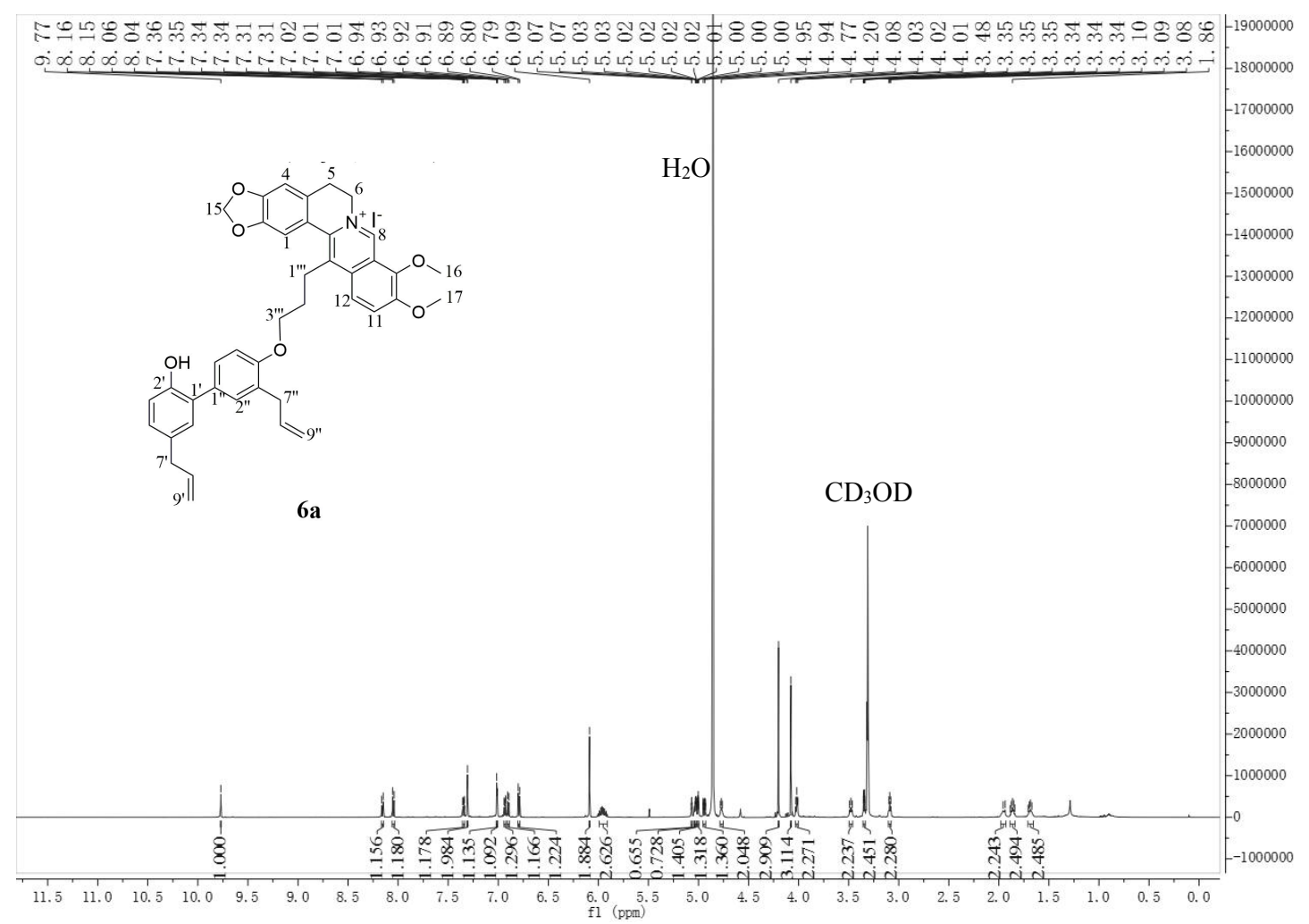

Figure S78. ${ }^{1} \mathrm{H}$ NMR spectrum of $6 \mathbf{a}$ in $\mathrm{CD}_{3} \mathrm{OD}$. 


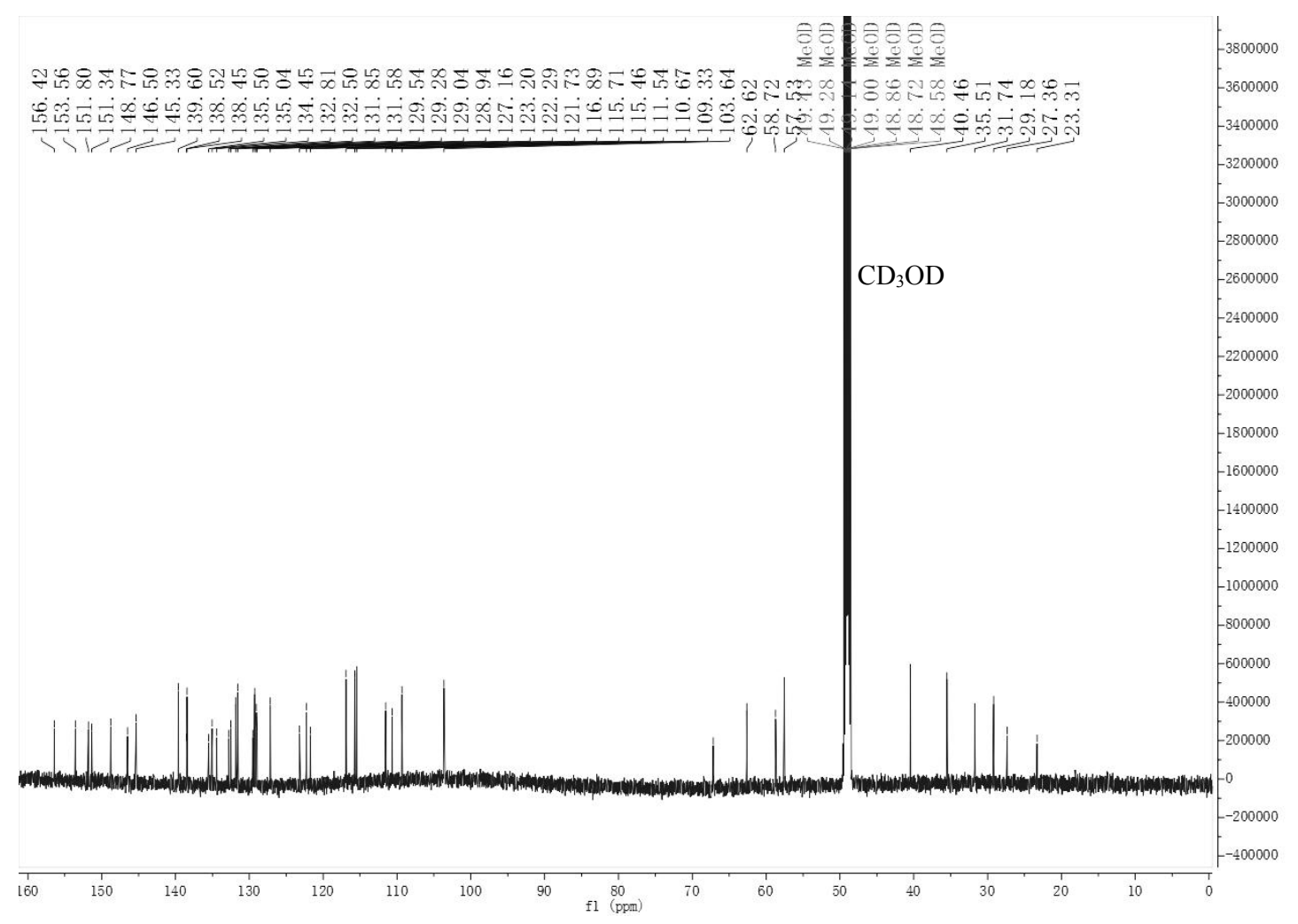

Figure S79. ${ }^{13} \mathrm{C}$ NMR spectrum of $\mathbf{6 a}$ in $\mathrm{CD}_{3} \mathrm{OD}$.

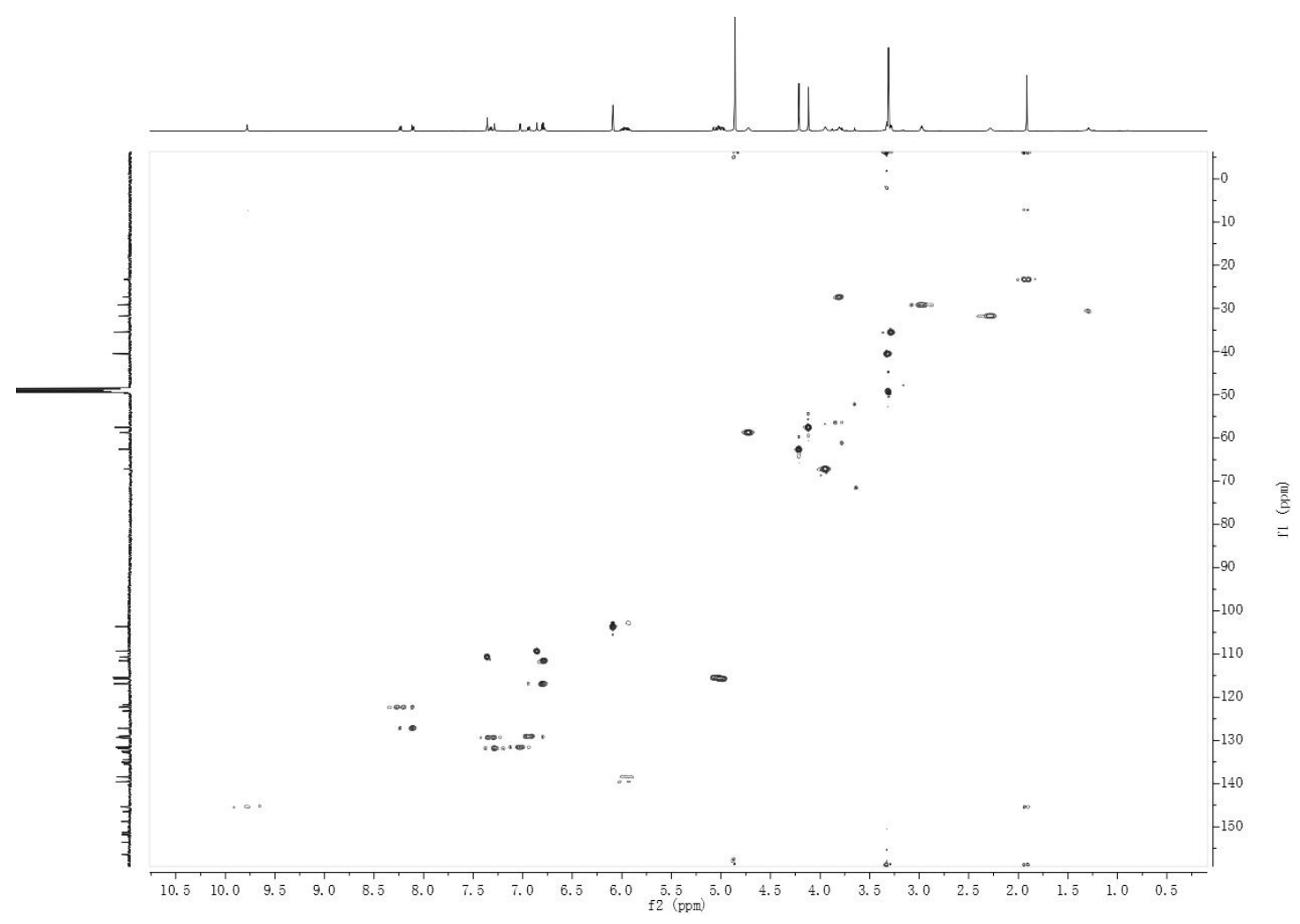

Figure S80. HSQC spectrum of $\mathbf{6 a}$ in $\mathrm{CD}_{3} \mathrm{OD}$. 


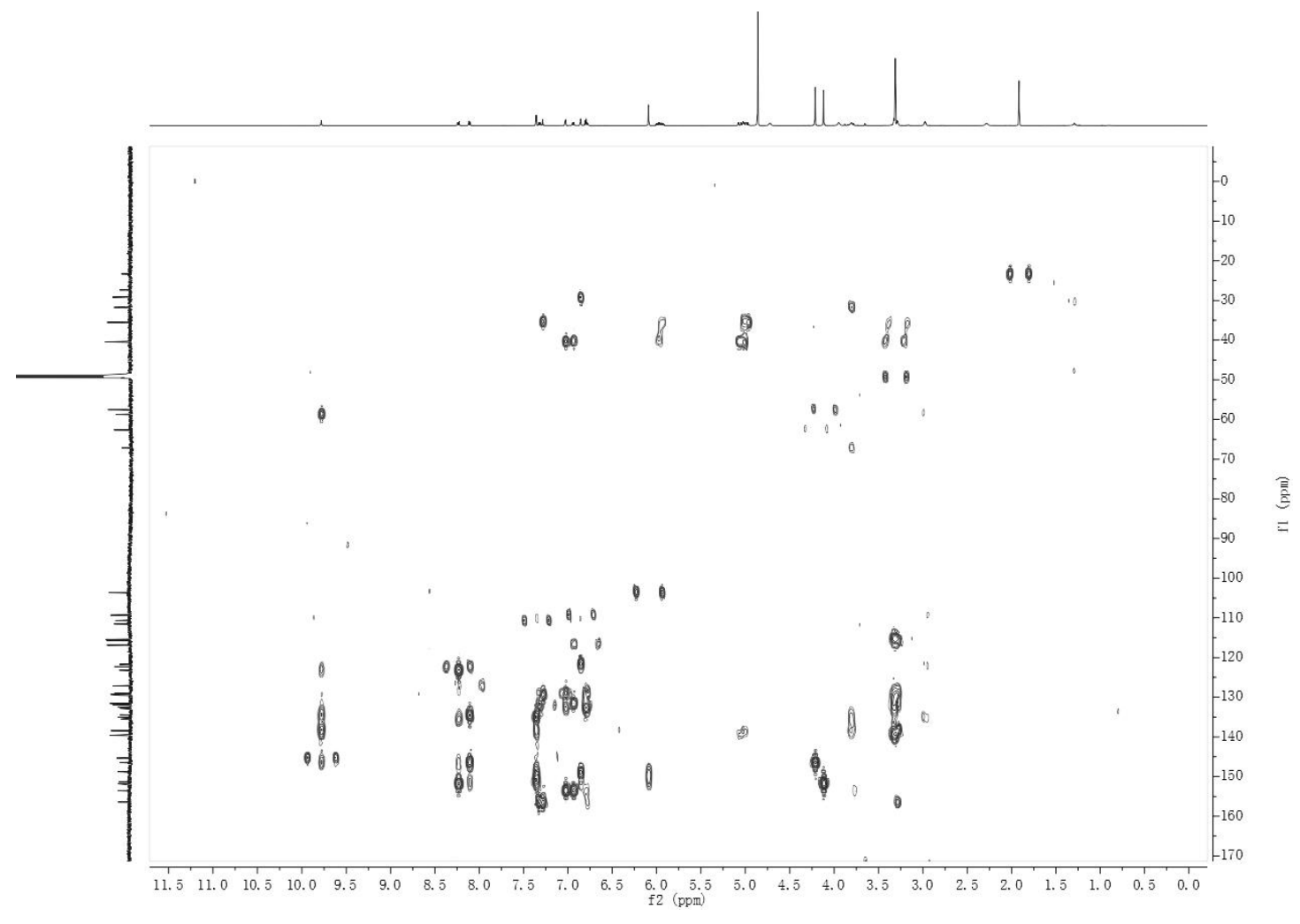

Figure S81. HMBC spectrum of $\mathbf{6 a}$ in $\mathrm{CD}_{3} \mathrm{OD}$.

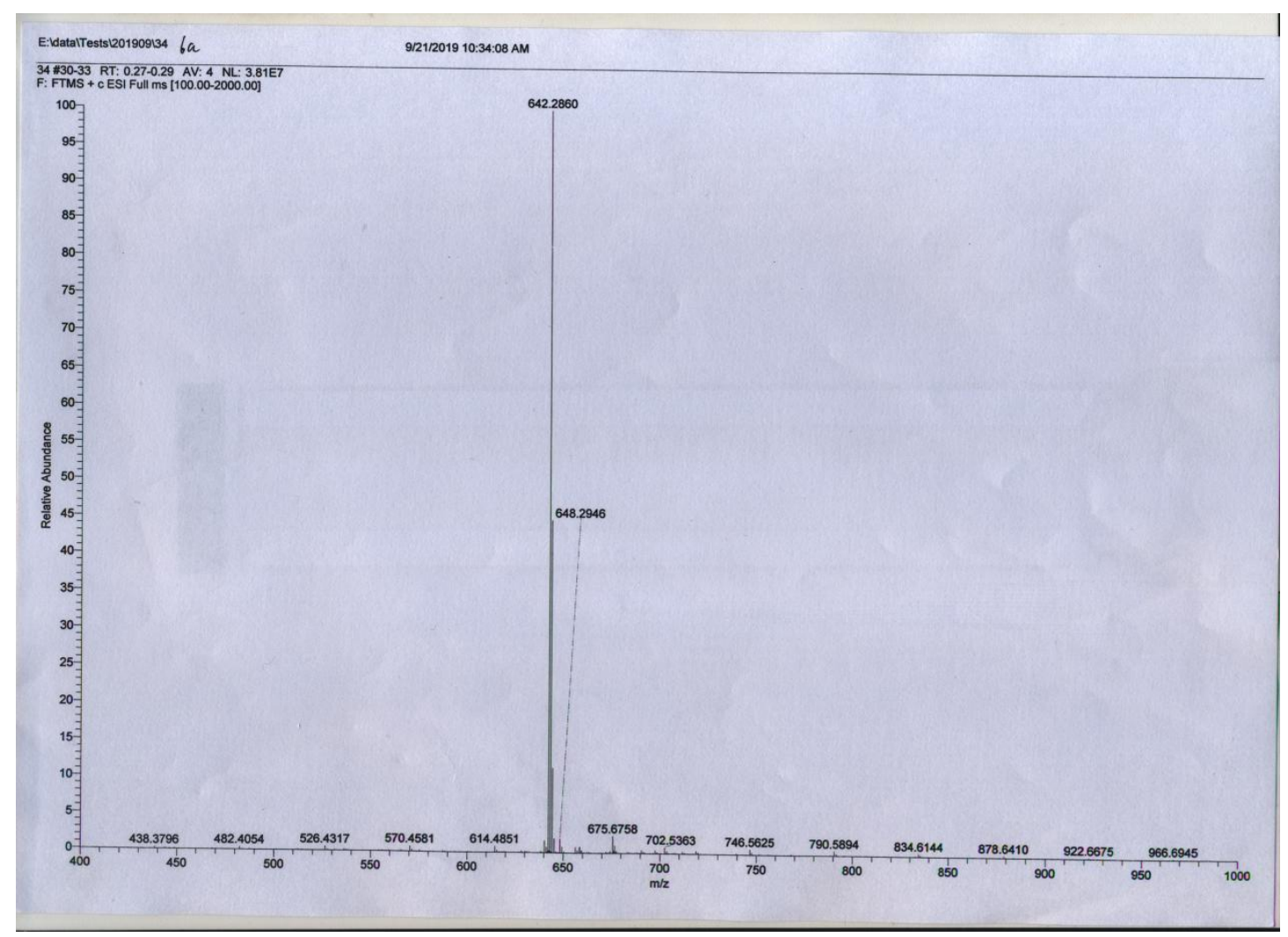

Figure S82. HR-ESI-MS spectrum of $\mathbf{6 a}$. 


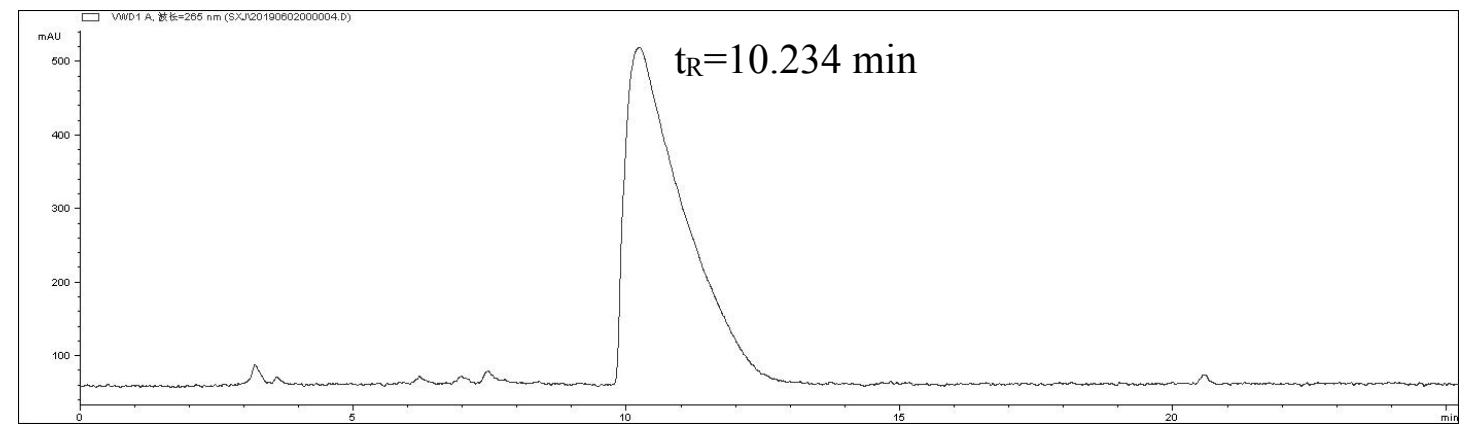

Figure S83. HPLC chromatogram of $6 \mathbf{a}$.

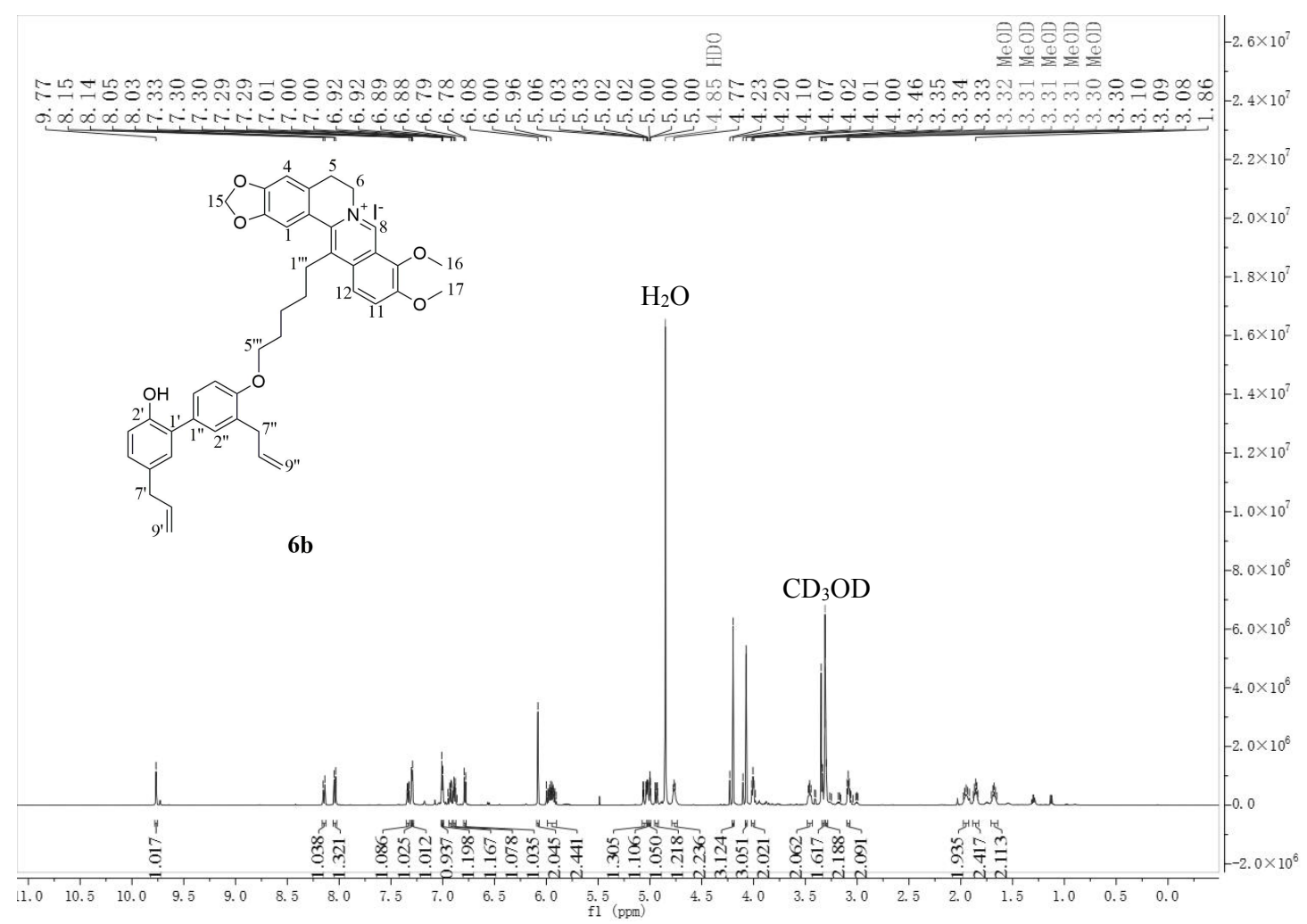

Figure S84. ${ }^{1} \mathrm{H}$ NMR spectrum of $\mathbf{6 b}$ in $\mathrm{CD}_{3} \mathrm{OD}$. 


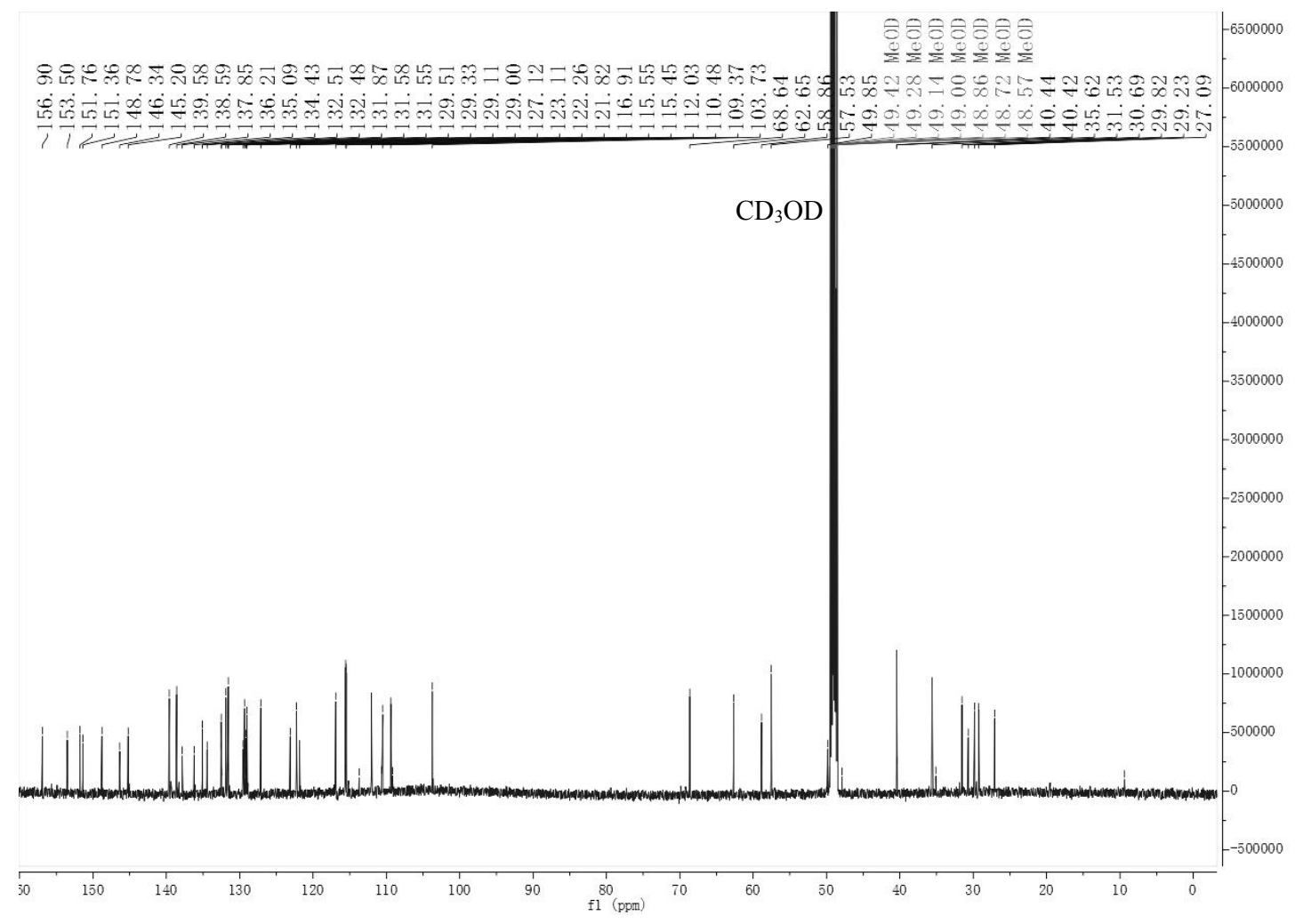

Figure S85. ${ }^{13} \mathrm{C}$ NMR spectrum of $6 \mathbf{b}$ in $\mathrm{CD}_{3} \mathrm{OD}$.

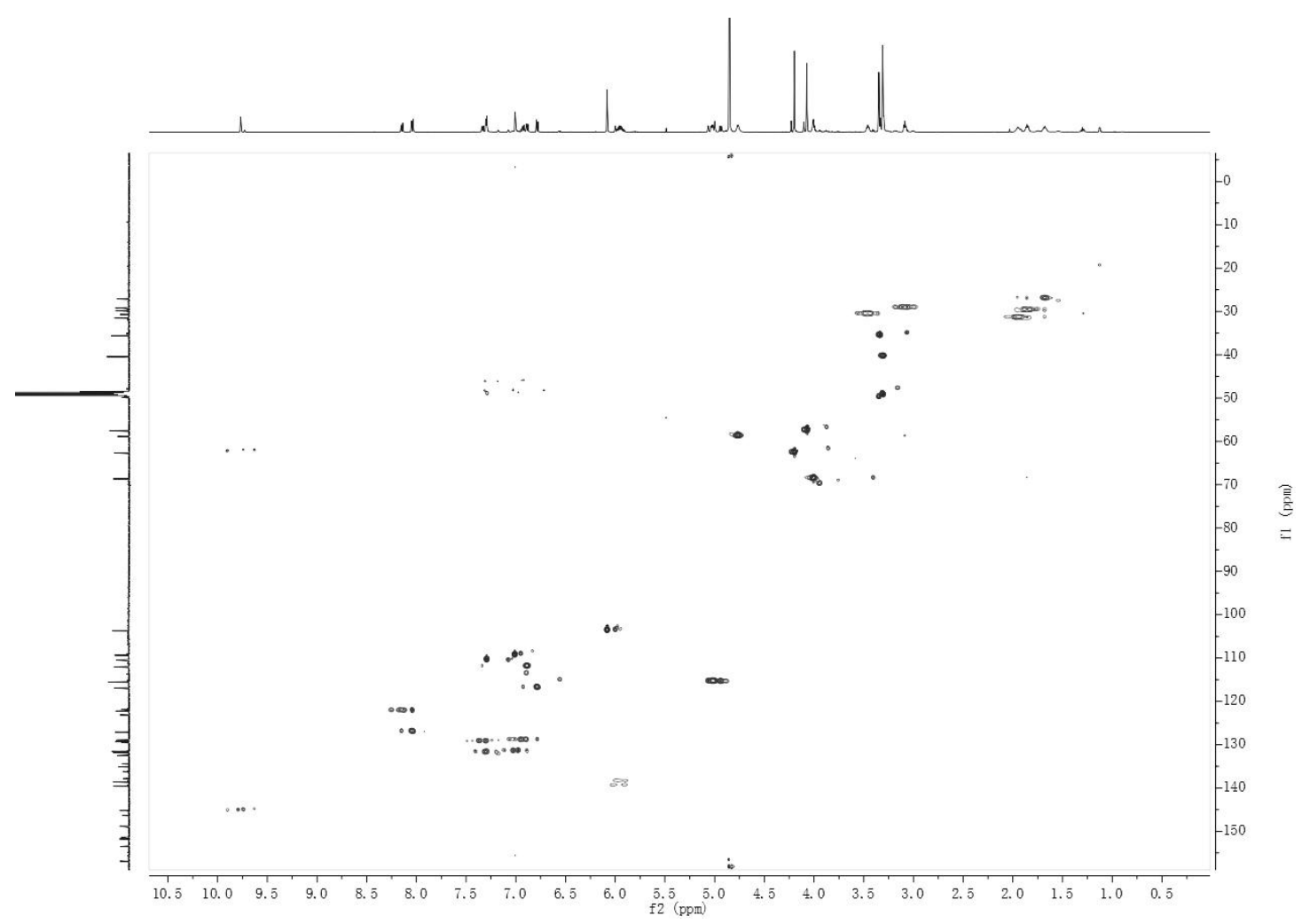

Figure S86. HSQC spectrum of $\mathbf{6 b}$ in $\mathrm{CD}_{3} \mathrm{OD}$. 


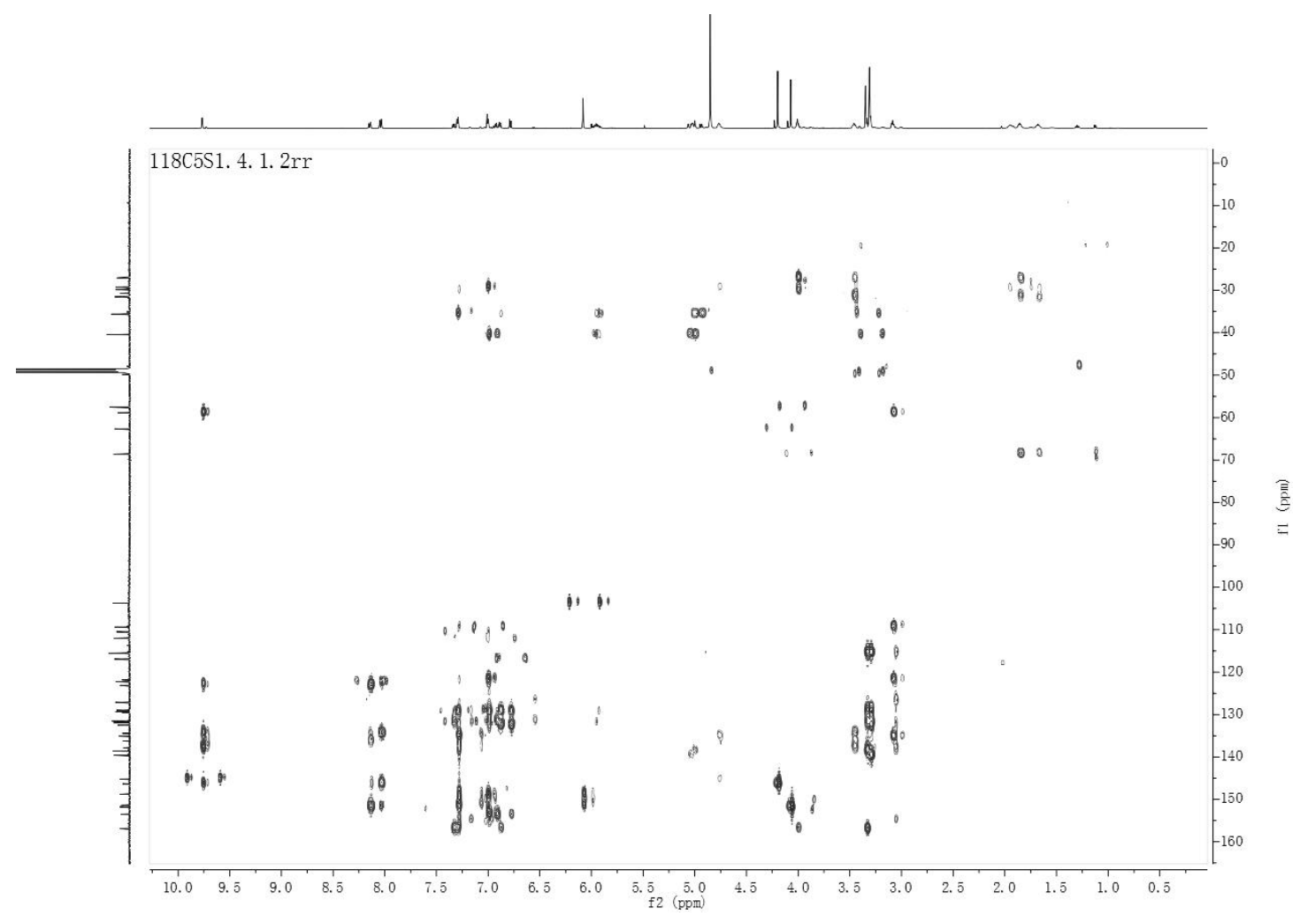

Figure S87. $\mathrm{HMBC}$ spectrum of $\mathbf{6 b}$ in $\mathrm{CD}_{3} \mathrm{OD}$.

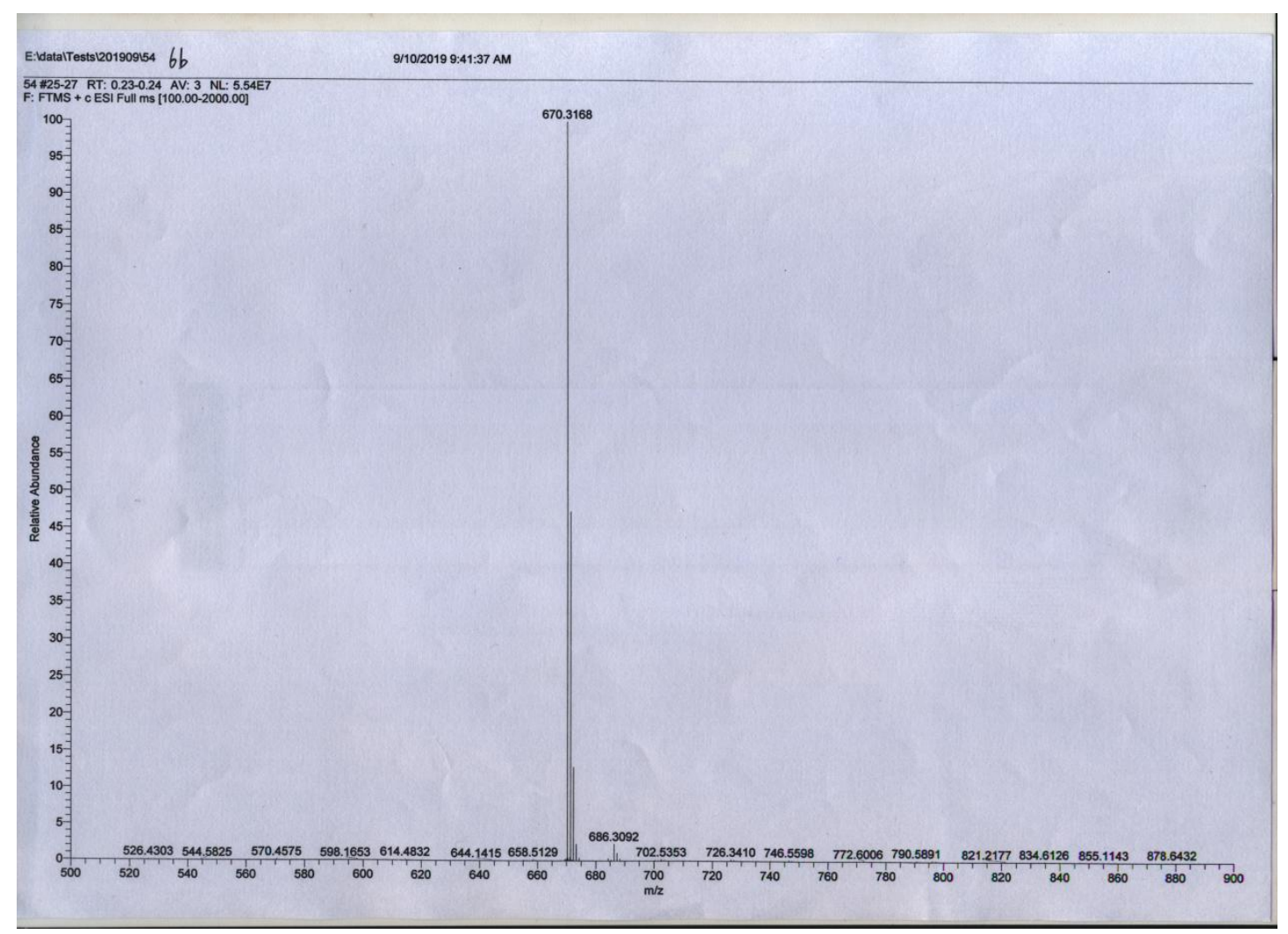

Figure S88. HR-ESI-MS spectrum of $\mathbf{6 b}$. 


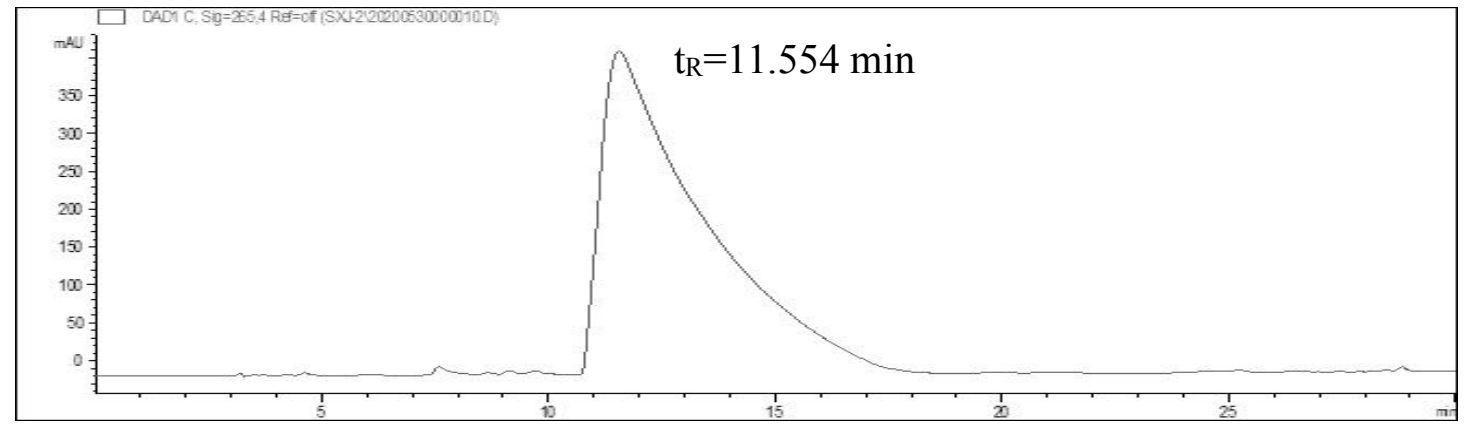

Figure S89. HPLC chromatogram of $\mathbf{6 b}$.

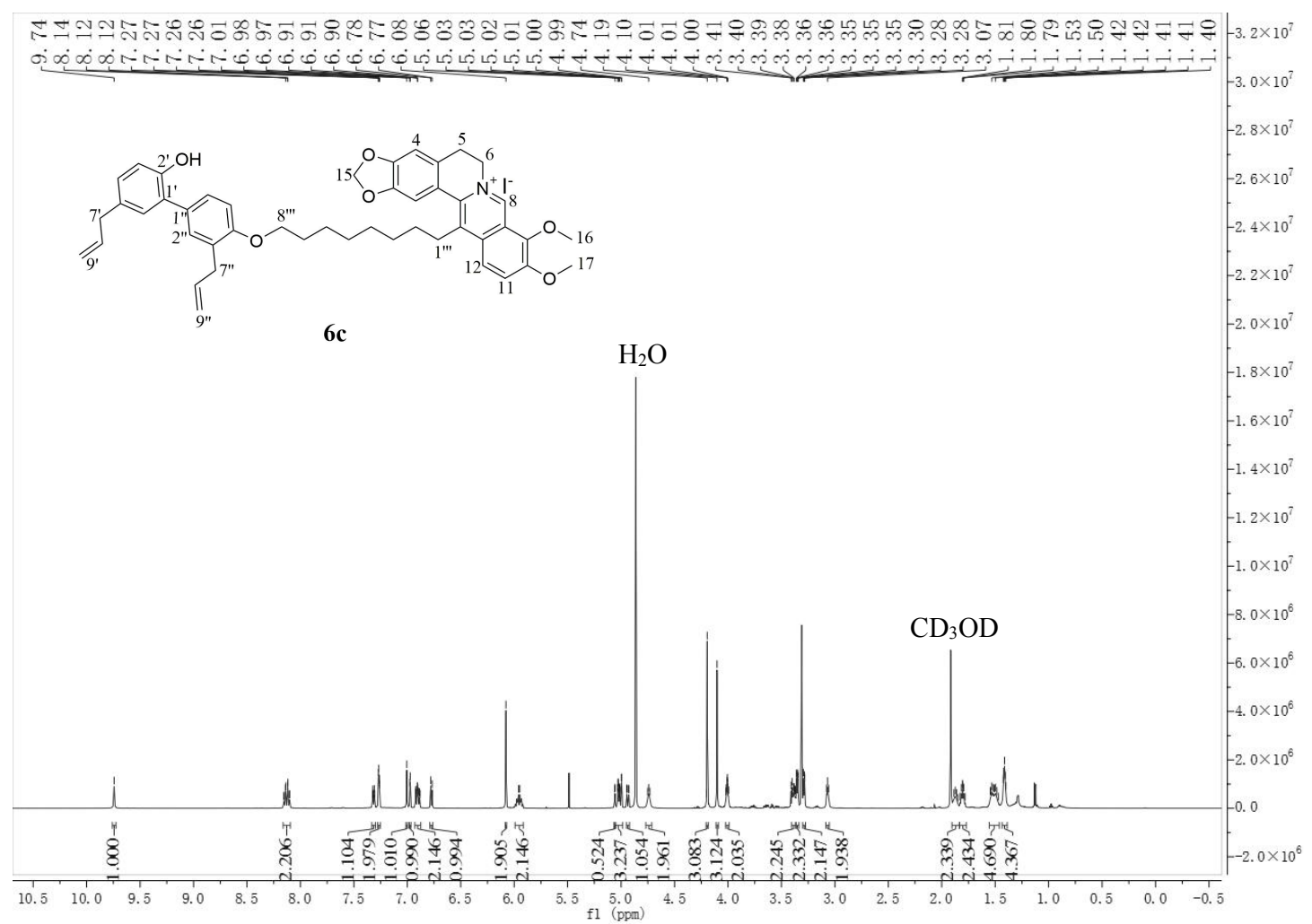

Figure S90. ${ }^{1} \mathrm{H}$ NMR spectrum of $\mathbf{6 c}$ in $\mathrm{CD}_{3} \mathrm{OD}$. 


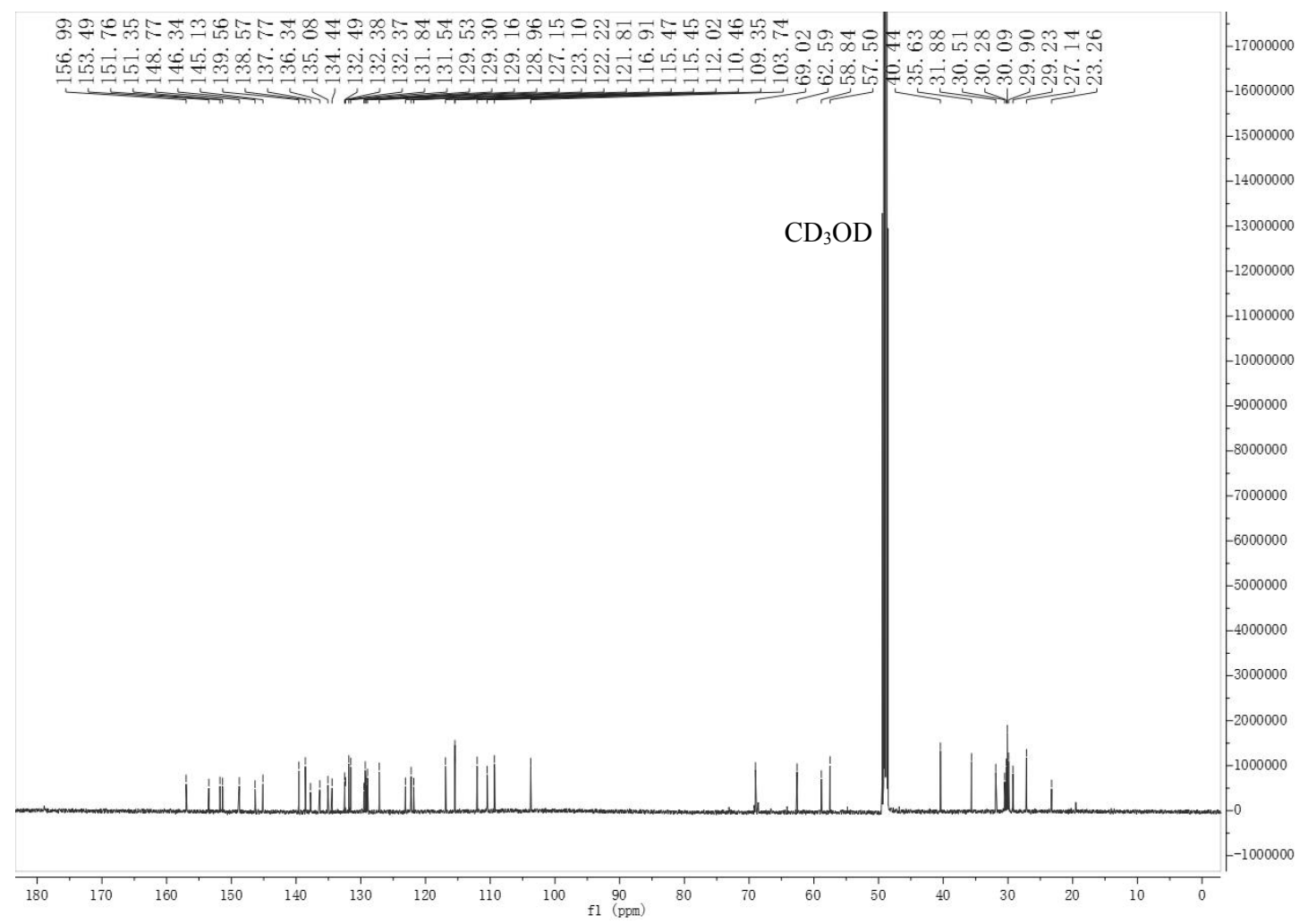

Figure S91. ${ }^{13} \mathrm{C}$ NMR spectrum of $\mathbf{6 c}$ in $\mathrm{CD}_{3} \mathrm{OD}$.

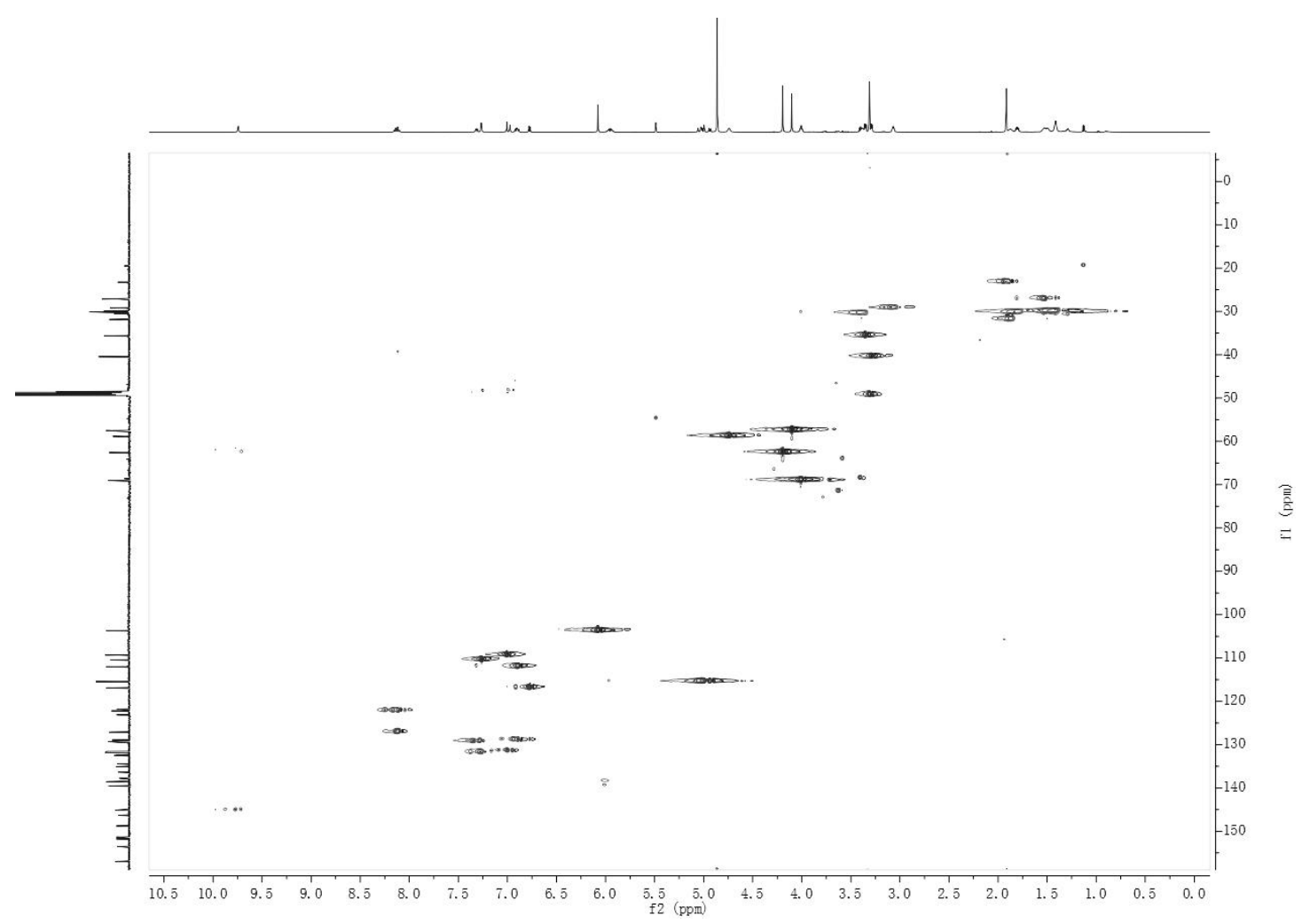

Figure S92. HSQC spectrum of $\mathbf{6 c}$ in $\mathrm{CD}_{3} \mathrm{OD}$. 


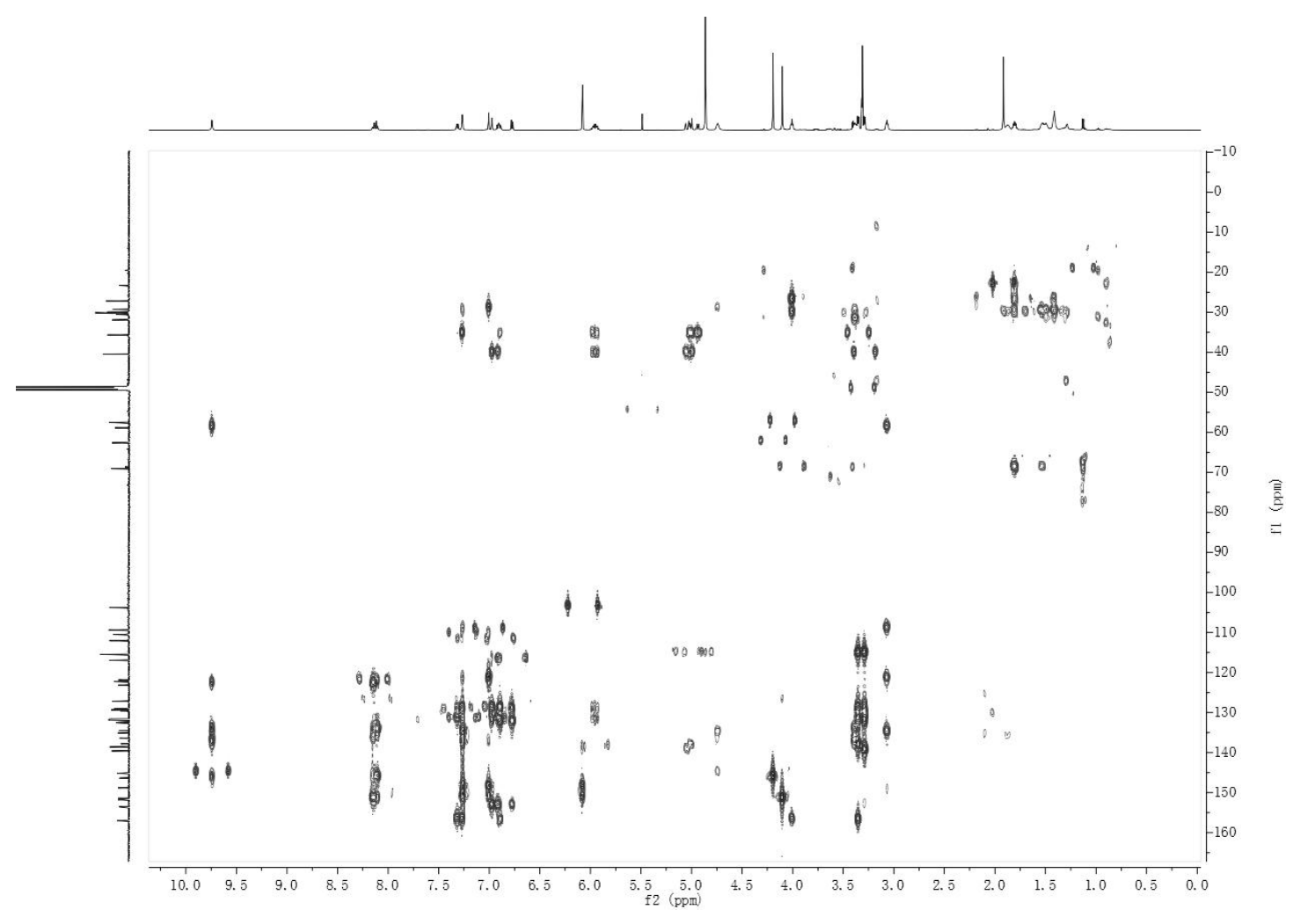

Figure S93. $\mathrm{HMBC}$ spectrum of $\mathbf{6 c}$ in $\mathrm{CD}_{3} \mathrm{OD}$.

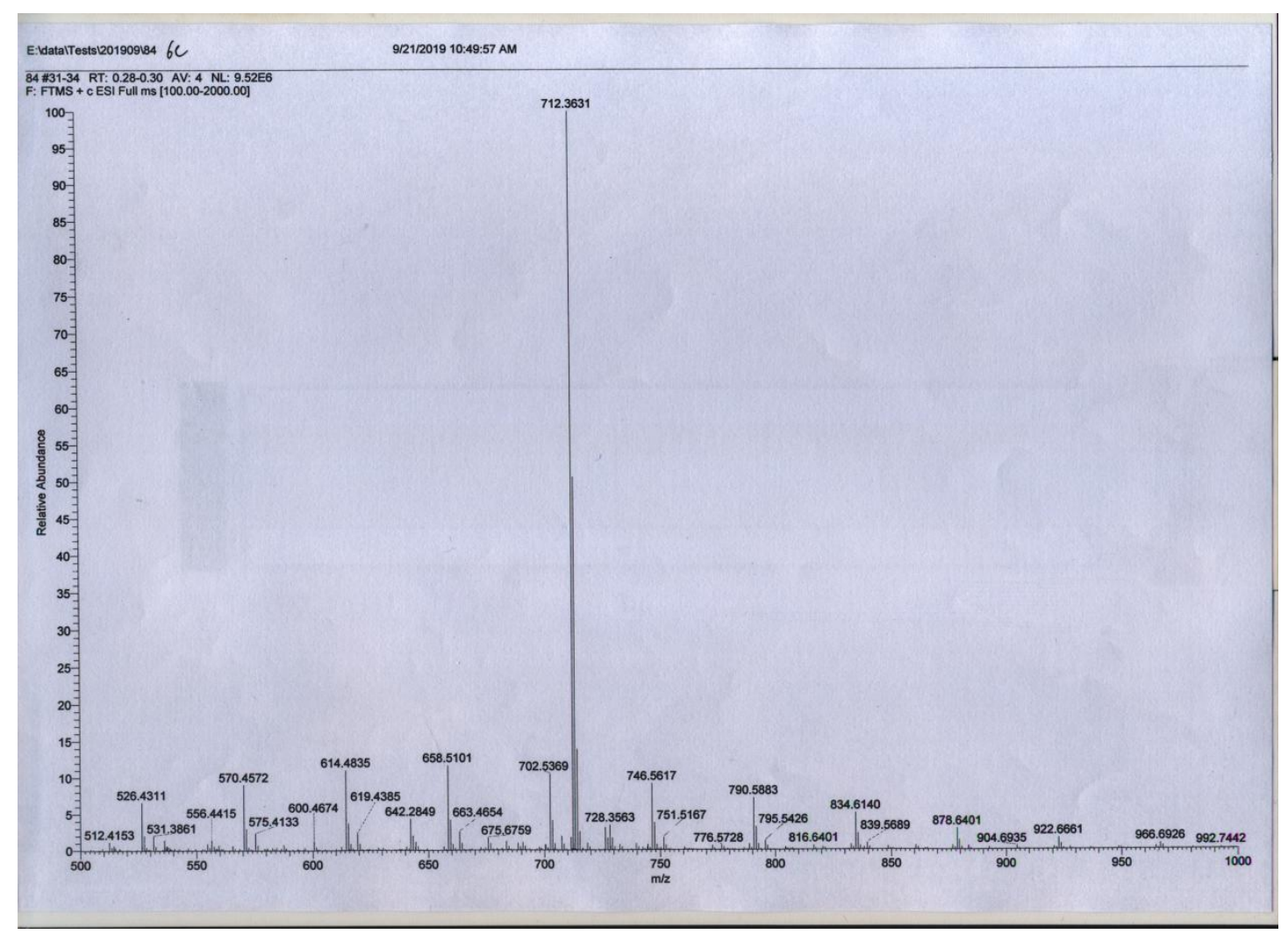

Figure S94. HR-ESI-MS spectrum of $6 \mathbf{c}$. 


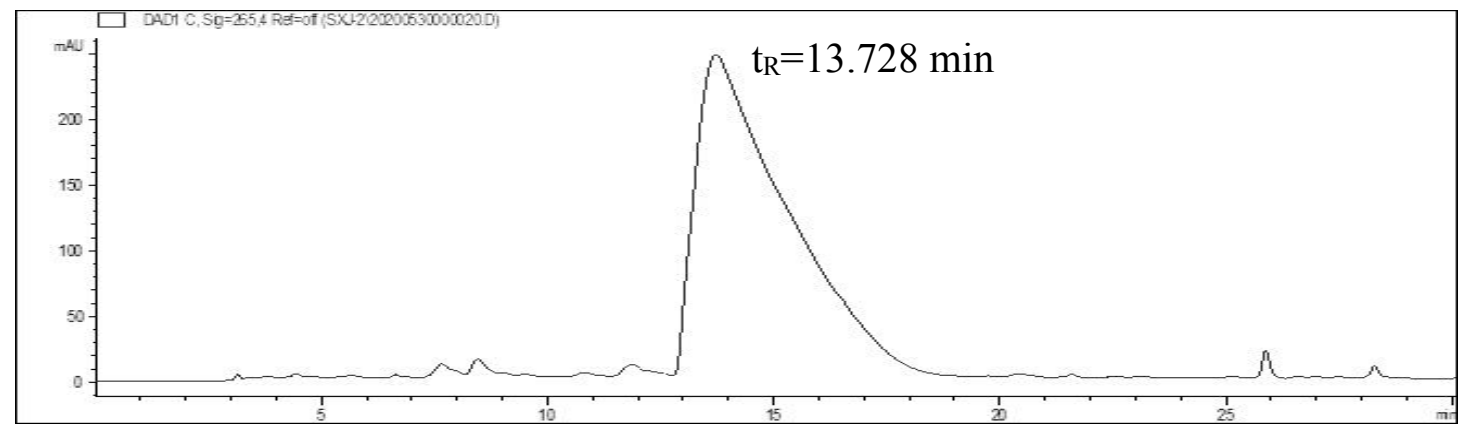

Figure S95. HPLC chromatogram of $6 \mathbf{c}$.

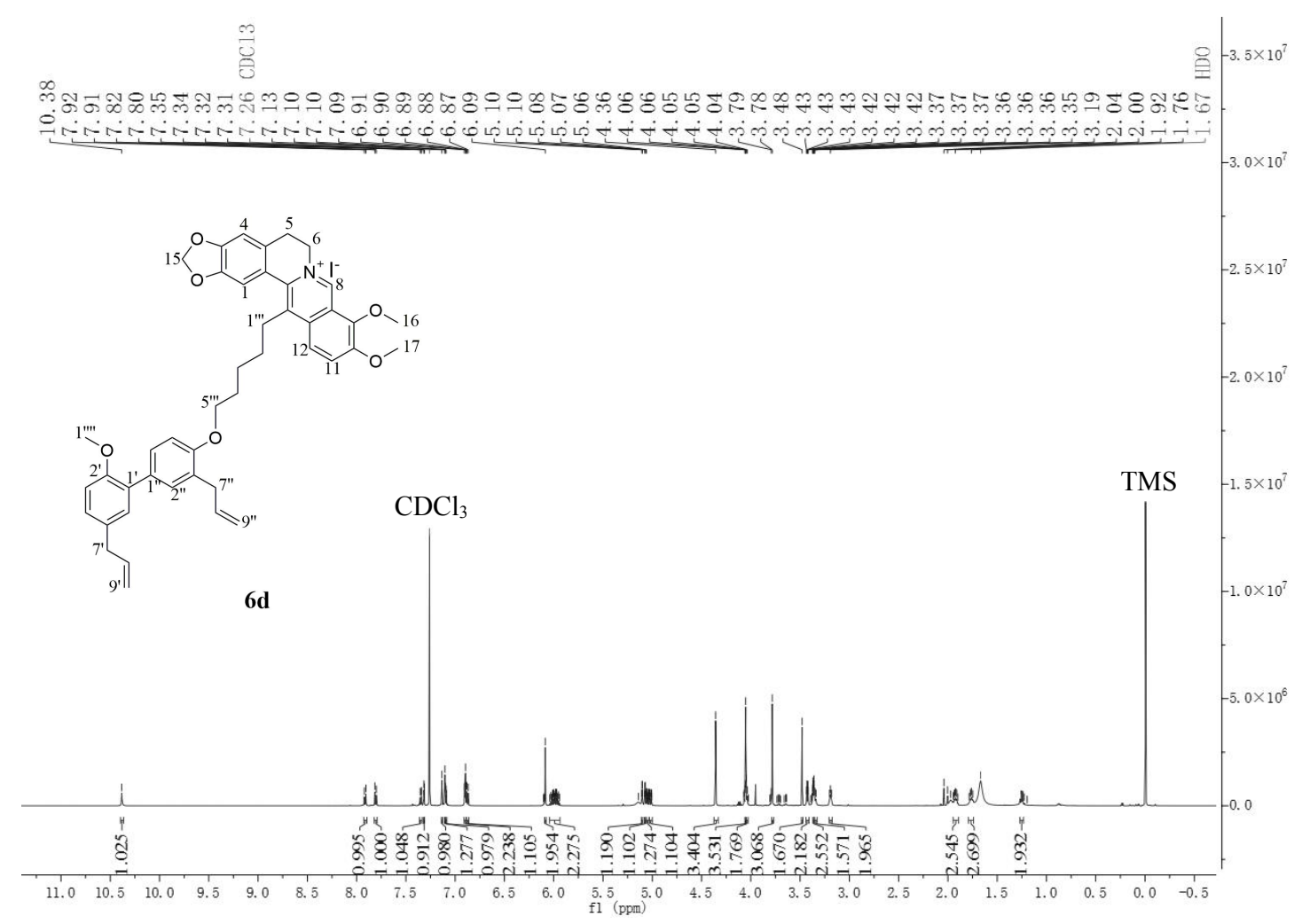

Figure S96. ${ }^{1} \mathrm{H}$ NMR spectrum of $\mathbf{6 d}$ in $\mathrm{CDCl}_{3}$. 


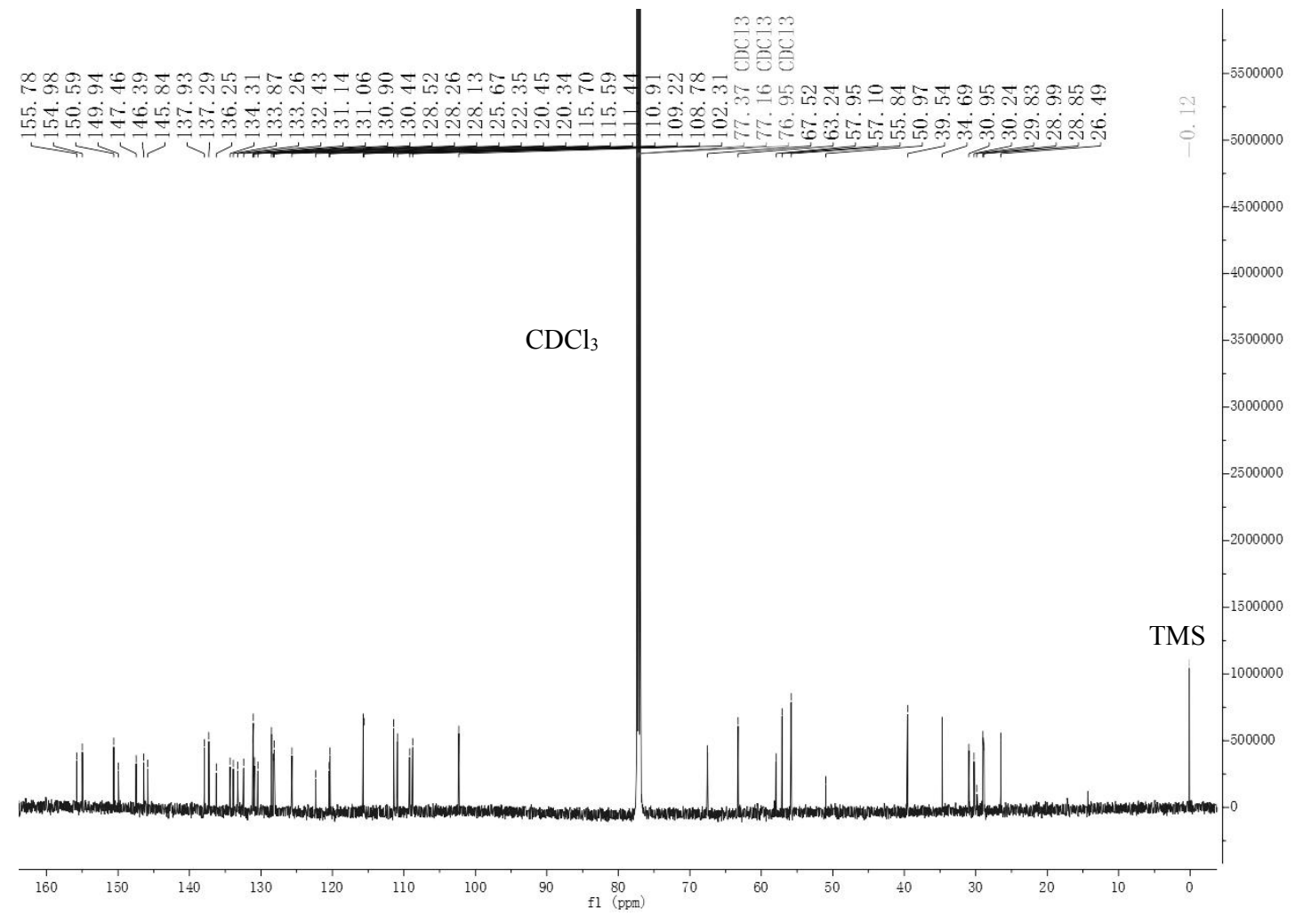

Figure S97. ${ }^{13} \mathrm{C}$ NMR spectrum of $\mathbf{6 d}$ in $\mathrm{CDCl}_{3}$.

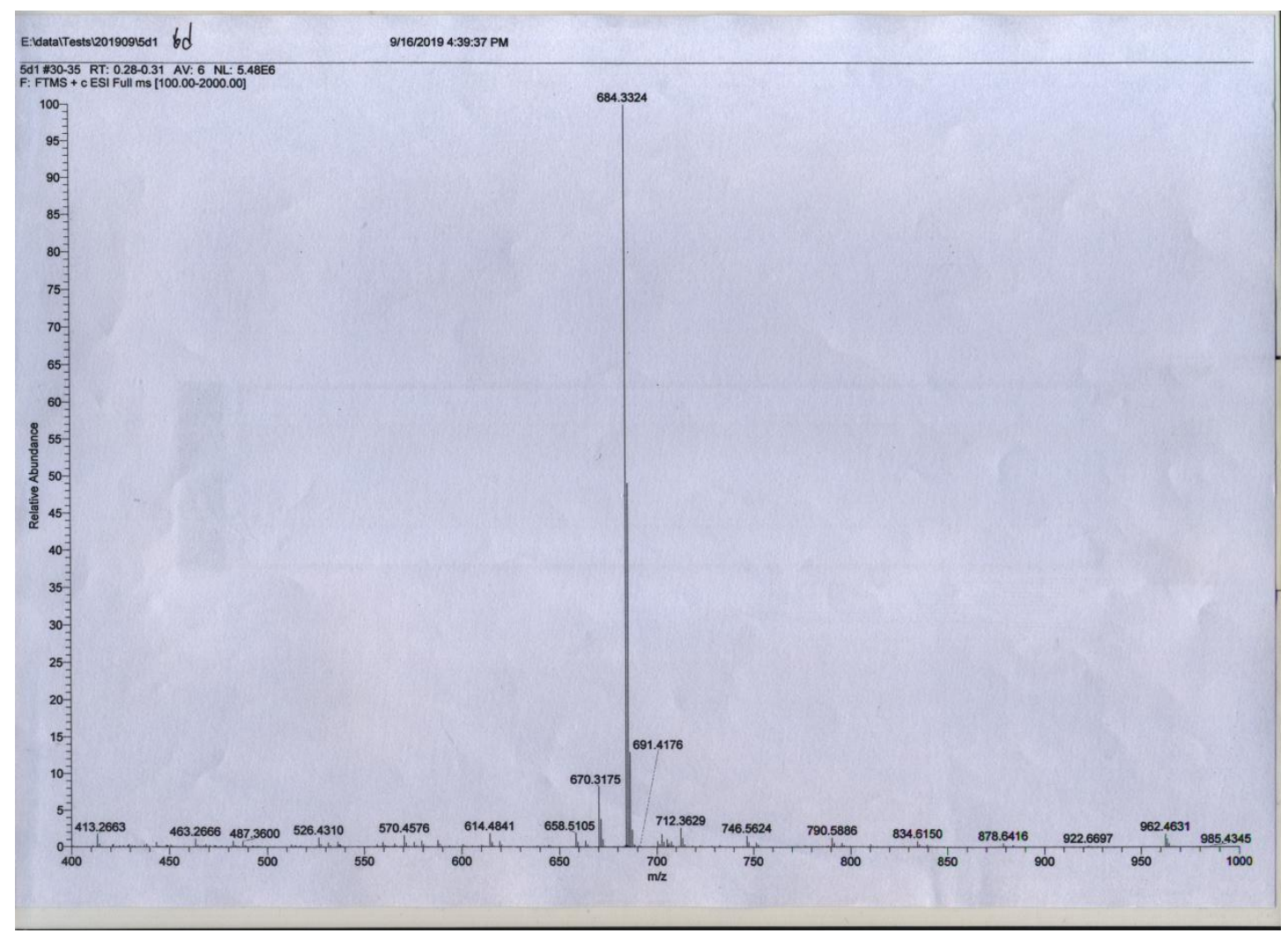

Figure S98. HR-ESI-MS spectrum of $6 \mathbf{d}$. 


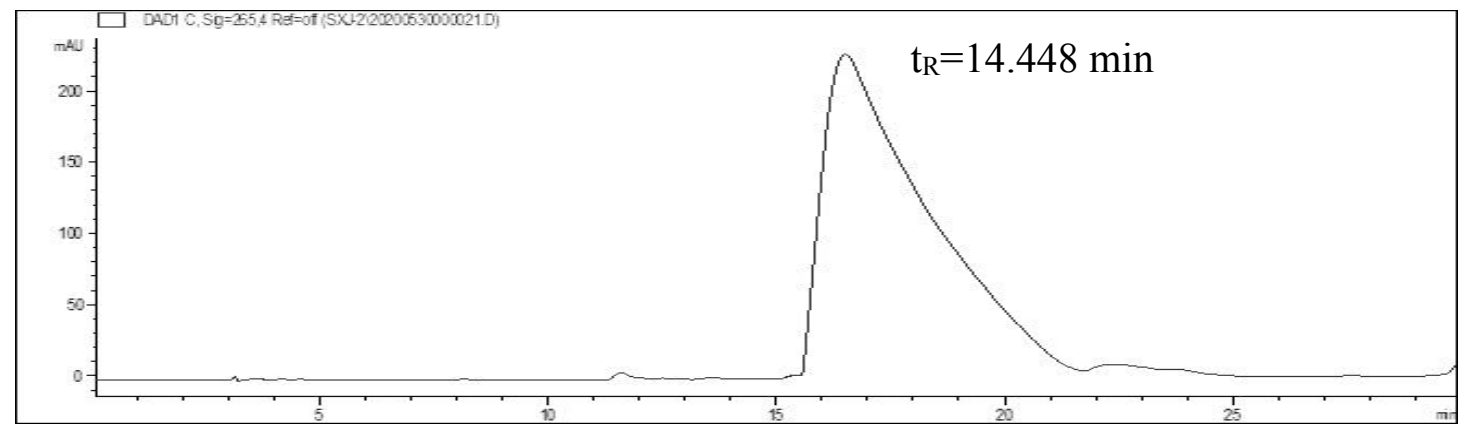

Figure S99. HPLC chromatogram of $6 \mathbf{d}$.

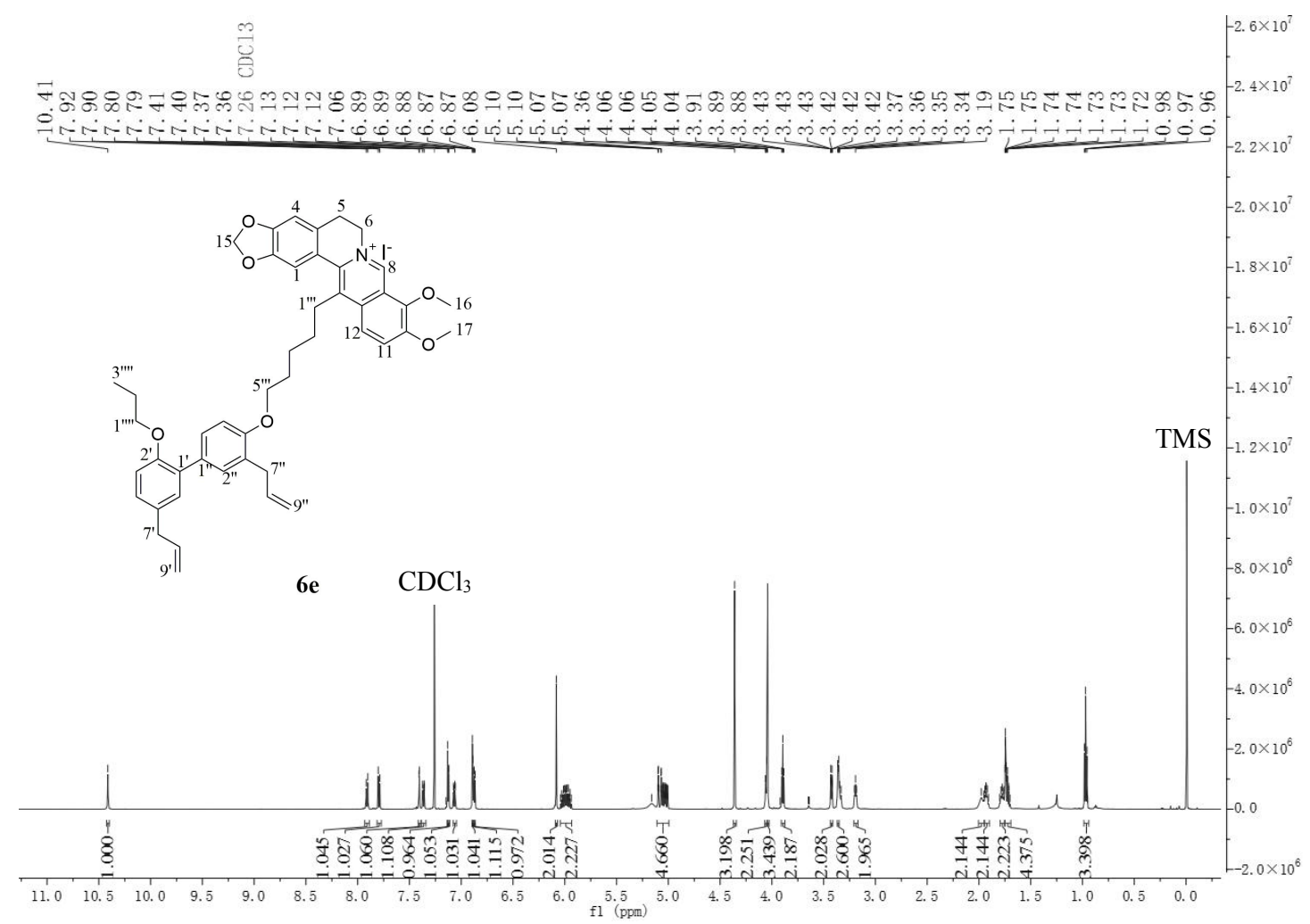

Figure S100. ${ }^{1} \mathrm{H}$ NMR spectrum of $6 \mathbf{e}$ in $\mathrm{CDCl}_{3}$. 


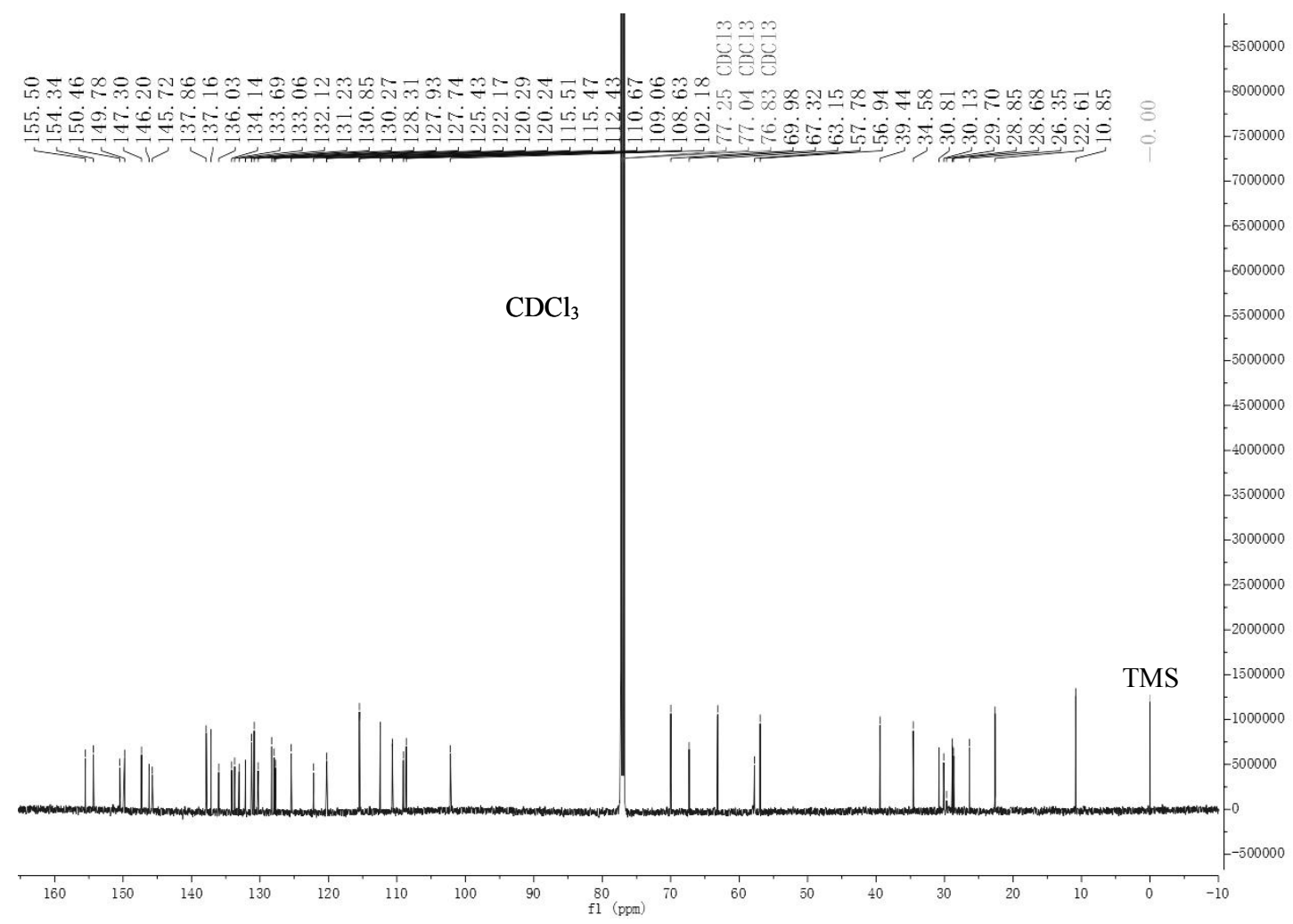

Figure S101. ${ }^{13} \mathrm{C}$ NMR spectrum of $6 \mathbf{e}$ in $\mathrm{CDCl}_{3}$.

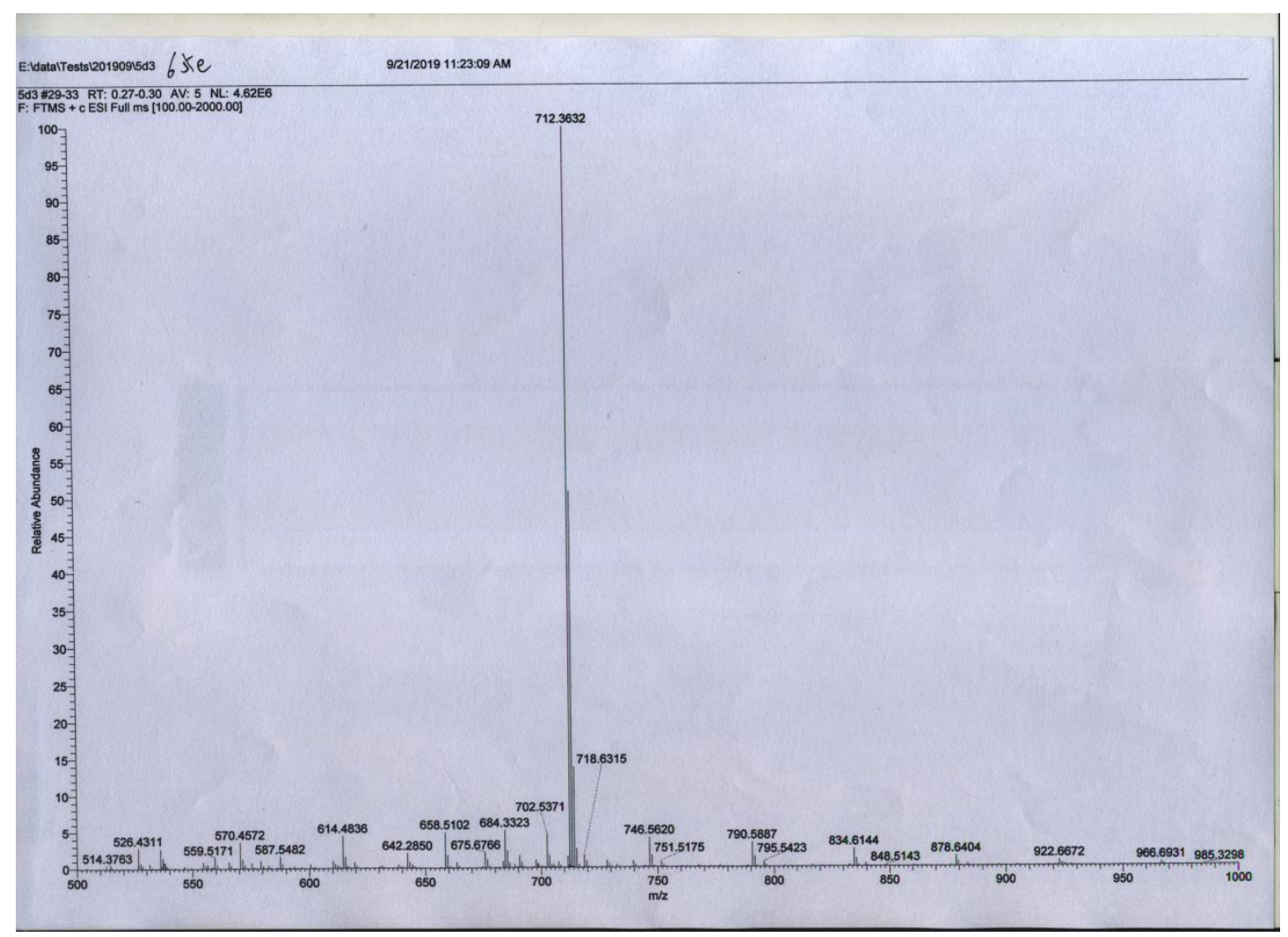

Figure S102. HR-ESI-MS spectrum of $6 \mathbf{e}$. 


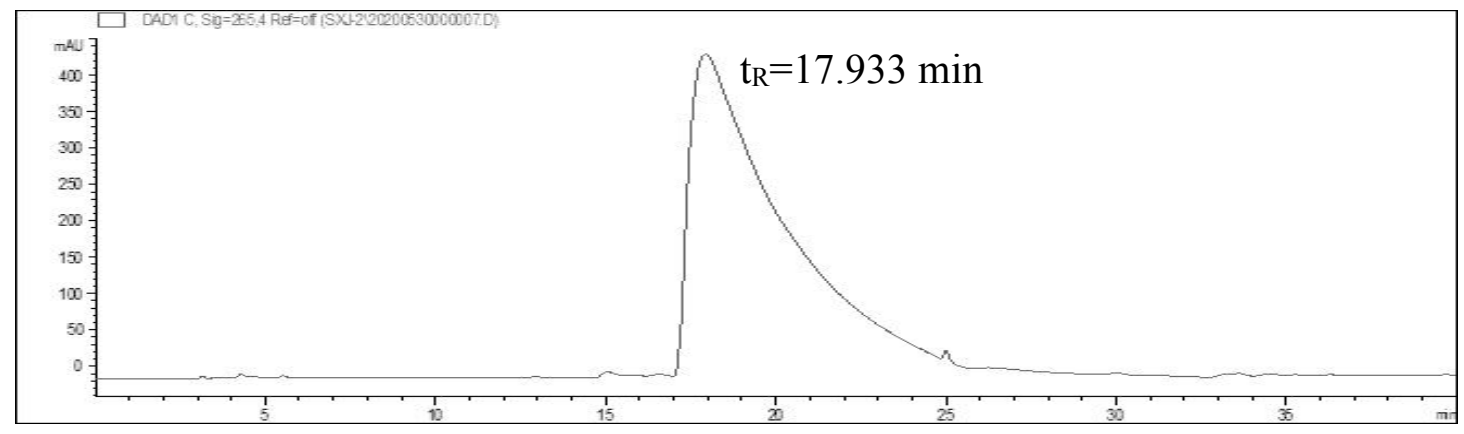

Figure S103. HPLC chromatogram of $6 e$. 